\title{
Entry, Descent, and Landing Aerothermodynamics: NASA Langley Experimental Capabilities and Contributions
}

\author{
Brian R. Hollis ${ }^{*}$, , Karen T. Berger ${ }^{*}$, , Scott A. Berry ${ }^{*}$, , Gregory, J. Brauckmann ${ }^{*}$, , Gregory M. Buck ${ }^{* \dagger}$, Michael \\ DiFulvio $^{\S}$, Thomas J. Horvath ${ }^{*}$, , Derek S. Liechty ${ }^{*, \star}$, N. Ronald Merski ${ }^{* *}, \dagger$, Kelly J. Murphy ${ }^{*}$, Shann J. Rufer ${ }^{*,+}$, and \\ Mark Schoenenberger ${ }^{\dagger \dagger, t}$ \\ NASA Langley Research Center, Hampton, VA 23681
}

\begin{abstract}
A review is presented of recent research, development, testing and evaluation activities related to entry, descent and landing that have been conducted at the NASA Langley Research Center. An overview of the test facilities, model development and fabrication capabilities, and instrumentation and measurement techniques employed in this work is provided. Contributions to hypersonic/supersonic flight and planetary exploration programs are detailed, as are fundamental research and development activities.
\end{abstract}

\section{Introduction}

In this paper, experimental aerothermodynamic capabilities for Entry, Descent, and Landing (EDL) at the NASA Langley Research Center (LaRC) will be reviewed and a resume of recent flight mission support and research and development activities will be presented. Historically, NASA LaRC has provided experimental aerothermodynamic support to all of the Agency's hypersonic flight programs from the initial Gemini-Mercury-Apollo space race to development of the Space Shuttle and exploration of Mars. More recently, LaRC experimental capabilities have been key contributors to the Mars Science Laboratory and Orion Multi-Purpose Crew Vehicle programs. The focus of this review will be on mid to low lift-to-drag (L/D) ratio type vehicle geometries; LaRC contributions to other types of hypersonic flight programs (e.g. winged craft, propulsion demonstrations), such as the Shuttle Orbiter, "XPlanes" (e.g. X-33, X-34, X-38), and hypersonic flight research (X-43, HIFire, etc.) have been documented extensively elsewhere.

Mission safety and success for any EDL program requires a detailed understanding of the aerothermodynamic environment, which encompasses the inter-related areas of aerodynamics (static, dynamic, and aeroelastic), heattransfer (convective and radiative), fluid mechanics (shock-shock interactions, boundary-layer transition, flow separation and attachment) and high-temperature thermodynamics (gas kinetics and chemistry). Aerothermodynamic EDL environments can be defined through ground-test experimentation, Computational Fluid Dynamics (CFD) simulations, and/or flight-testing. For most EDL missions, none of these disciplines alone can provide all the required aerothermodynamic information and in an ideal situation all three would be employed. In general though, flight-testing is prohibitively expensive, whereas CFD simulation capabilities are less expensive and have seen extensive development in the last few decades, supplanting ground-test experimentation as the primary tool for the design and development of EDL missions. However, there are many complex aerothermodynamic phenomena for which CFD methods are impractical, inaccurate, or un-validated such as: boundary-layer transition; micro-feature environments (surface gaps, cavities, protrusions, etc.); unsteady wake flows; shock-shock interactions; retropropulsion and reaction control system (RCS) jet performance and interactions; and surfaceroughness heating augmentation which must instead be defined through wind tunnel testing. In recent years, obtaining high-fidelity data for computational model development and validation for such phenomena has become one of the primary roles of wind tunnel testing, in addition to its customary role of producing data for vehicle design, development, and performance evaluation. Therefore, the discipline of experimental aerothermodynamics will continue to be a critical contributor to EDL for the foreseeable future.

\footnotetext{
* Aerospace Engineer, Aerothermodynamics Branch, Research and Technology Directorate

${ }^{\dagger}$ AIAA Associate Fellow

* AIAA Senior Member

$\S$ Branch Head, Supersonic/Hypersonic Testing Branch, Research and Technology Directorate

*** Branch Head, Aerothermodynamics Branch, Research and Technology Directorate

${ }^{\dagger}$ Aerospace Engineer, Atmospheric Flight and Entry Systems Branch, Engineering Directorate
}

1

American Institute of Aeronautics and Astronautics 


\section{Review of EDL Facilities and Capabilities at NASA LaRC}

\section{A. Facility Roster}

The Langley Aerothermodynamic Laboratories (LAL) current roster includes four conventional, perfect-gas, hypersonic blow-down wind tunnels (Figure 1): the 31-Inch Mach 10 Air Tunnel; the 20-Inch Mach 6 Air Tunnel; the 15-Inch High-Temperature Mach 6 Air Tunnel; and the 20-Inch Mach $6 \mathrm{CF}_{4}$ tunnel. The 31-Inch Mach 10 and 20-Inch Mach 6 Air tunnels are the workhorse facilities of the LAL in which the majority of testing is conducted. The 15-Inch High-Temperature Air tunnel, which is a leg of the 31-Inch Mach 10 Air Tunnel, is primarily used for instrumentation development and diagnostics. The 20-Inch Mach $6 \mathrm{CF}_{4}$ tunnel is currently mothballed and nonoperational. Detailed descriptions of these facilities and a historical perspective on their operation, maintenance, and upgrades can be found in Refs. 1 and 2.

In addition to the LAL hypersonic tunnels, the supersonic NASA Langley Unitary Plan Wind Tunnel (UPWT) has also at times been employed in an EDL aerothermodynamics role. The UPWT (Figure 2) is a closed-circuit, continuous-flow pressure tunnel with separate low supersonic Mach number (1.5 to 2.86) and high supersonic Mach number (2.3 to 4.63) legs. A detailed description of this facility and its capabilities is given in Refs. 3 and 4. Operations in the UPWT are currently maintained by Jacobs Engineering under a NASA Space Act Agreement

Information on all NASA wind tunnels across the speed range at Langley (and other centers) can be found at the NASA Aeronautics Program website http://www.aeronautics.gov/atp.

1. LaRC 31-Inch Mach 10 Air Tunnel

The 31-Inch Mach 10 Air Tunnel is a perfect-gas blow-down facility that uses dried, filtered air as the working fluid. The tunnel has been calibrated for reservoir conditions varying from $150 \mathrm{psi}$ to $1450 \mathrm{psi}$ at an operating temperature of $1850 \mathrm{deg}-\mathrm{R}$, which produces free-stream Reynolds numbers from $0.25 \times 10^{6} / \mathrm{ft}$ to $2.2 \times 10^{6} / \mathrm{ft}$. The nozzle is water-cooled, has a 3-D contour and ends with 1.07 in-square throat. The 31-inch square test section features abundant optical access (side, top and bottom windows) for visual imaging techniques and has a sidemounted injection system with a -10-deg to +45 -deg pitch range and \pm 5 -deg yaw range. The test core varies from approximately 12 -in $\times 12$-in. at the lowest Reynolds number to 14-in. $\times 14$-in. at the highest Reynolds number. This tunnel has the highest Mach number of the LAL facilities and is mainly employed in aerodynamic studies and fluidmechanics studies. The high stagnation temperature of the facility also make it suitable for aftbody/wake heating studies where heating rates are much lower than those on the forebody and are more difficult to measure accurately.

\section{LaRC 20-Inch Mach 6 Air Tunnel}

The 20-Inch Mach 6 Air Tunnel is a perfect-gas, blow-down facility that uses dried, filtered air as the working fluid. The tunnel has been calibrated for reservoir conditions varying from 30 psi to 475 psi at operating temperatures from $760 \mathrm{deg}-\mathrm{R}$ to $940 \mathrm{deg}-\mathrm{R}$, which produce free-stream Reynolds numbers from $0.5 \times 10^{6} / \mathrm{ft}$ to $8.0 \times$ $10^{6} / \mathrm{ft}$ at Mach numbers from 5.75 to 6.05 . The nozzle has a 2-D (top and bottom) contour with parallel side-walls that end in a 0.399 -in $\times 20$-in. throat. The 20.5-in $\times 20$-in. test section has a core size that varies with Reynolds number from approximately 13 -in. $\times 12$-in. to 14 -in $\times 16$-in. Optical access is provided through windows on the top and sides. The injection system is bottom mounted and has a -5 -deg to +55 -deg pitch range and \pm 10 -deg yaw range. With its wide Reynolds number operating range capable of producing laminar, transitional and turbulent flow, the tunnel is primarily used for heat-transfer and boundary-layer transition studies.

3. LaRC 15-Inch Mach 6 High-Temperature Air Tunnel

The 15-Inch Mach 6 Air High-Temperature Tunnel is a perfect-gas, blow-down facility that uses dried, filtered air as the working fluid. It operates from the same supply gas reservoir as the 31-Inch Mach 10 Tunnel and so it is considered to be a leg of that facility. While this facility operates at approximately the same Mach number and Reynolds numbers as the 20-Inch Mach 6 Air Tunnel, the stagnation temperature is much higher and thus it is referred to as a "high-temperature" Mach 6 tunnel in contrast to the 20-Inch Mach 6 Air Tunnel. The tunnel has been calibrated for reservoir conditions from $50 \mathrm{psi}$ to $450 \mathrm{psi}$ at temperatures of $940 \mathrm{deg}-\mathrm{R}$ to $1260 \mathrm{deg}-\mathrm{R}$ which $0.5 \times 10^{6} / \mathrm{ft}$ to $6.0 \times 10^{6} / \mathrm{ft}$. The axisymmetric nozzle has a 1.81 -in. throat diameter and a 14.57 -in. diameter exit into an open-jet test section. The test core is approximately 10 -in. diameter. The injection system is floor-mounted and has a pitch range of -10 -deg to +50 -deg and a yaw range of \pm 10 -deg. Because of its high stagnation temperature, this facility is primarily used as a test-bed for development of non-intrusive flow-field diagnostic techniques such as laser-induced fluorescence.

4. LaRC 20-Inch Mach $6 \mathrm{CF}_{4}$ Tunnel

The 20-Inch Mach $6 \mathrm{CF}_{4}$ Tunnel is a blow-down facility that uses pure $\mathrm{CF}_{4}$ for the working fluid to produce a much higher shock density ratio than the other perfect-gas air tunnels $\left(\rho_{2} / \rho_{1} \sim 11\right.$ for $\mathrm{CF}_{4}$ as opposed to $\rho_{2} / \rho_{1} \sim 5-6$ for air). The tunnel is calibrated for reservoir conditions from $100 \mathrm{psi}$ to $2000 \mathrm{psi}$ at a stagnation temperature of 1100 deg-R to $1480 \mathrm{deg}-\mathrm{R}$, which produces free-stream Reynolds numbers from $0.5 \times 10^{6} / \mathrm{ft}$ to $0.75 \times 10^{6} / \mathrm{ft}$ at a 
Mach number of 5.9 to 6.0. The tunnel's axisymmetric nozzle has a 0.446 -in. throat and a 20.0-in. exit into an openjet test section. The injection system is floor-mounted and has a pitch range of -10 -deg to +50 -deg and a yaw range of \pm 10 -deg. This facility is primarily used in an aerodynamics role. Because the thermodynamic properties of $\mathrm{CF}_{4}$ produce shock-density ratios comparable to that of high-temperature, reacting air at Mach numbers of 13 to 18 , it provides a low-cost simulation of aerodynamic characteristics at "flight-like" conditions.

5. LaRC Unitary Plan Wind Tunnel

The UPWT is a closed-circuit, continuous flow tunnel with two separate, $4 \mathrm{ft} \times 4 \mathrm{t}$ cross-section, $7 \mathrm{ft}$ long test sections. Test Section 1 operates over a Mach number range of 1.50 to 2.86 with a stagnation pressure of up to 50 psia. Test Section 2 operates over a Mach number range of 2.30 to 4.63 with a stagnation pressure of up to 100 psia. Air supply is provided by a $100,000 \mathrm{hp}$ compressor. Both test sections have axisymmetric, sliding-block nozzles that vary the throat-to-test-section ratio to provide their respective Mach number ranges. With its continuous flow operational mode, the facility is primarily used for aerodynamic database development, although aerodynamic configuration screening and aeroheating testing can also be performed.

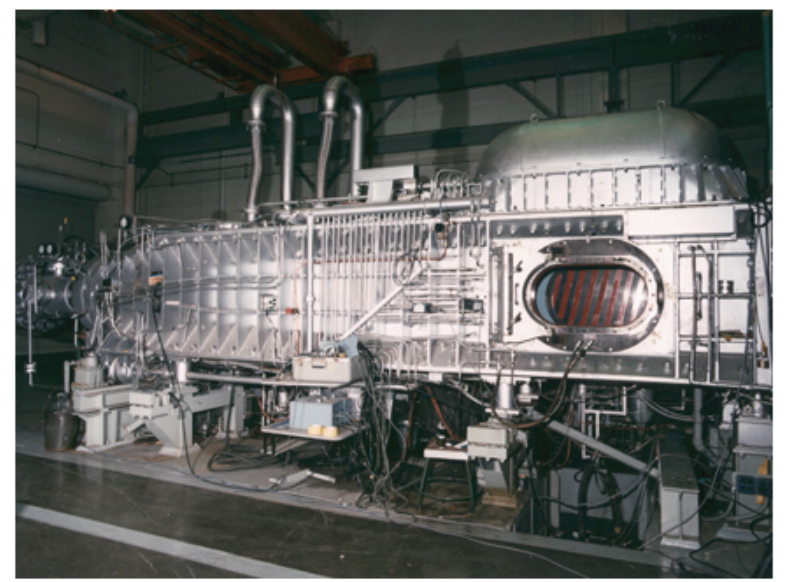

LaRC 31-Inch Mach 10 Air Tunnel

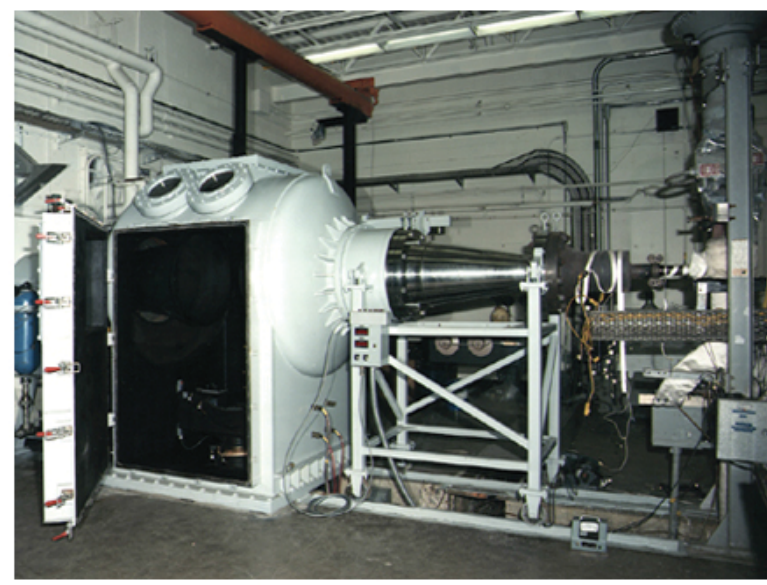

LaRC 20-Inch Mach 6 CF4 Tunnel

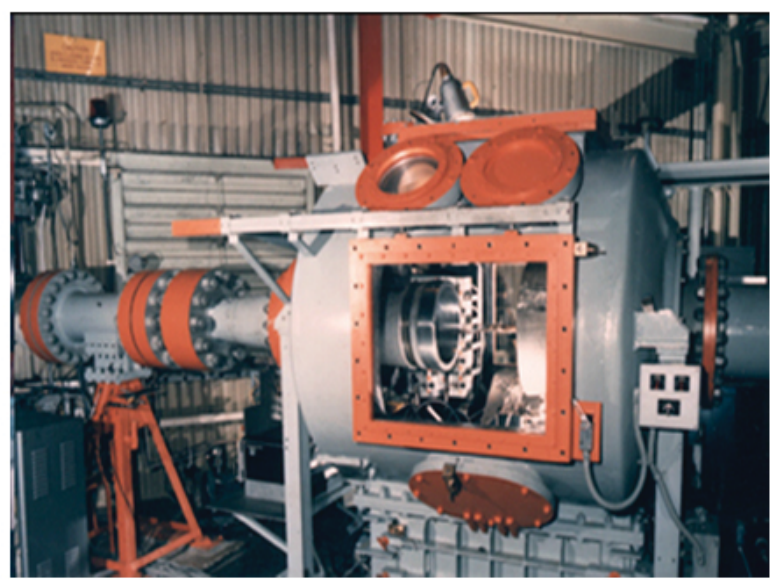

LaRC 15-Inch Mach 6 High Temperature Air Tunnel

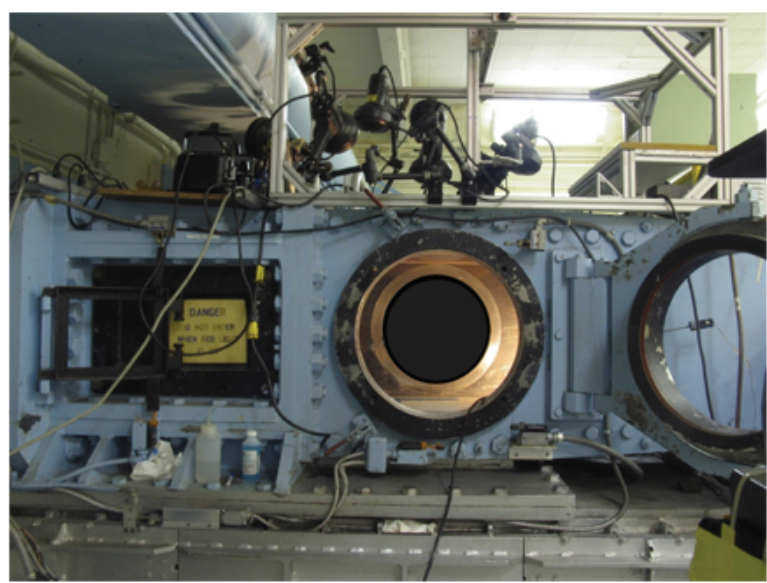

LaRC 20-Inch Mach 6 Air Tunnel

Figure 1. Hypersonic Wind Tunnels of the Langley Aerothermodynamic Laboratories 

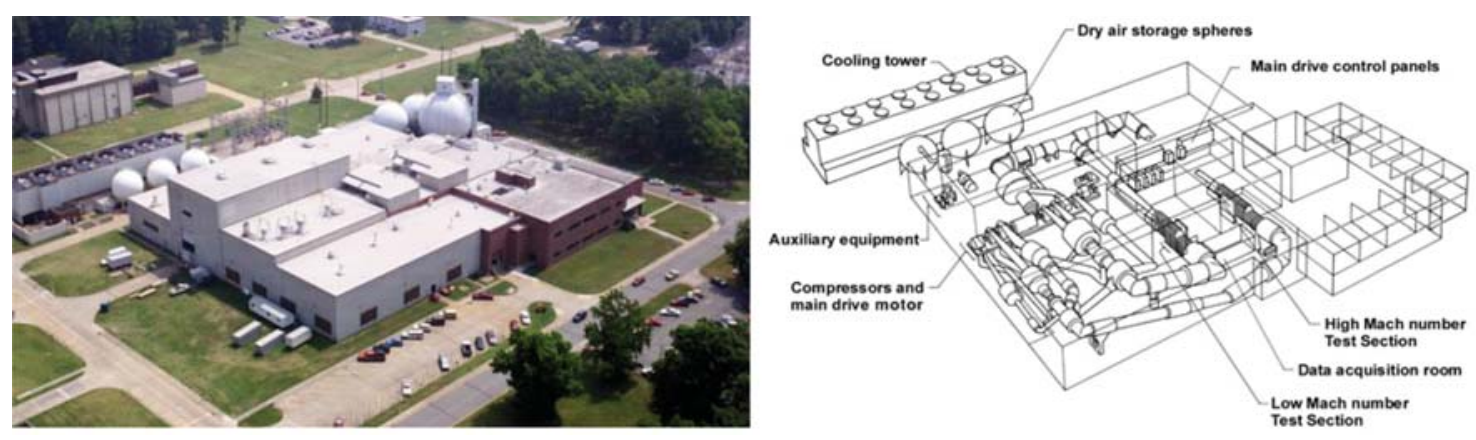

Figure 2. Langley Unitary Plan Wind Tunnel

\section{B. Personnel}

Experimental EDL activities at LaRC are centered in the Aerothermodynamics Branch, which maintains primary responsibility for testing in the LAL hypersonic facilities. This branch is also the center for development, maintenance, and application of high fidelity CFD tools for EDL studies. EDL testing in the LaRC UPWT is mainly conducted by the LaRC Configuration Aerodynamics Branch personnel and occasionally by Aerothermodynamics Branch personnel. EDL activities dealing with systems integration, mission simulation, and flight-database development are performed in the LaRC Atmospheric Flight and Entry Systems Branch. The complement of these organizations is in excess of 100 researchers, although not all are continuously involved in EDL-related activities.

\section{Test Techniques}

Measurement capabilities available in these hypersonic and supersonic facilities include a variety of discrete and global surface heat-transfer techniques; surface pressure and aerodynamic force-and-moment measurements, including stage-separation and RCS interactions; and flow-field visualization and diagnostics.

1. Global Surface Measurement Techniques

Phosphor thermography (Refs. 5 and 6) is the most commonly used heat-transfer measurement technique in the LAL hypersonic tunnels. This technique provides global heat-transfer (and boundary-layer transition onset) information with an order-of-magnitude more data points than discrete-gage techniques at a fraction of the cost. Phosphor-thermography measurements are performed on cast-ceramic models that have been coated with a phosphor compound that fluoresces in two distinct regions (green and red) of the visible light spectrum. Wind tunnel models are illuminated by ultraviolet light sources to stimulate emissions and images of the resulting fluorescent intensity are recorded before and during a run. The intensity data are converted to temperatures and then heat-transfer distributions are computed from the difference between pre-run and run temperatures using onedimensional, constant heat-transfer coefficient conduction theory. The resulting heat-transfer data are provided as two-dimensional (2-D) image data files and line-plot data sets can be extracted from the images at various stations. Additionally, image mapping of the 2-D data set to a three-dimensional surface geometry can be performed for use in data visualization software, which allows for direct comparisons to computed surface heating distributions.

Infrared thermography (Ref. 7) can also be employed in the LAL hypersonic tunnels as well as in the UPWT. In this technique, infrared emissions from a wind tunnel model are recorded and converted to temperatures using the emissivity of the model surface, which must be determined before testing. The pre-run and run temperature distributions are then used to determine heat-transfer rates using the same methods as for phosphor-thermography. As with phosphor thermography, this technique provides quantitative global surface heating data.

Pressure-sensitive and temperature-sensitive paint techniques (Ref. 8) are available for obtaining global surface pressure and temperature data. Both techniques depend on paint coatings that incorporate oxygen-sensitive luminescent materials; for PSP, the sensitivity is pressure dependent and for TSP the sensitivity is temperature dependent. These techniques provide 2-D mappings of surface pressure or temperature and methods of mapping these data to three-dimensional surfaces are available.

Oil flow visualization is employed to obtain surface flow-field patterns. In this technique, smooth-surfaced models are painted black and then coated with oils of various viscosities (depending on expected surface shear levels) that have been mixed with white pigment. Shear-forces at the surface cause the oil to move and coalesce along near-surface streamlines patterns and flow separation and reattachment lines.

2. Discrete Surface Measurement Techniques

A variety of discrete surface temperature, pressure, and heat-transfer measurement techniques are available in both the LAL hypersonic tunnels and the UPWT. Discrete measurement techniques are generally more expensive

4

American Institute of Aeronautics and Astronautics 
than global techniques and provide less spatial resolution. However, their use is often necessitated in situations when temporal data are required (e.g. for unsteady surface pressure or heat-transfer measurements), when optical access for imaging techniques is not possible (e.g. under wings or flaps), or when the properties to be measured are outside the range of optical techniques (e.g. very low surface temperature changes).

Discrete surface temperature and heat-transfer measurement techniques include thin-film resistance heat-transfer gages, coaxial thermocouples, and thin-skin calorimeter gages (i.e. back-face thermocouples), all of which also provide surface temperature measurements from which heat-transfer rates can be determined. Typical applications of these techniques are presented for thin-films in Ref. 9, thin-skin gages in Ref. 10, and coaxial thermocouples in Ref. 11. A general overview of the principles, applications and analysis methods for these techniques is provided in Ref. 12.

Discrete surface pressure instrumentation can be used for measurements of static and high-frequency, fluctuating pressures. Electronically-scanned pressure (ESP) transducer models are typically used for static measurements and PCB piezoelectric transducers or Kulite piezoresistive transducers are used for dynamic measurements (e.g. Ref. 13).

\section{Aerodynamic Force and Moment Measurements}

Force and moment measurements are performed using internal strain-gage balances. A roster of balances is available that covers a wide ranges of loads and sensitivities. Most balances provide six-component (normal, axial, and side forces and roll, pitch and yaw moments) and are water-cooled to compensate for aerodynamic heating. Typical balance applications are for the measurement of static forces and moments generated on a single model due to aerodynamic loads. However, multiple balances can employed for stage separation and interactions studies (e.g. Ref. 14). Aerodynamic performance and interaction effects due to RCS and retropropulsion jet firings can also be measured with five-component (no axial force) flow-through balances.

4. Flow-Field Diagnostics and Visualization Techniques

Schlieren systems are available for visualization of flow-field shock structures in all tunnels; laser vapor screening can also be employed in the UPWT. A variety of planar laser-induced fluorescence (PLIF) techniques (Refs. 15 and 16) can be employed to obtain velocimetry information on flow-field features such as boundary-layer transition, RCS plume expansion, etc. Pressure surveys can be performed using pitot probes to measure both timeaveraged (Ref. 17) flow quality and fluctuations (Ref. 18) that contribute to boundary-layer transition.

\section{Model Fabrication and Instrumentation}

Several methods are employed for fabrication of modesl to be tested in the LAL hypersonic tunnels and the UPWT. Depending on the model type and instrumentation requirements, model fabrication can be performed "inhouse" at Langley (Refs. 19 and 20) or models can be supplied by the test customer.

Machining of metallic force-and-moment models can be performed by Langley or its contractors or by the customer. Rapid-prototyping methods for force-and-moment models using casting or deposition processes are also available at Langley

For discrete surface pressure measurements, commercially available sensors are purchased and integrated into models. For global surface pressure (and temperature) coating of models with PSP (or TSP) is performed on-site

For discrete surface heat-transfer measurements with coaxial thermocouple, commercially-available sensors are purchased and integrated into a model. Thin-film and thin-skin sensors are usually produced and integrated at Langley. Techniques exist for use of thin-films on machined ceramic (e.g. Macor) or quartz models or on inserts, as well as for deposition on silica cast-ceramic models.

The fabrication of models for use with phosphor thermography is a specialized technique developed at Langley for this application. Model patterns are first generated (typically) using a rapid-prototyping stereo-lithography apparatus (SLA). An investment mold is then constructed from the SLA patterns and cured. A silica-ceramic slip cast is then made from the mold and sintered at high-temperature. Finally, the slip-cast ceramic model is and fired at high temperature and then coated with thermographic phosphor.

\section{E. Synergy with In-House Computational Capabilities}

Experimental studies at Langley are typically conducted in conjunction with computational simulations. The joint experimental-computational approach allows for validation of computational models, CFD definition of parameters for correlation or scaling to flight of the experimental data, and the use of computed flow-field properties to provide insight into the flow-physics (e.g. shock structure and interactions, boundary-layer separation and reattachment, sonic-line location, etc.) that produce the experimentally-measured properties.

For hypersonic conditions, the most commonly used tool is the LAURA (Langley Aerothermodynamic Upwind Relaxation Algorithm) code (Ref. 21). LAURA is a three-dimensional, structured, finite-volume Navier-Stokes 
codes which provides a variety of models for thermodynamic, kinetic and radiation phenomena. For computations at LAL wind tunnel conditions, a perfect-gas thermodynamic model is usually employed along with algebraic turbulence models when required.

For supersonic flow simulations, the FUN3D and OVERFLOW solvers are typically employed. Both are threedimensional, compressible-flow, Navier-Stokes solvers. To deal with complex topologies, FUN3D (Ref. 22) uses unstructured grids, while OVERFLOW (Ref. 23) uses multiple, overset structured grids. FUN3D can also be employed for simulation of complex geometries and flow-fields at low-enthalpy, hypersonic conditions and kinetic/thermodynamic models required for high-enthalpy, hypersonic simulations are being developed and validated for FUN3D (Ref. 24).

For the more specialized application of boundary-layer transition prediction, the stability code LASTRAC (Langley Stability and Transition Analysis Code) can be employed in conjunction with experimental studies. LASTRAC (Ref. 25) uses both quasi-parallel linear stability theory (LST) and Parabolized Stability Equations (PST) for stability analysis and $\mathrm{N}$-factor correlation of boundary layers.

\section{F. Off-site Testing Support}

In addition to conducting testing in the hypersonic LAL tunnels and the UPWT, the research staff has extensive experience in conducting research at other NASA, government, and commercial/academic facilities. In the following sections, testing performed by Langley researchers at off-site facilities such as CUBRC (Calspan University of Buffalo Research Center), AEDC (Arnold Engineering Development Center) and NASA ARC (Ames Research Center) will also be highlighted along with discussions of testing conducted at Langley.

\section{Flight Programs}

\section{A. Mars Science Laboratory (MSL)}

The successful landing of the Mars Science Laboratory's "Curiosity" Rover in August 2012 was enabled through EDL environment definition studies performed by NASA, including wind tunnel testing. Because the MSL entry vehicle (Figure 3) had the largest size $(4.5 \mathrm{~m} \mathrm{diam}$.) and greatest mass $(\sim 3380 \mathrm{~kg})$ of any probe ever sent to Mars, extensive computational modeling and experimental testing was conducted (e.g. Ref. 26) in order to define aeroheating environments, boundary-layer transition characteristics, aerodynamics, and RCS performance and interactions. These computational studies were complemented by experimental work conducted in Langley's hypersonic/supersonic wind tunnels or led by LaRC researchers working at other off-site facilities.
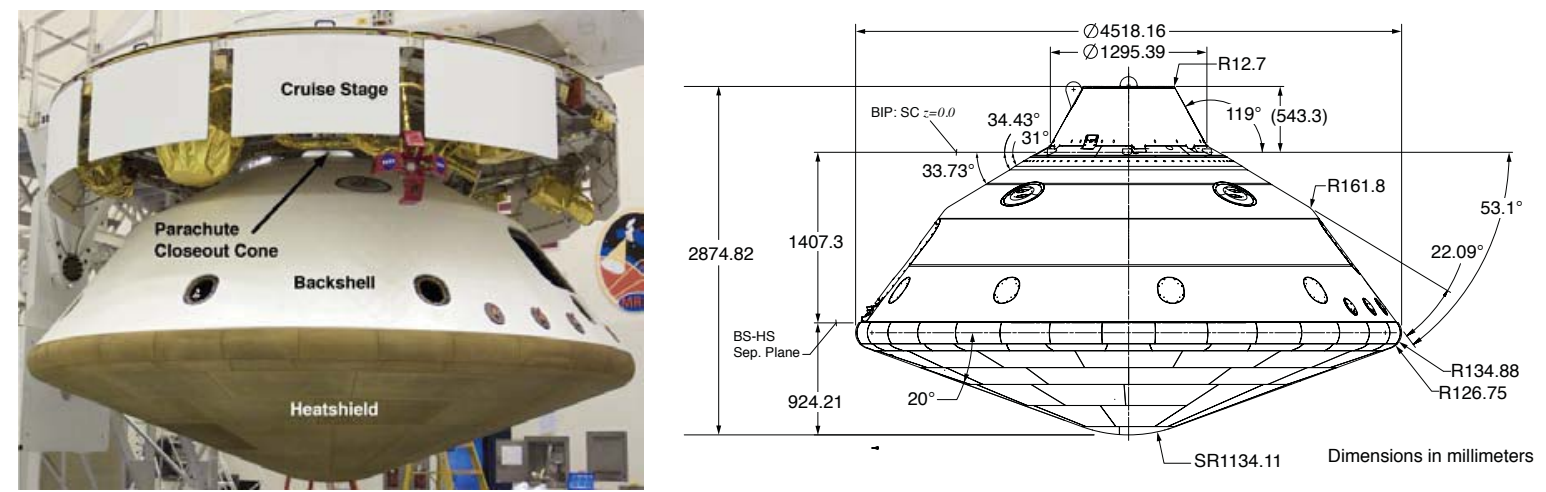

Figure 3. Mars Science Laboratory entry vehicle photograph and schematic

\section{Heat Shield Attachment-Point Cavities}

During initial development of the MSL entry vehicle, the mission configuration called for it to be mounted on the launch vehicle stack with the heat shield facing down (Figure 4). The attachment points for mounting the entry vehicle to the cruise stage thus would have been on the heat shield, leaving cavities in the heat shield after it separated from the cruise stage. Aeroheating tests (Ref. 27) were conducted in the LaRC 20-Inch Mach 6 Air Tunnel using global phosphor thermography to define the effects of the cavities on boundary-layer transition and heating. Data from MSL models with a range of cavity diameters and locations (Figure 5) were classified according to the cavity's effects on the boundary layer as "laminar", "local disturbance", "transition downstream", and "turbulent at cavity". Correlations were then developed (Figure 6) in terms of the ratio of cavity diameter to 
boundary-layer height $(w / \delta)$ vs. momentum thickness Reynolds number $\left(\operatorname{Re}_{\theta}\right)$ for the boundaries below which all data were laminar and above which all data were turbulent at the penetration. When applied to the MSL entry trajectory conditions, the correlations showed that the heat-shield cavities would produce transition very early in the flight. These expected adverse heating effects contributed to the decision to re-orient the heat shield to face upward, with the attachment points relocated to the aftbody where their effects would be less severe.

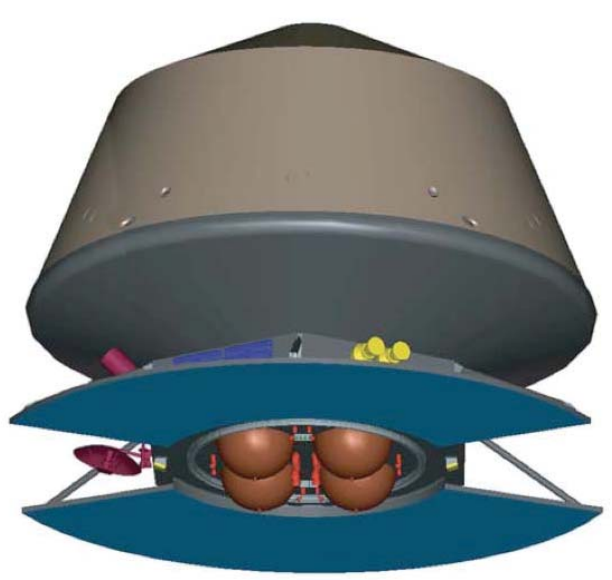

Figure 4. MSL entry vehicle (early configuration) and cruise stage

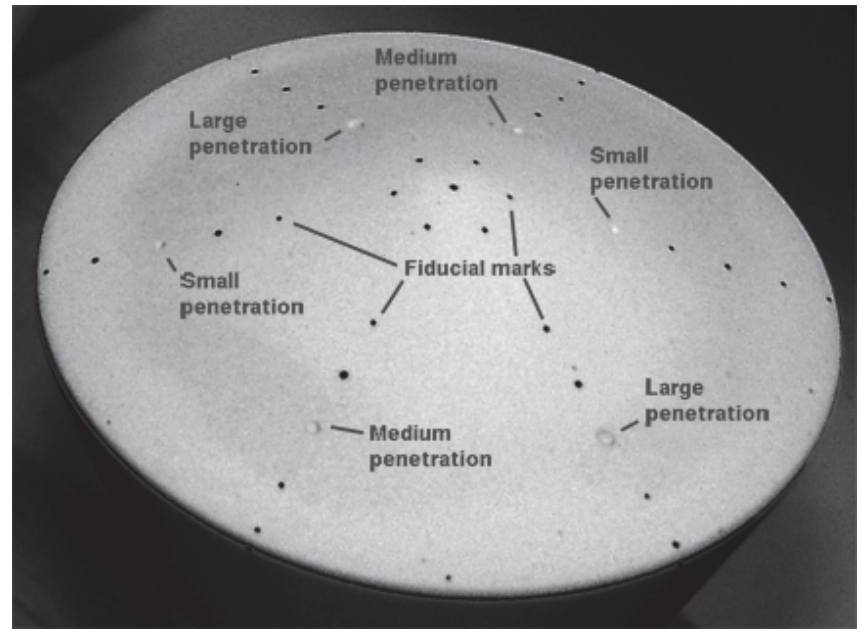

Figure 5. MSL heat-shield cavity wind tunnel model

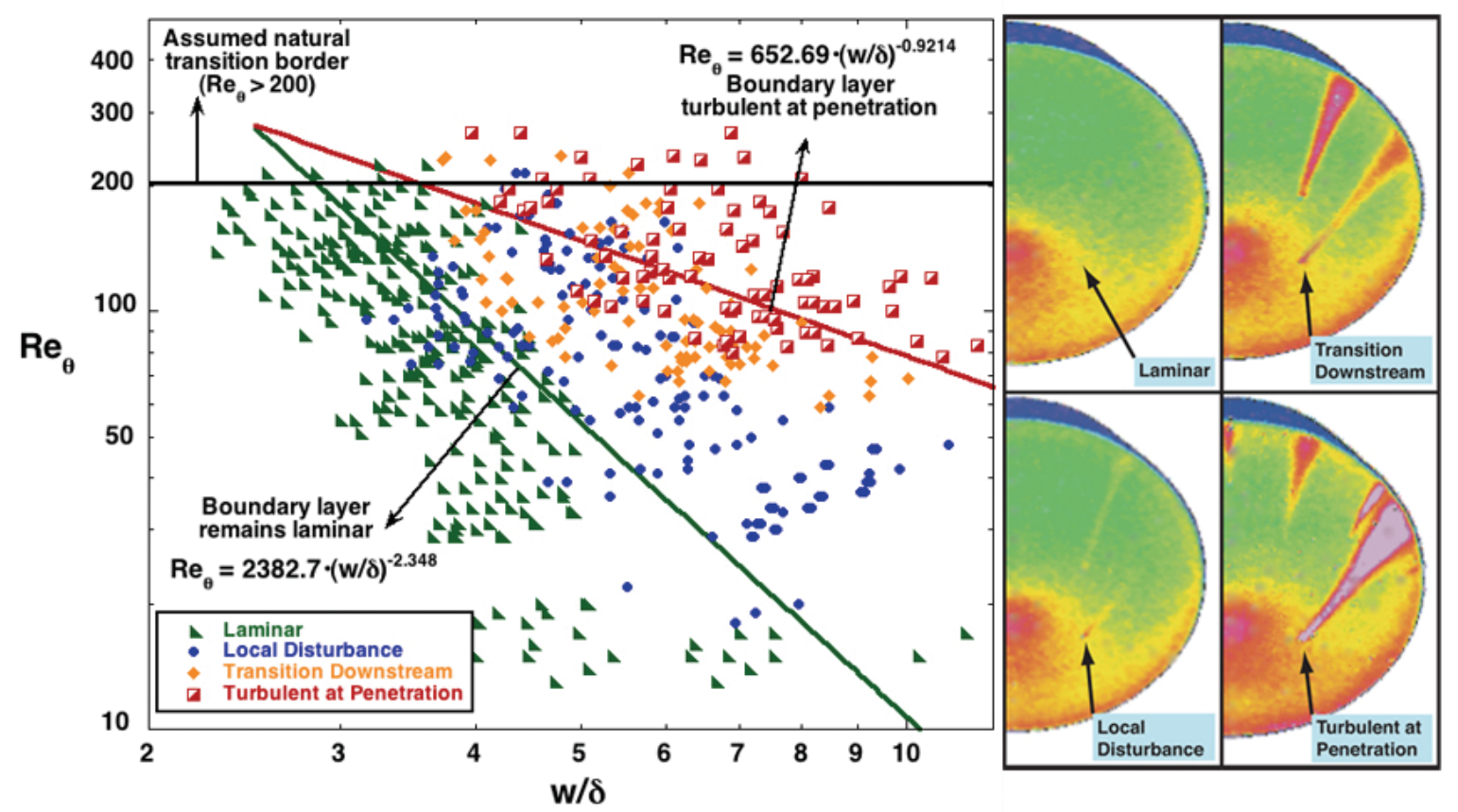

Figure 6. Correlation of MSL heat-shield cavity transition data from LaRC 20-Inch Mach 6 Air Tunnel

\section{Turbulent Aeroheating}

Because of the large size of its aeroshell (4.5 m diam.), high-angle of attack ( 16-deg) and high-entry velocity $(\sim 5.6 \mathrm{~km} / \mathrm{s})$ the possibility of turbulent flow being produced on the leeside of the aeroshell was an early design consideration. Preliminary testing in the LaRC 20-Inch Mach 6 Air Tunnel (Ref. 28) was conducted using 6-in. and 7 -in. diameter models over a Reynolds number range of $4.0 \times 10^{6} / \mathrm{ft}$ to $7.3 \times 10^{6} / \mathrm{ft}$ at angles of attack of 11 -deg to 20-deg using global phosphor thermography. The data (Figure 7 - Figure 8) showed boundary-layer transition leeward of the heat shield stagnation point with heating levels up to $25 \%$ higher than the peak laminar level at the nose. LaRC-led testing (Ref. 29) was conducted next in the AEDC Hypervelocity Tunnel 9. Testing was performed 
at high Reynolds numbers to obtain a fully-turbulent data set for comparison with CFD predictions in order to help assess computational uncertainty levels. Aeroheating measurements were made using a coaxial-thermocouple instrumented model (Figure 9). Based on the resulting good comparisons between turbulent data and predictions, such as for the sample case shown in Figure 10, the algebraic Baldwin-Lomax model was adopted as the design method for turbulent conditions.

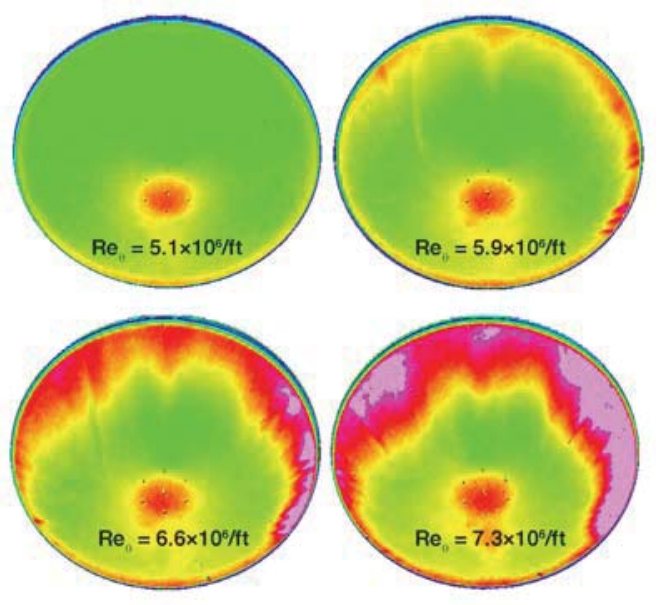

Figure 7. MSL global heating data from LaRC 20-Inch Mach 6 Air Tunnel
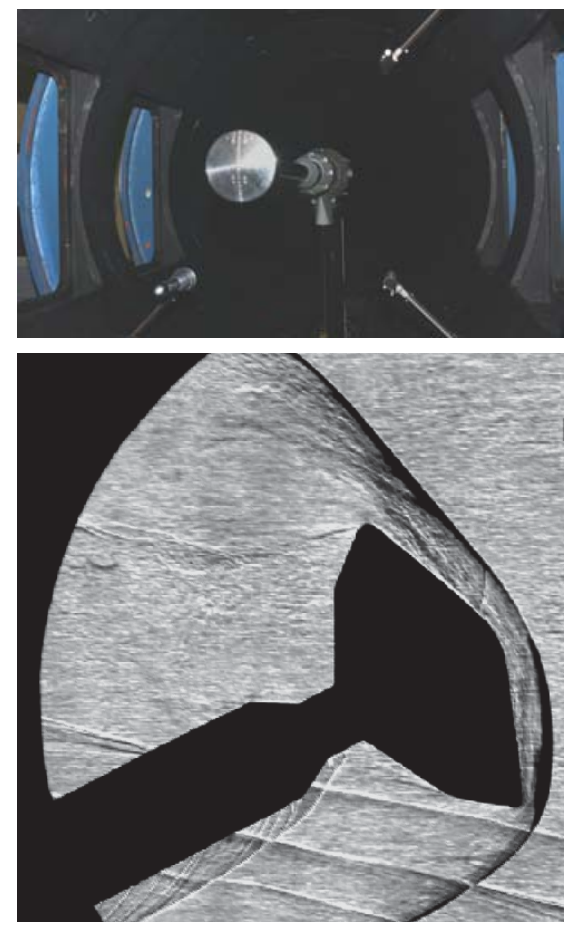

Figure 9. MSL heat-transfer model in AEDC Tunnel 9

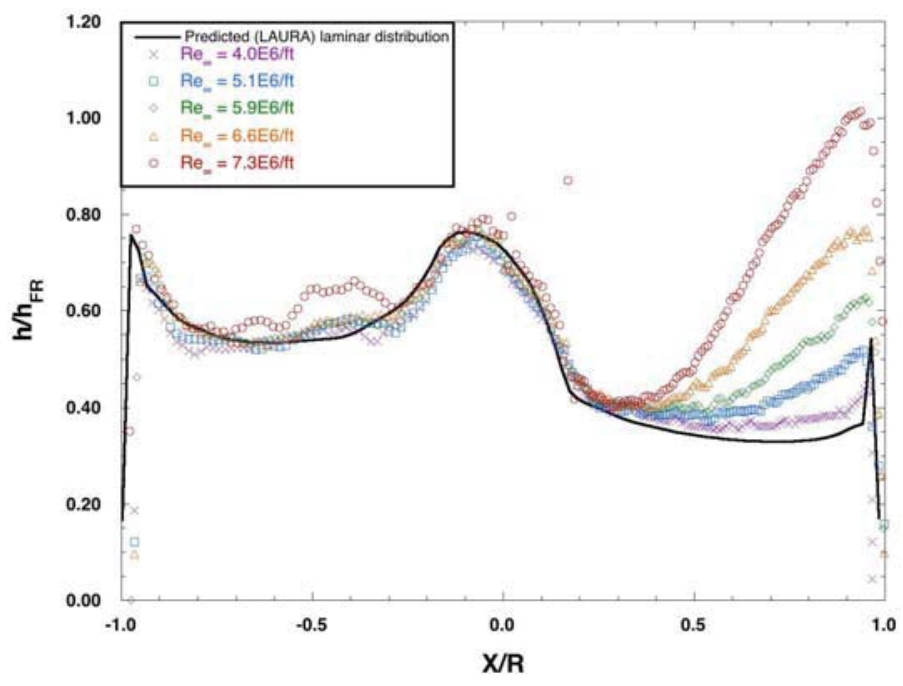

Figure 8. MSL centerline heating data from LaRC 20-Inch Mach 6 Air Tunnel

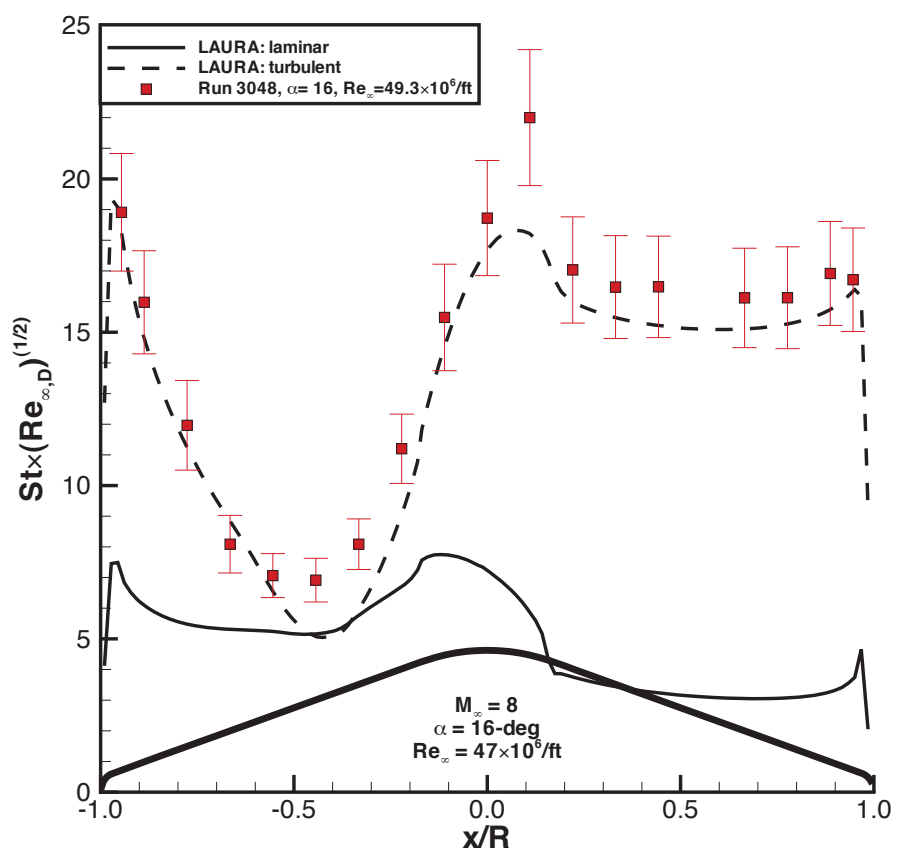

Figure 10. MSL centerline heating data from AEDC Tunnel 9 


\section{Supersonic Aerodynamics}

While the hypersonic aerodynamics of the MSL entry vehicle were based in part on heritage data and analysis from the Mars Viking mission and in part on modern CFD predictions, aerodynamic force-and-moment testing was performed (Ref. 30) in the LaRC UPWT (Figure 11) to verify the expected supersonic performance. Data were obtained for Mach numbers of 1.6 to 4.5 with angles-of-attack up to 36-deg. Good comparisons (Figure 12) were obtained between Viking-heritage data, CFD, and the new wind tunnel aerodynamic data.
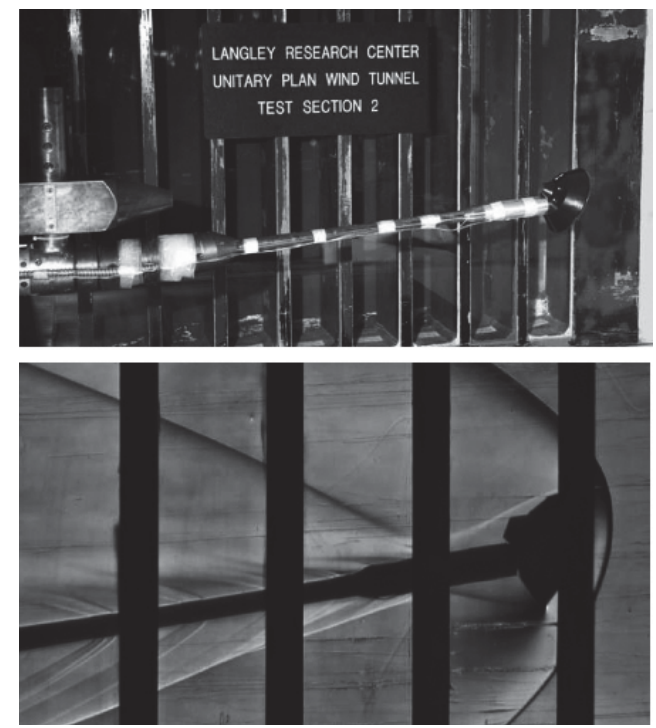

Figure 11. MSL force-and-moment model in LaRC UPWT

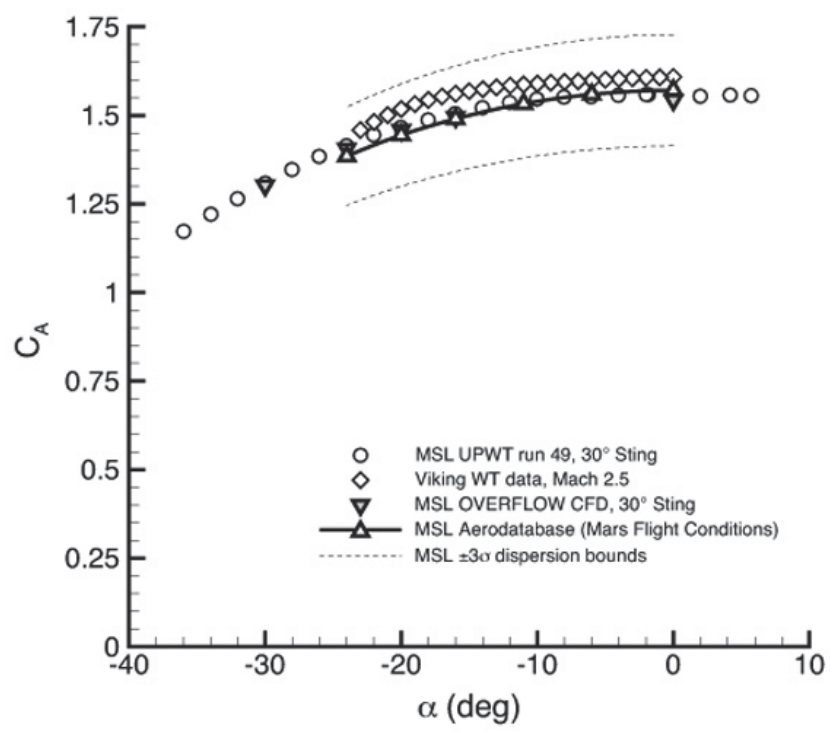

Figure 12. MSL axial force data from LaRC UPWT

\section{RCS Performance and Interactions}

The MSL entry vehicle has 4 pairs of dual jets oriented to provide roll, pitch, and yaw control through firings of different pairs. This configuration (Figure 13) is considerably different from that of Viking, so heritage data did not apply. The computational challenges in modeling wake flows with RCS were considerable, therefore, supersonic and hypersonic testing of the RCS jets was conducted (Ref. 30, 31) in the LaRC UPWT and LaRC 31-Inch Mach 10 Air Tunnel, respectively to gather aerodynamic interaction data. Data were obtained (Figure 14) at angles-of-attack of 0-deg to -30-deg in the 31-Inch Mach 10 Air Tunnel and at -15-deg to +15-deg, in the UPWT with Mach numbers of $2.5-4.5$. Flow-field imaging of the RCS jet structure (Figure 15) was also performed in the 31-Inch Mach 10 Air Tunnel tests using PLIF (Ref. 32). Because of the difficulties in both computational and experimental simulations of RCS jet interactions only qualitative results were obtained. However, the general finding was that the maximum interaction effects were less than $30 \%$ of the RCS-generated torques, which was within the control authority of the system. 


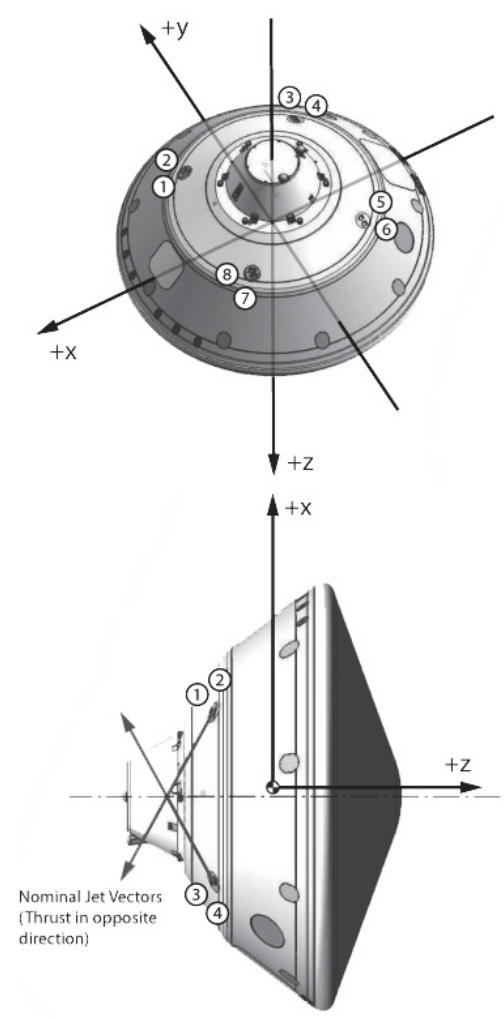

Figure 13. MSL RCS layout

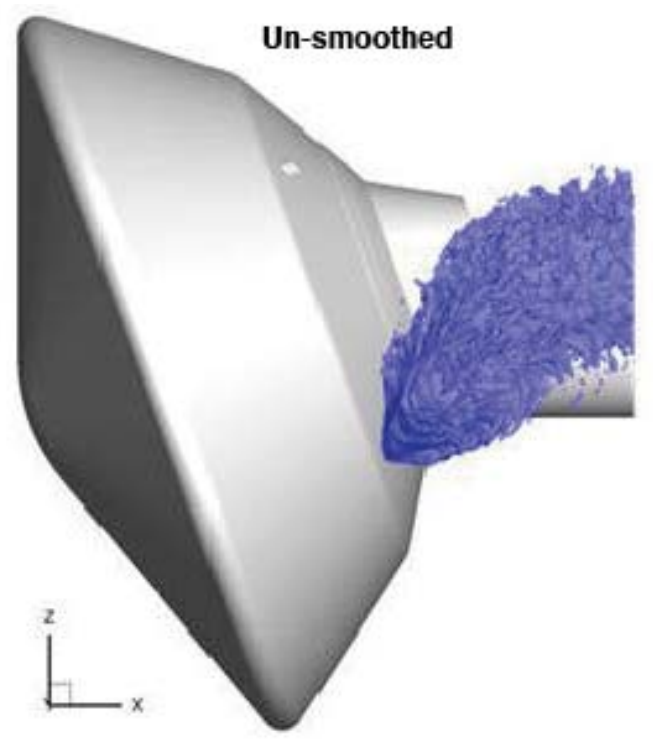

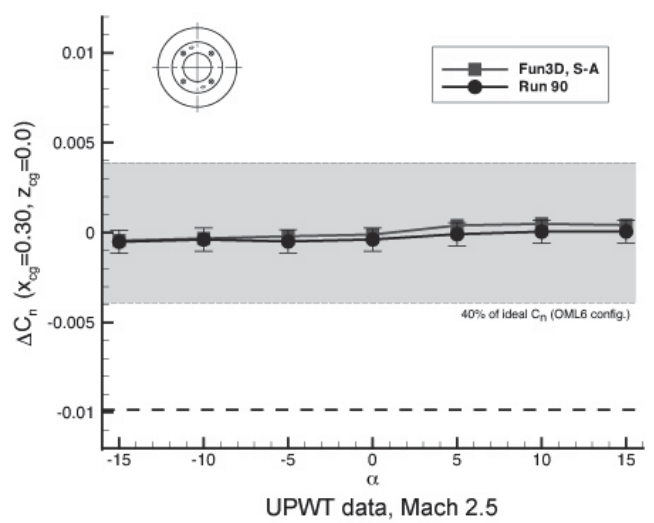

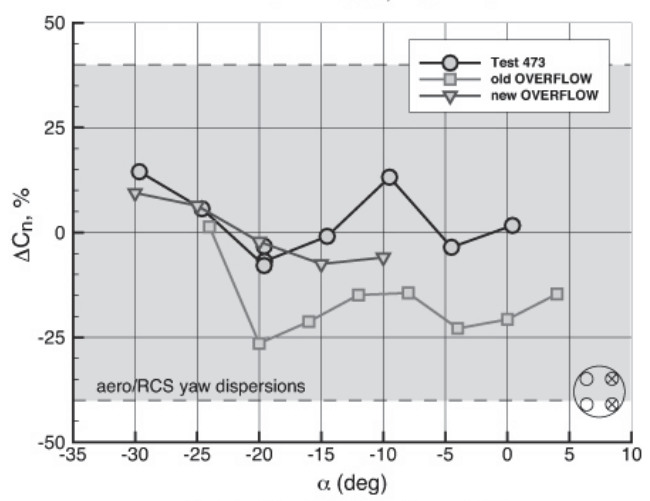

31-Inch Mach 10 Air Tunnel data

Figure 14. MSL RCS interaction data from LaRC UPWT and 31-Inch Mach 10 Air Tunnels

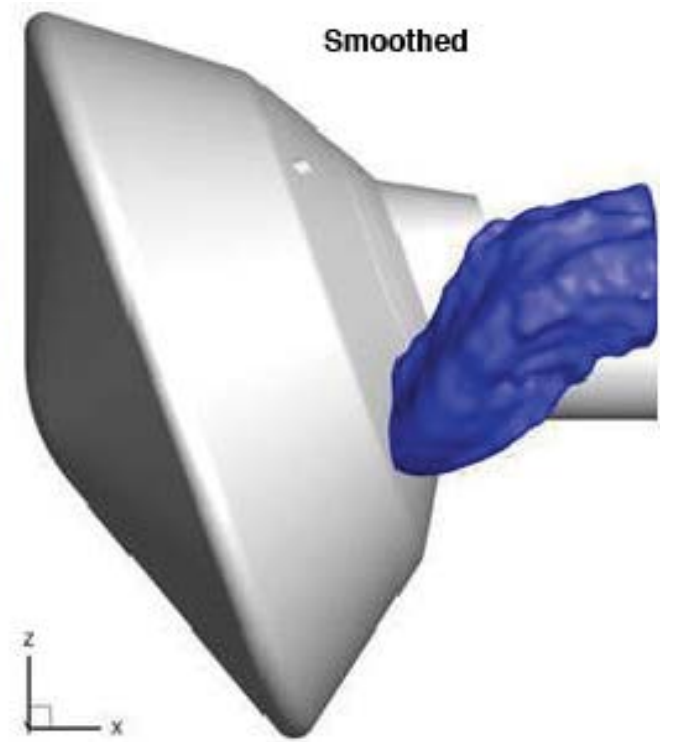

Figure 15. PLIF Visualization of MSL RCS jet flow field from 31-Inch Mach 10 Air Tunnel

\section{MMRTG Breakup Analysis}

MSL's Curiosity rover is powered by a Multi-Mission Radioisotope Thermoelectric Generator (MMRTG), which converts the heat released by the decay of Plutonium-238 into electricity. Because the MMRTG (Figure 16) contains radioactive material, a breakup analysis was performed to verify the safety of the MMTRG in case of a launch accident. The multiple-finned geometry of the MMRTG was too complex for efficient simulation using 
CFD, therefore the safety analysis was based in part on aerodynamic force-and-moment and global phosphor thermography aeroheating data (Figure 17) obtained through testing in the LaRC 31-Inch Mach 10 Air Tunnel.

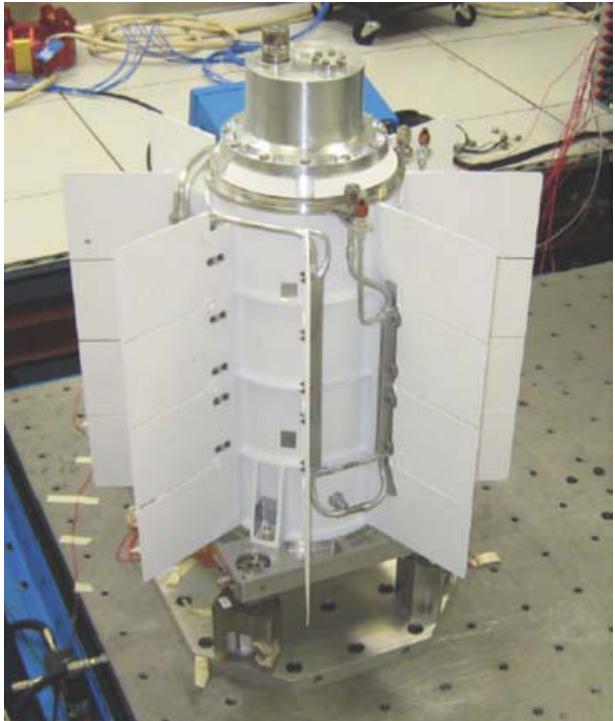

Figure 16. MMRTG power unit for MSL Curiosity rover

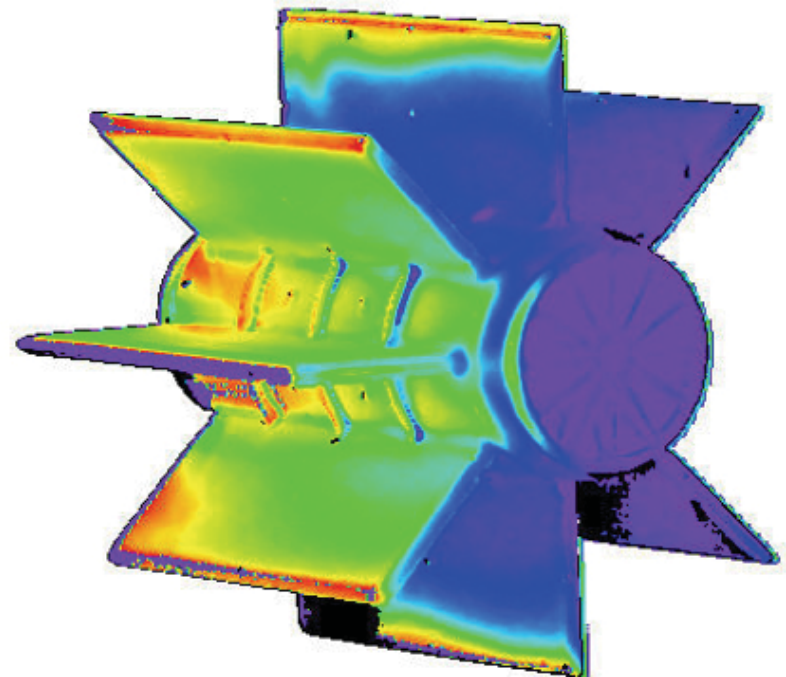

Figure 17. MMRTG global heating data from LaRC 31-Inch Mach 10 Air Tunnel

\section{B. Orion MPCV}

The Orion Multi-Purpose Crew Vehicle (MPCV), which was previously known as the Crew Exploration Vehicle (CEV), is an Apollo-like capsule being developed by NASA as a re-entry vehicle for human missions beyond Low Earth Orbit (LEO), as well as possibly for use in servicing the International Space Station. Despite some heritage relationship with the Apollo design, the Orion (Figure 18) will be considerably larger, with higher heating rates and aerodynamic loads, and will differ geometrically from Apollo (mainly in the shape of the crew-compartment). Therefore, an intensive computational and experimental analysis was performed by the CEV Computational Aerosciences Project (CAP) to define aerothermodynamic environments for the vehicle. Overall summaries of the CAP experimental aeroheating and aerodynamic test programs are presented in Refs. 33 and 34, respectively. Studies performed at LaRC facilities or led by LaRC researchers at off-site facilities are discussed below.
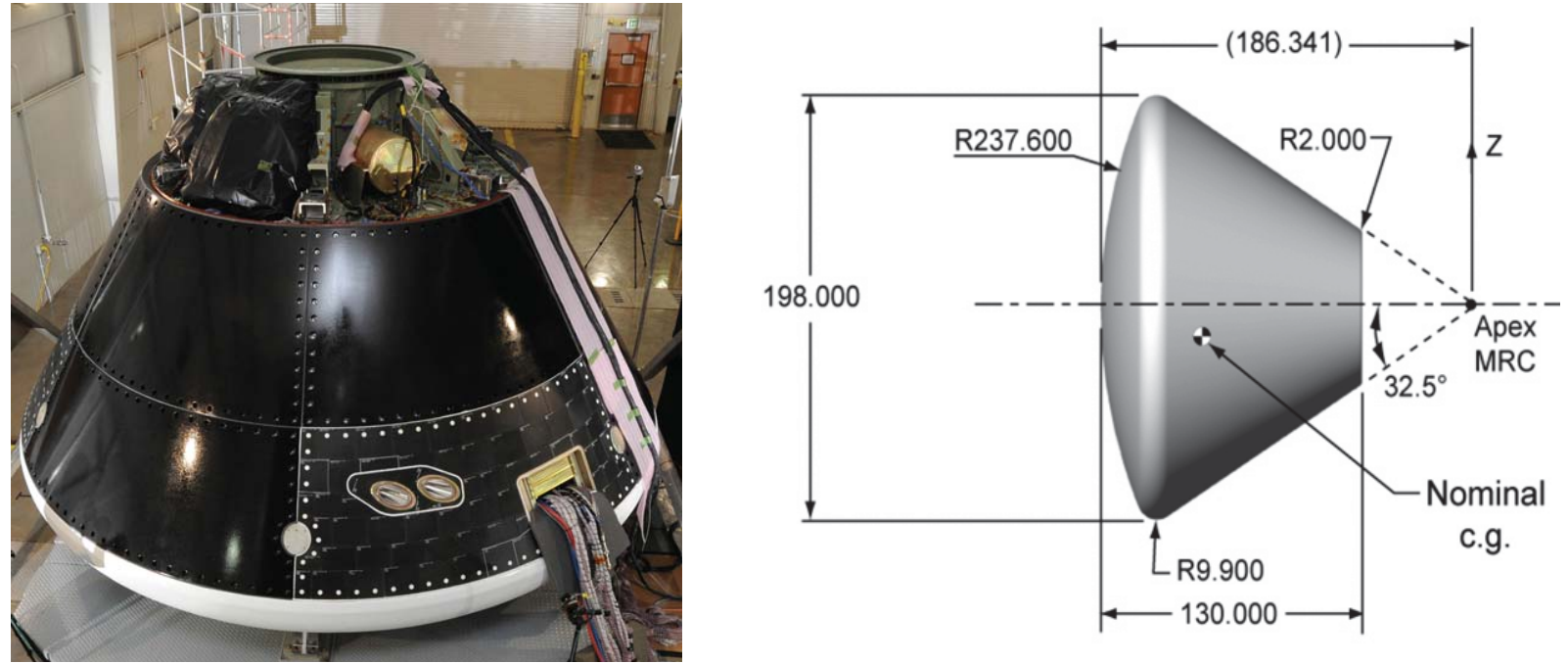

Figure 18. Orion Multi-Purpose Crew Vehicle preliminary design - photograph of mock-up and schematic 


\section{Boundary-Layer Transition and Turbulence}

Because of the large size of the Orion ( $5 \mathrm{~m}$ diam.), its high-angle of attack during entry (18-deg to 28-deg), and it high entry velocity (up to $11 \mathrm{~km} / \mathrm{sec}$ for Lunar return missions), a turbulent flow design environment has been specified for the vehicle. Several experimental studies were thus conducted to obtain turbulent aeroheating data on the vehicle.

In the first test series (Refs. 35 and 36), aeroheating data were obtained in the LaRC 20-Inch Mach 6 Air Tunnel (CAP Test 31-CH) and 31-Inch Mach 10 Air Tunnel (CAP Test 32-CH) using global phosphor thermography. Aeroheating data were gathered on the heat-shield (forebody) and crew compartment (aftbody) in both tests. Sample heat-shield data from the Mach 6 tests (with turbulent flow produced using boundary-layer trips) are shown in Figure 19 and Figure 20. Turbulent CFD predictions compared well to the tripped heat-shield data. Sample crew-compartment data from the Mach 10 tests are shown in Figure 21. Flow on the crew-compartment was found to remain laminar at the test conditions.
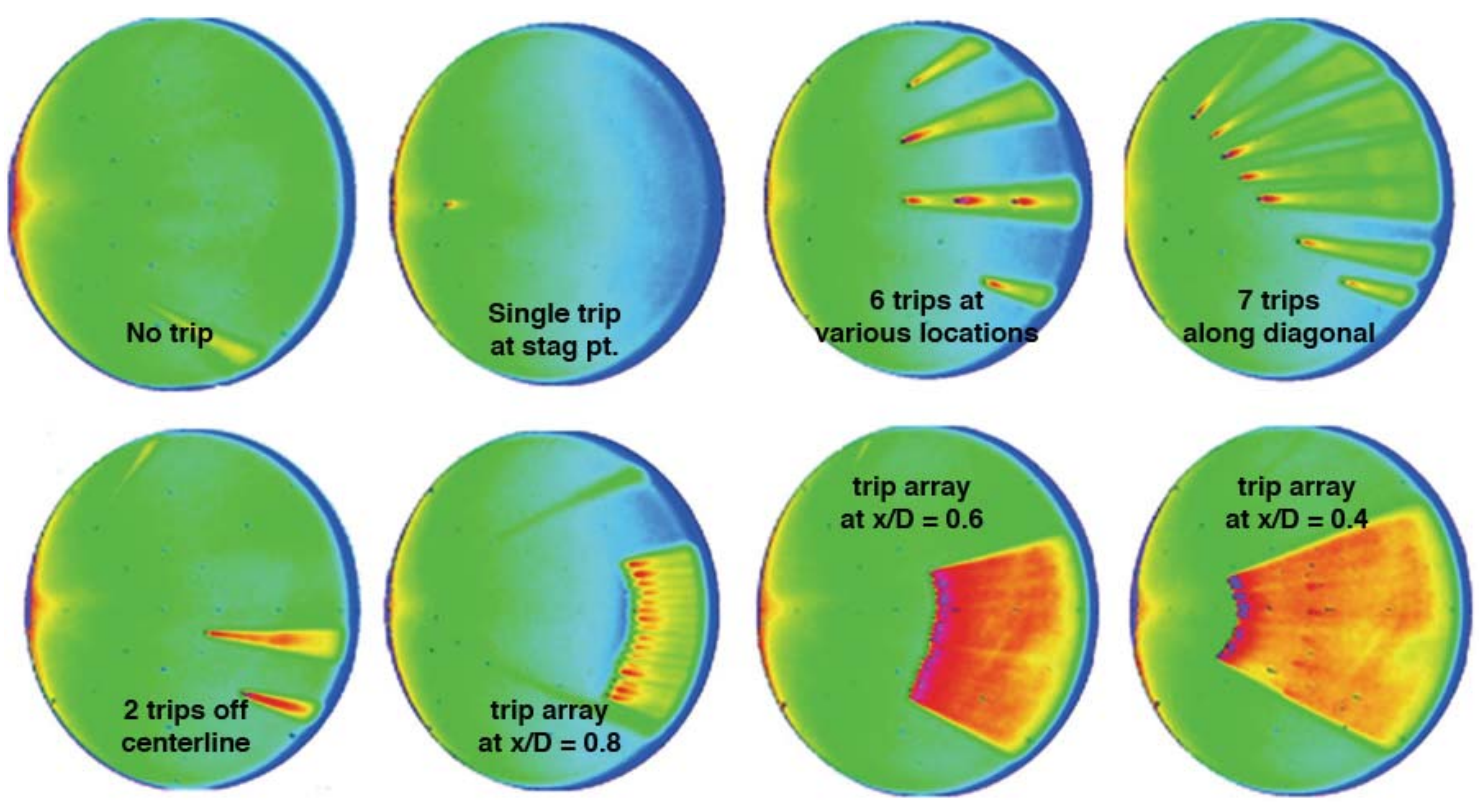

Figure 19. Orion heating data from LaRC 20-Inch Mach 6 Air Tunnel showing effects of trip placement

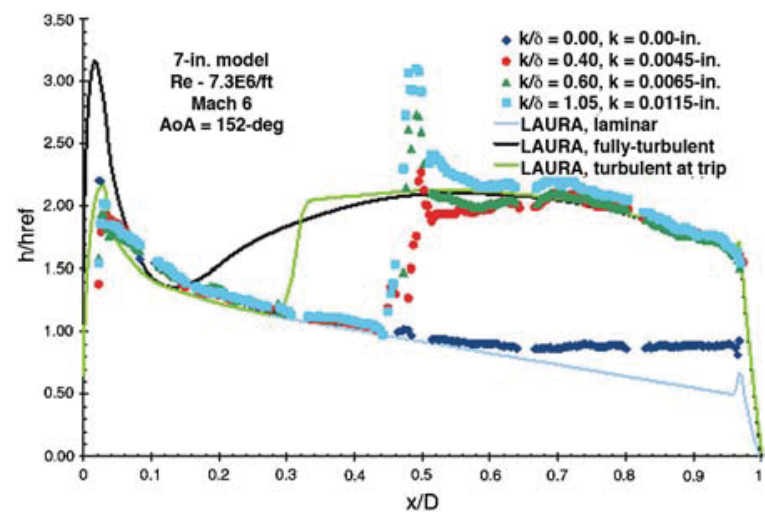

Figure 20. Orion heat-shield centerline heating data from LaRC 20-Inch Mach 6 Air Tunnel and comparisons with CFD

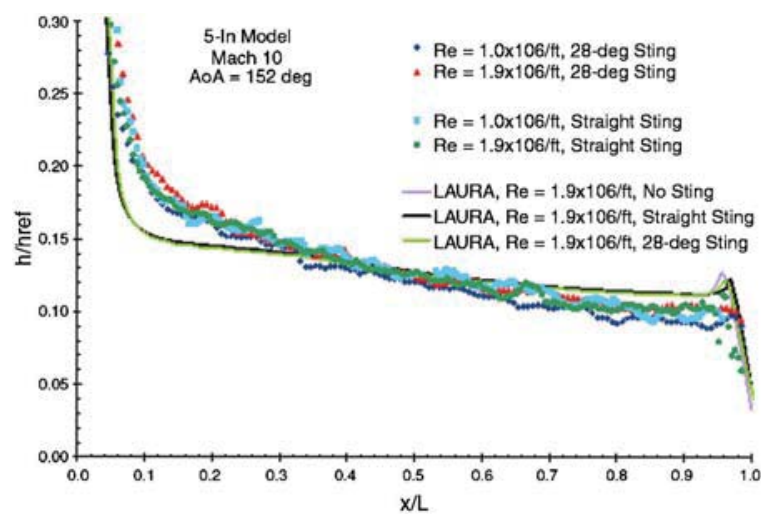

Figure 21. Orion crew-compartment centerline heating data from LaRC 31-Inch Mach 10 Air Tunnel and comparisons with CFD

LaRC-led testing was then conducted (Ref. 37) in the AEDC Hypervelocity Tunnel 9 (CAP Test 36-CH) in order to obtain naturally turbulent data at very high Reynolds numbers for comparisons with CFD turbulence models. Aeroheating data were obtained at discrete heat-shield and crew-compartment locations using a thermocoupleinstrumented model. Algebraic turbulence models (Cebeci-Smith and Baldwin-Lomax) were demonstrated to 
compare very well to these experimental data and were adopted as the design methodology for the program. Computational predictions were in good agreement with both laminar and turbulent data at Mach 8 and Mach 10 test conditions (Figure 22). Preliminary, smooth-wall transition correlations were also generated from these data; heatshield transition occurred in the $\operatorname{Re}_{\theta}=200-300$ range, while transition on the crew compartment occurred around $\operatorname{Re}_{\theta}=400$.

The wind tunnel model fabricated for the AEDC test was also tested in the LaRC 20-Inch Mach 6 Air Tunnel (CAP Test 56-CH). Boundary-layer trips were employed to obtain data at turbulent flow conditions (Ref. 38) and the onset of natural boundary-layer transition was examined (Ref. 39). The boundary-layer transition data from this test reinforced the turbulent design philosophy of the program by demonstrating transition at $\operatorname{Re}_{\theta}$ levels comparable to those expected in flight. Additionally, the tripped data from this test and from the AEDC test of the same model were used to formulate preliminary protuberance boundary-layer transition criteria (Figure 23 - Figure 24). Finally, this test-series provided an opportunity to validate the acquisition of heat-transfer data during continuous pitchsweep operating mode as was done in the prior AEDC test.
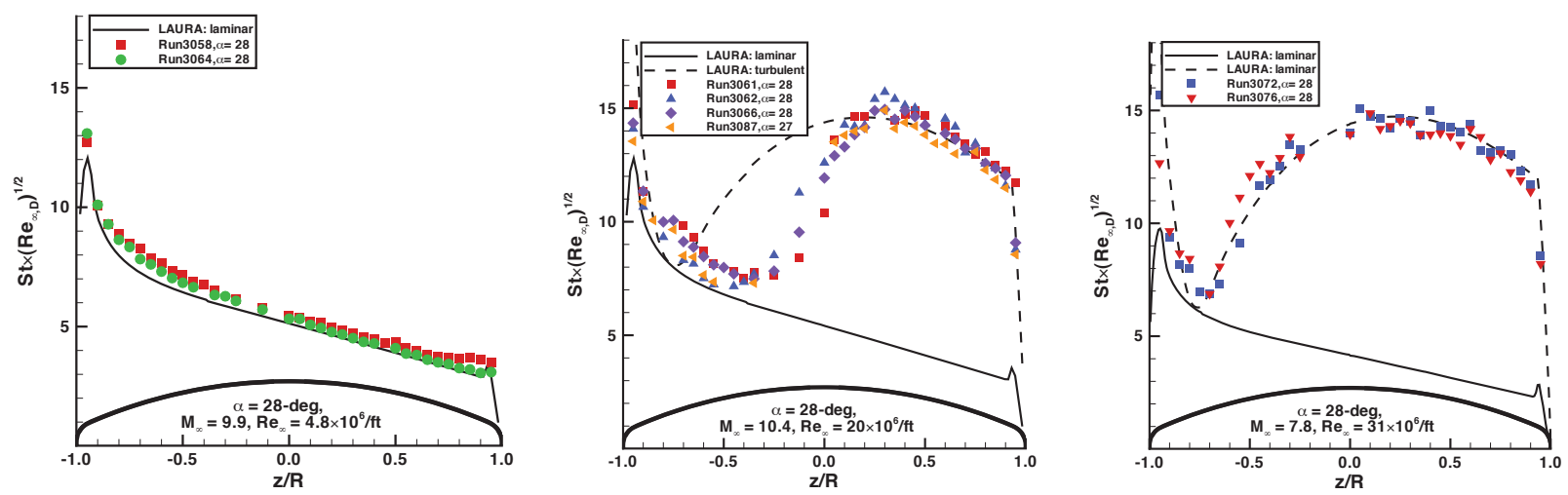

Figure 22. Orion heat-shield centerline heating data at multiple Reynolds numbers from AEDC Hypervelocity Tunnel 9 and comparisons with CFD

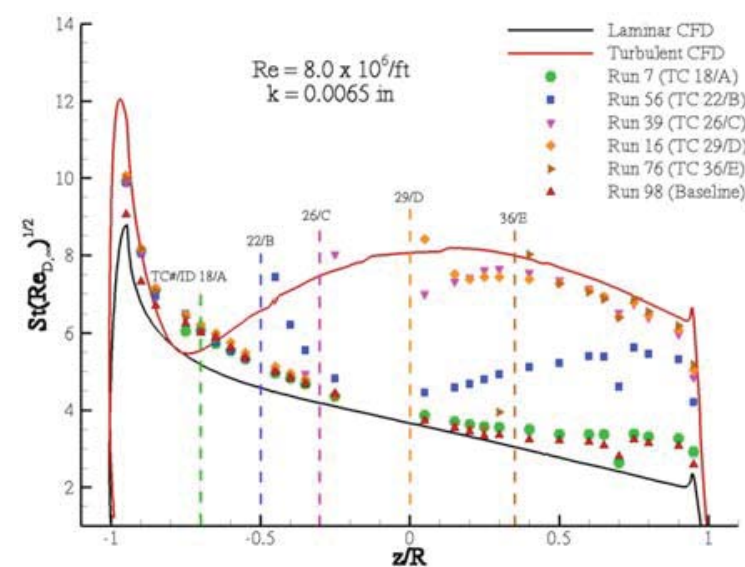

Figure 23. Orion heat-shield data from LaRC 20-Inch Mach 6 Air Tunnel showing trips effects at various locations

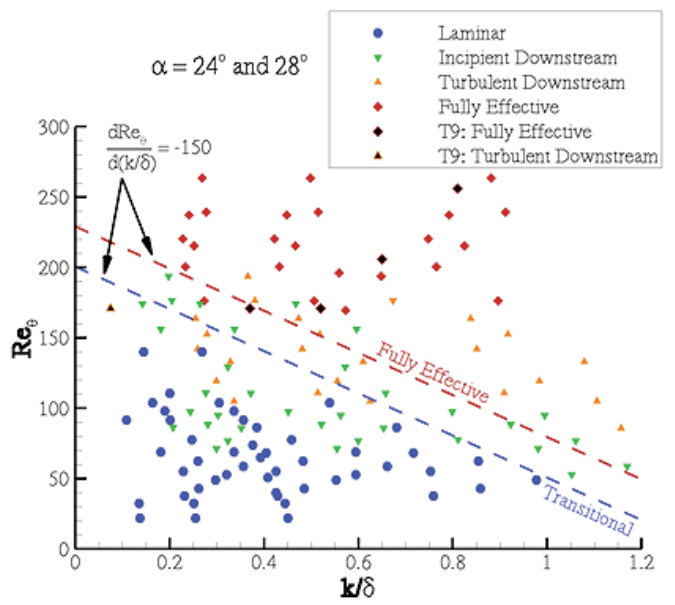

Figure 24. Trip-effectiveness correlation developed from LaRC and AEDC data sets on Orion heatshield

\section{Compression Pad Cavities}

Unlike MSL, Orion will carry crew who must be seated in an upright position during launch. Thus, the vehicle must be oriented heat-shield downward which means that the cavities for the compression pad attachment points will be located on the heat-shield. The mechanical design of the attachment mechanism has gone through many design iterations. Initially, an 8-pad layout was considered with the possibility that tension ties would remain protruding from the heat-shield after separation from the service module. Various cavity and tension-tie sizes and tension tie locations were examined (Figure 25) through global phosphor thermography testing (Refs. 40 and 41 ) in 
the LaRC 20-Inch Mach 6 Air Tunnel (CAP Test 30-CH). Heating augmentation levels of up to 3 times that of a smooth OML were measured (Figure 26).

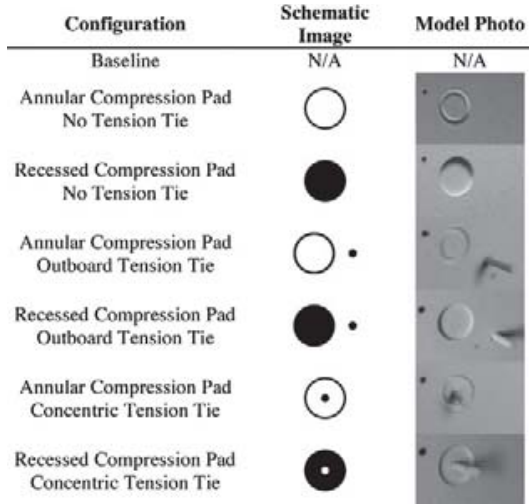

Figure 25. Initial Orion compression-pad parameters
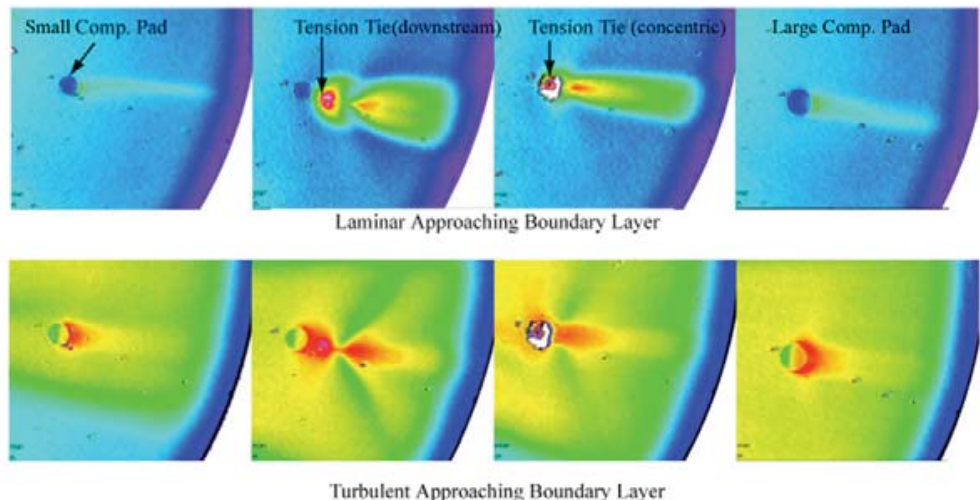

Figure 26. Orion heating data from LaRC 20-Inch Mach 6 Air Tunnel showing compression-pad effects

In the next design iteration, a 6-pad layout with recessed compression-pad cavities of various depths, diameters and bevel angles was considered (Refs. 42 - 44). Global phosphor thermography aeroheating measurements were made at laminar, transitional, and turbulent boundary-layer conditions in the LaRC 31-Inch Mach 10 Air and 20Inch Mach 6 Air Tunnels (CAP Tests 66-CH, 86-CH, and 87-CH). Similarly to the previous compression pad study, heating augmentation levels of up to 3 times that of a smooth OML were measured (Figure 27 and Figure 28). Boundary-layer transition data from both of these tests were correlated in terms of flow-field parameters. Comparisons to similar data from the MSL program revealed that the MSL and Orion cavity aspect ratios (diameter/depth) differed so greatly that the two data sets could not be reconciled. As per the terminology used in cavity-flow studies, the MSL cavities are deep and narrow, producing "open" cavity flow (separated, rotating flow within the cavity) and the Orion cavities are wide and shallow, producing "closed" cavity flow (boundary-layer attachment on the cavity floor). A closed-flow transition correlation for these data (Figure 29) was developed in a similar manner to the open-flow correlation for the MSL program.
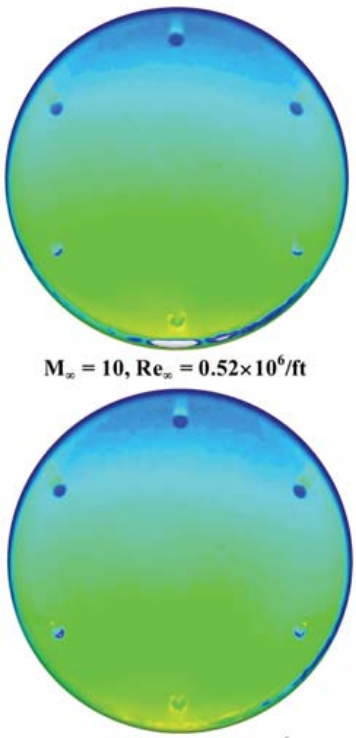

$M_{\infty}=10, \operatorname{Re}_{\infty}=1.02 \times 10^{6} / \mathrm{ft}$

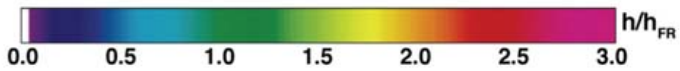

Figure 27. Orion compression-pad heating data from LaRC 31-Inch Mach 10 Air Tunnel

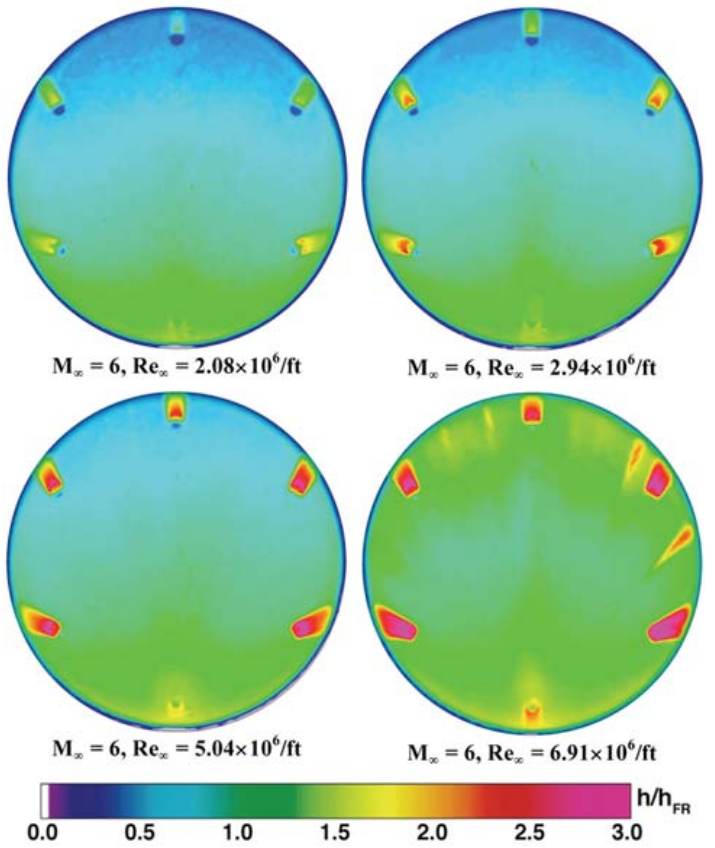

Figure 28. Orion compression-pad heating data from LaRC 20-Inch Mach 6 Air Tunnel 

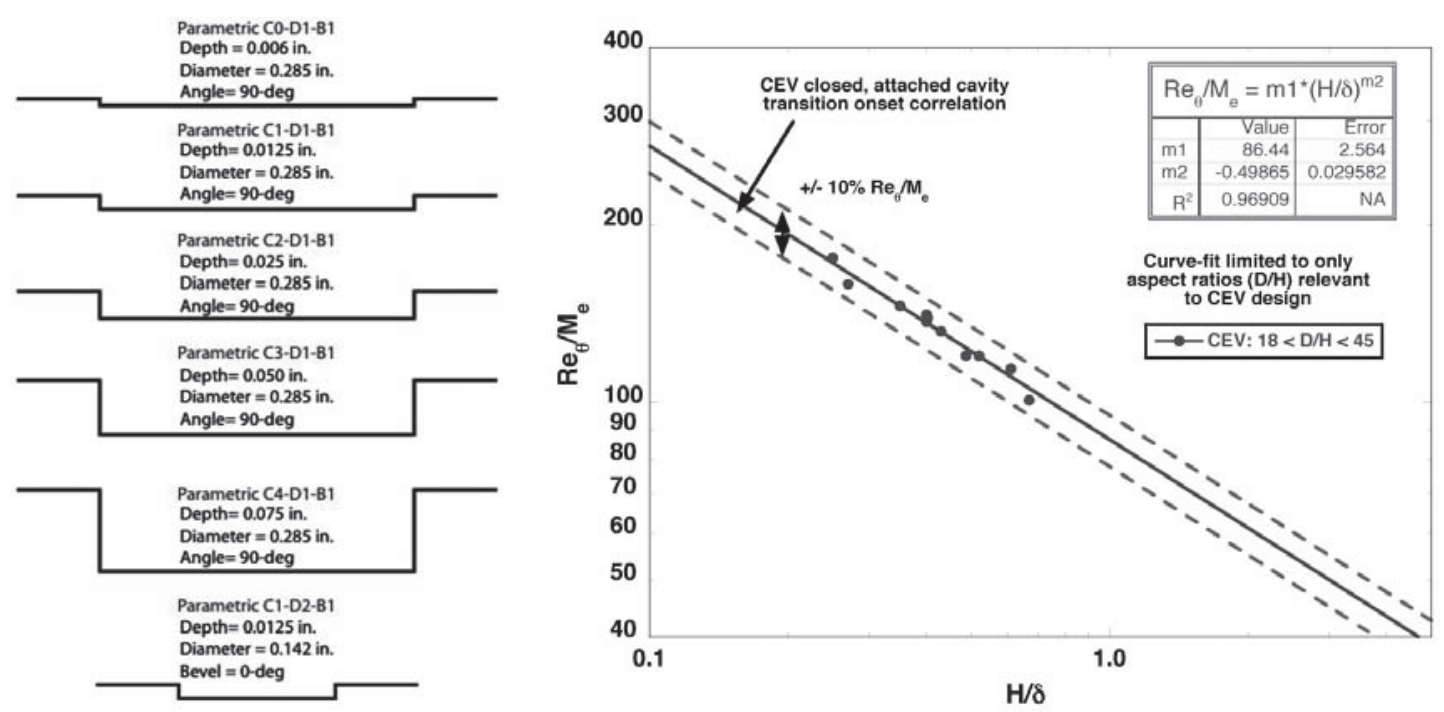

Figure 29. Correlation of Orion compression-pad transition onset data

\section{Roughness Effects}

The Orion heat shield is manufactured from Avcoat, which is an ablative material. Since ablative materials produce rough surfaces that can promote early boundary-layer transition and cause augmented turbulent heating levels (in comparison to smooth-surfaces), a preliminary investigation (Ref. 45) of these effects was conducted in AEDC Hypervelocity Tunnel 9 (CAP Test 41-CH). For this test, an Orion model with interchangeable forebody segments was fabricated; each segment was machined with patterned hemispherical roughness elements of different diameters and patterns (Figure 30). Augmented heating levels $125 \%$ to $175 \%$ of smooth-wall turbulent predictions were measured in these tests.

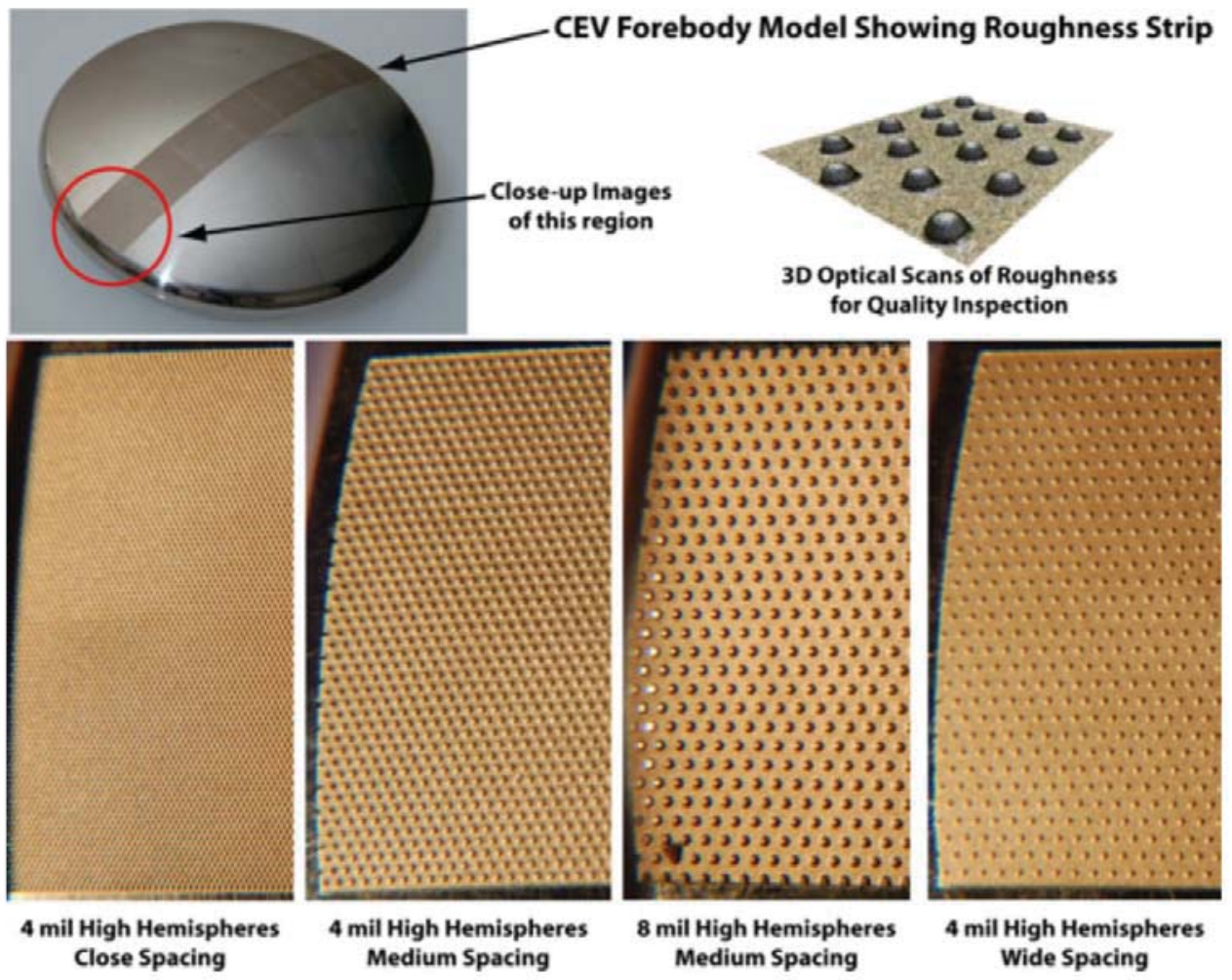

Figure 30. Sample heat-shield roughness patterns tested in AEDC Hypervelocity Tunnel 9 


\section{RCS Interactions}

The Orion will have several sets of RCS jets for pitch, roll and yaw control during entry. The effects of RCS jet firings on surface heating and pressure and on flow-field structure were studied during several tests in the 31-Inch Mach 10 Air Tunnel (CAP Tests 37-CH, 63-CH, and 95-CH). Pressure-sensitive and temperature-sensitive paints were employed to map the surface pressure and heating footprints of the RCS jets on the crew compartment (Refs. 8, 46 - 49). Typical pressure and heating interaction footprints for roll jet and yaw jet firings at different test conditions and jet exhaust pressures are shown in Figure 31 and Figure 32. RCS effects on the wake flow-structure were also examined using PLIF (Refs. 50 - 51) as shown in Figure 33.
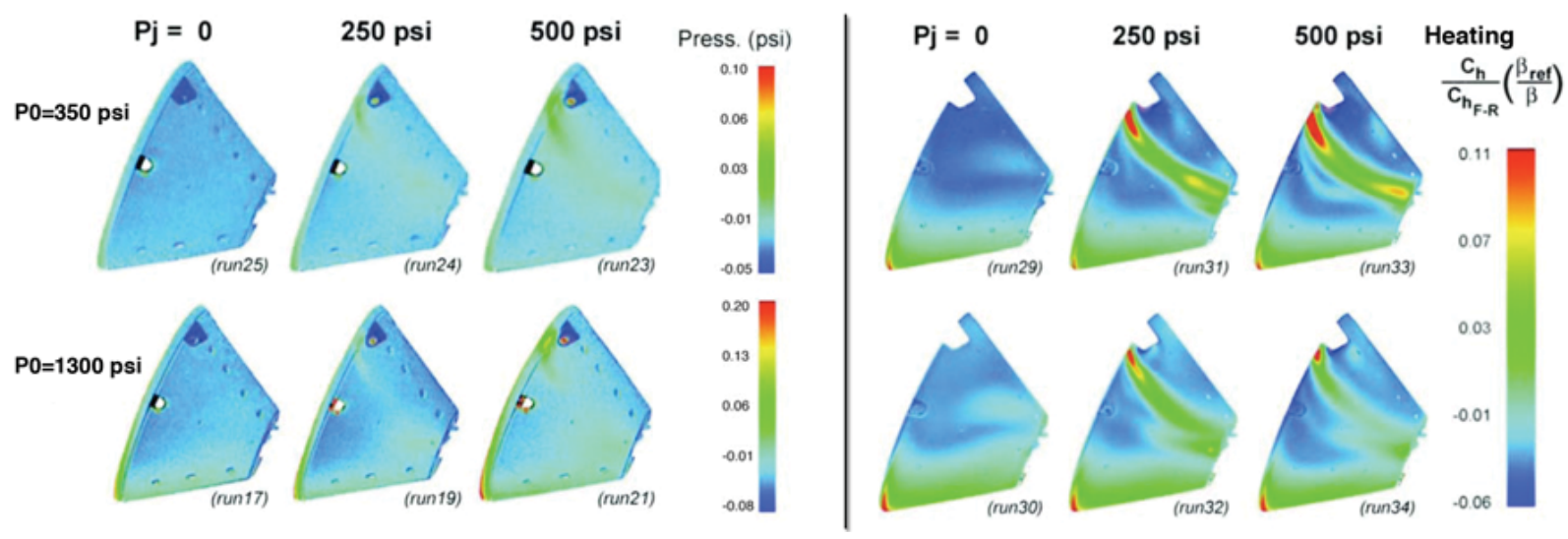

Figure 31. Orion RCS roll-jet interactions pressure and heating data from LaRC 31-Inch Mach 10 Air Tunnel

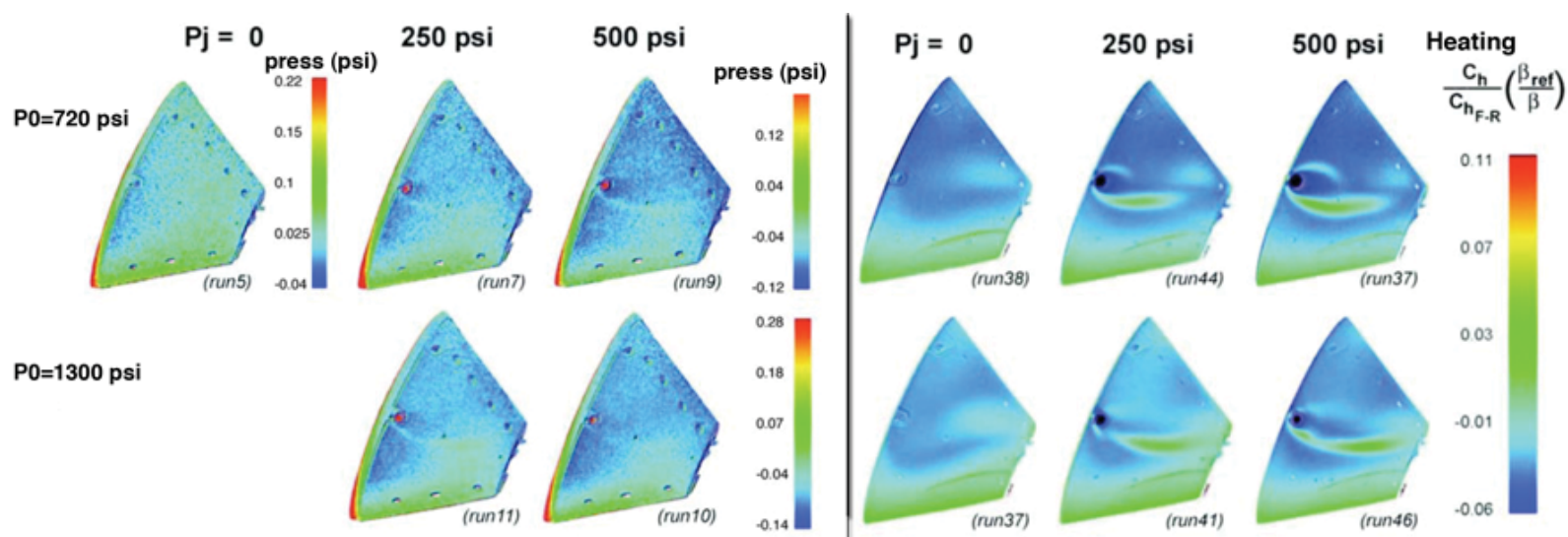

Figure 32. Orion RCS yaw-jet interactions pressure and heating data from LaRC 31-Inch Mach 10 Air Tunnel 

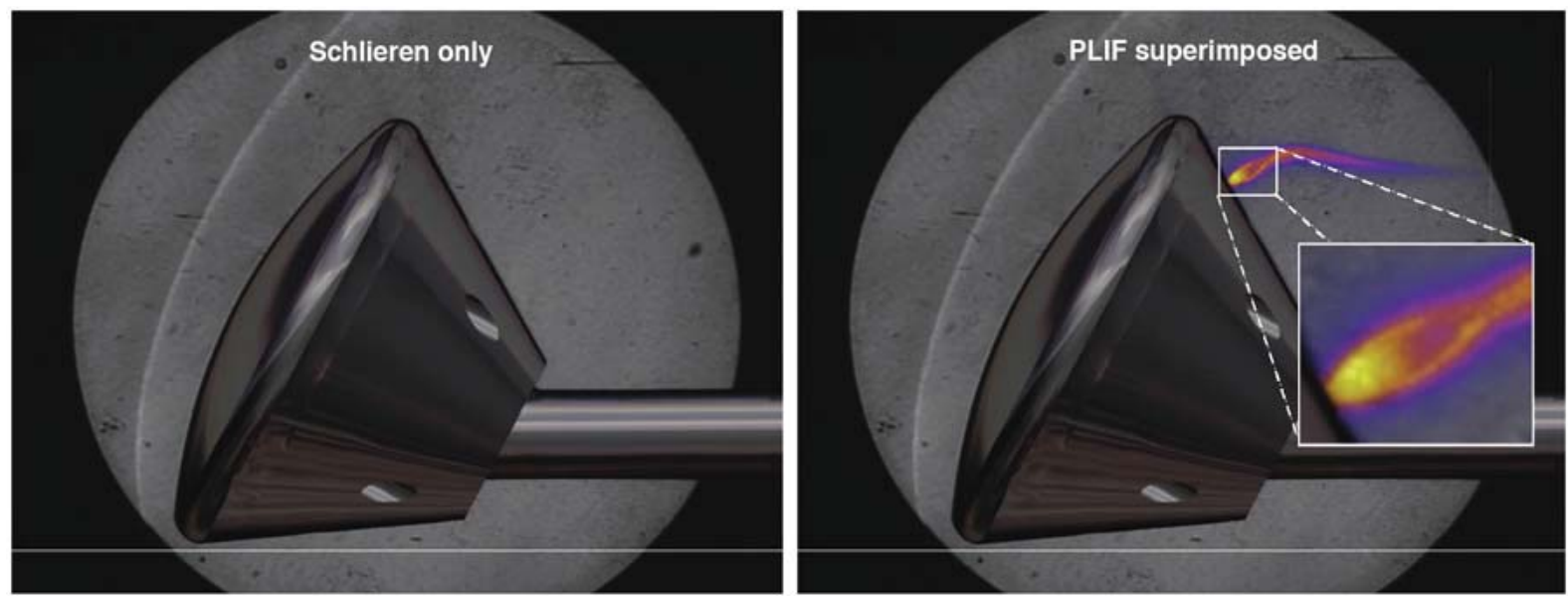

Figure 33. Schlieren and PLIF imaging of Orion RCS from LaRC 31-Inch Mach 10 Air

5. Crew Module Hypersonic and Supersonic Aerodynamics

A hypersonic aerodynamic database of force-and-moment, schlieren, and oil-flow measurements was generated (Refs. 52 - 53) on the Orion Crew Module in the LaRC 20-Inch Mach 6 Air Tunnel (CAP Test 05-CA). Six separate models with different sting mounting orientations were built to allow testing across a range of angles-of-attack from -5-deg to 185-deg to cover all possible launch-abort scenarios (Figure 34 - Figure 35).

Testing was conducted in the LaRC UPWT (CAP Test 03-CA) in order to develop a database on supersonic aerodynamics for the Orion (Ref. 52 and 54). Force-and-moment aerodynamic data were obtained at angles-ofattack of 140-deg to 170-deg on both a clean model and on a model with boundary-layer trips on the heat-shield (Figure 36). Surface pressure measurements were made using ESP sensors and boundary-layer transition information was obtained using temperature-sensitive paint and infrared thermography (Figure 37). Mach number and Reynolds number effects were studied through testing at Mach numbers of 1.6 to 4.5 with Reynolds numbers of $0.5 \times 10^{6}$ to $1.5 \times 10^{6}$ based on diameter.

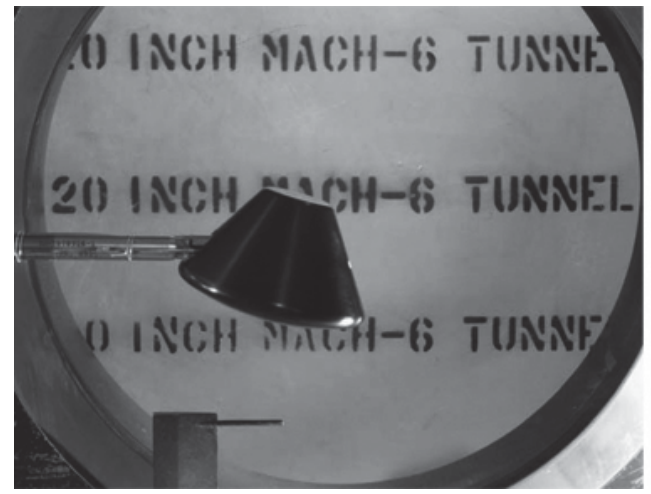

Model Photograph

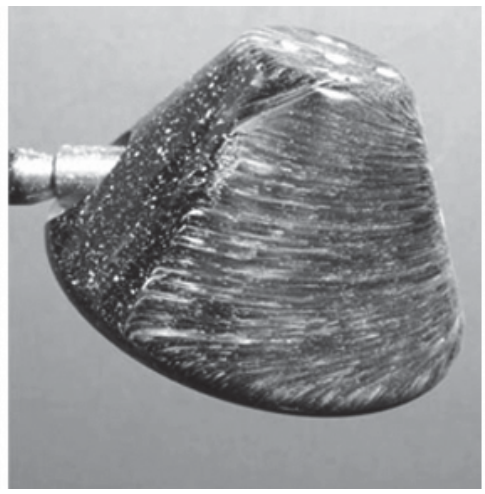

Oil Flow

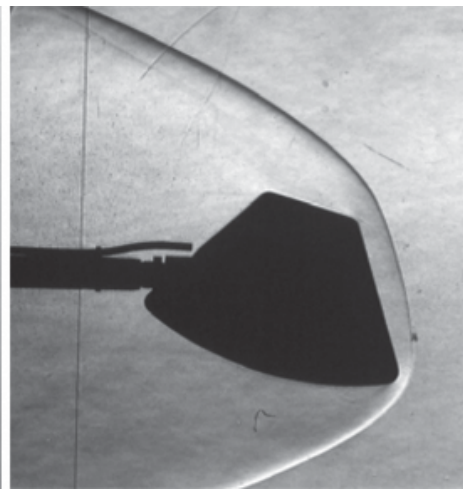

Schlieren

Figure 34. Orion CM Aerodynamic testing in LaRC 20-Inch Mach 6 Air Tunnel 


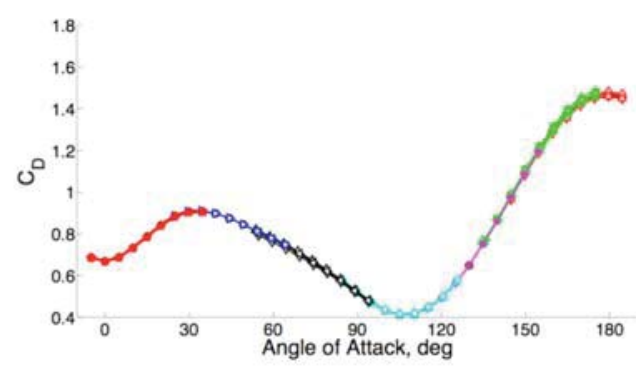

(a) $C_{D}$ versus $\alpha$

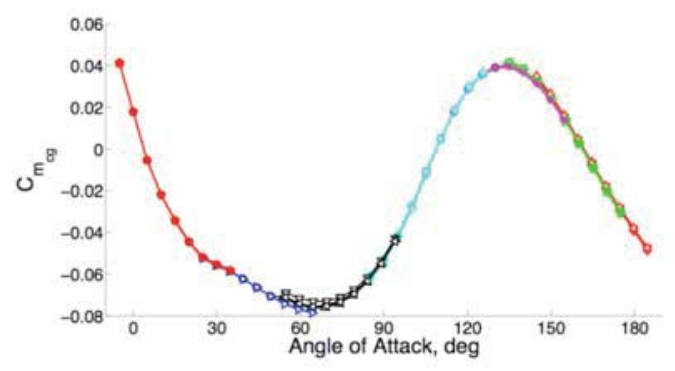

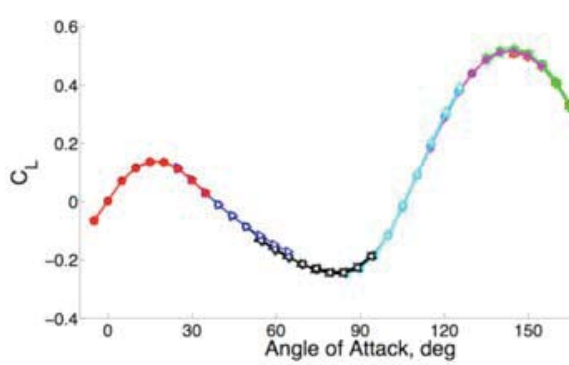

(b) $\mathrm{C}_{\mathrm{L}}$ versus $\alpha$

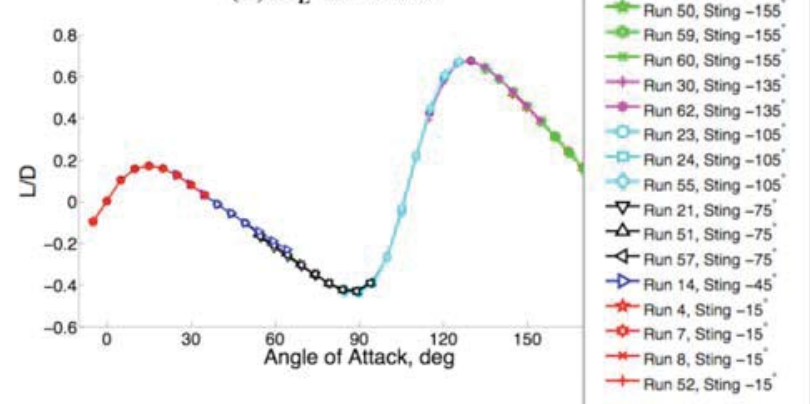

Figure 35. Orion CM Aerodynamic Data from testing in LaRC 20-Inch Mach 6 Air Tunnel

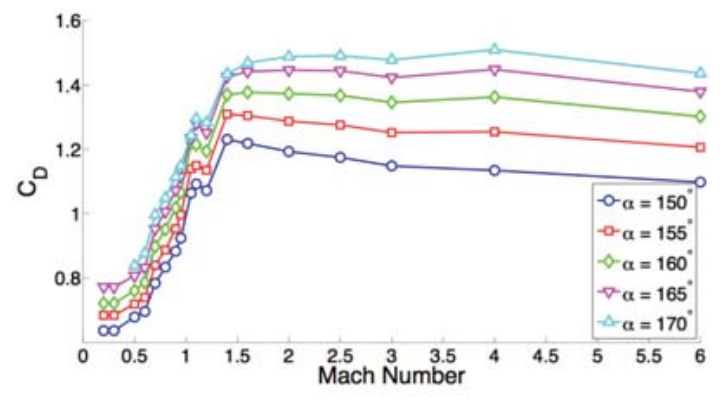

(a) $C_{D}$ versus $M$

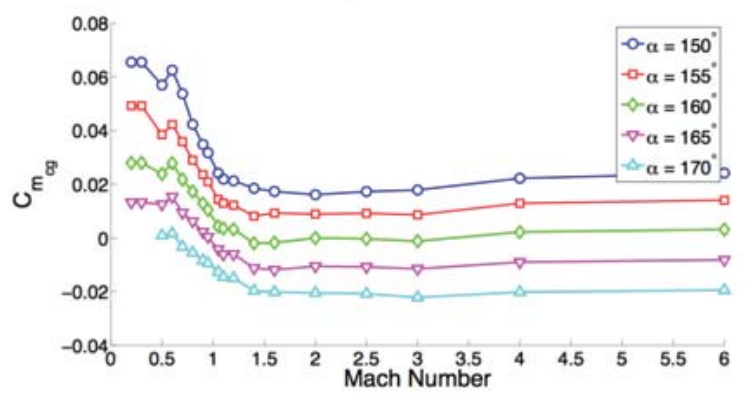

(c) $C_{m}$ versus $M$

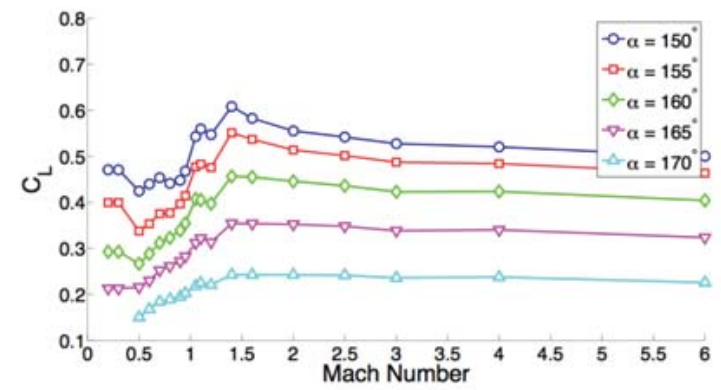

(b) $\mathrm{C}_{\mathrm{L}}$ versus $\mathrm{M}$

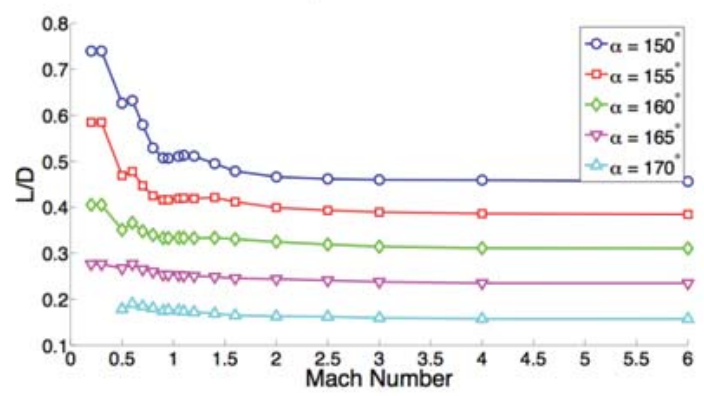

(d) $L / D$ versus $M$

Figure 36. Orion CM aerodynamic data as a function of Mach number from testing in LaRC UPWT 


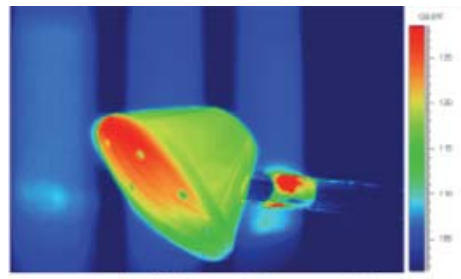

(a) Low Reynolds number, no trips

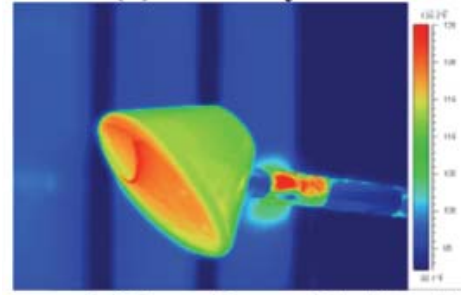

(c) Low Reynolds Number, with trips
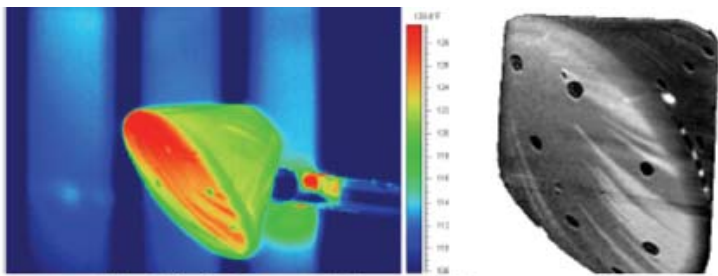

(b) High Reynolds number, no trips
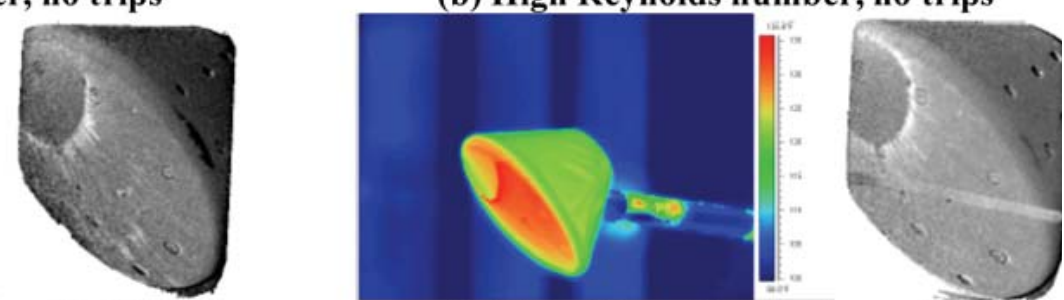

(d) High Reynolds number, with trips

Figure 37. Infrared and Temperature-Sensitive Paint images of Orion CM with and without boundary-layer trips from LaRC UPWT

\section{Launch Abort System Aerodynamics}

The Orion Launch Abort System (LAS) would be used to provide a safe abort in the case of an emergency on the pad or during ascent. The LAS (Figure 38) consists of a Launch Abort Tower (LAT) that is attached by a fairing to the Crew Module (CM). The LAT contains both an Abort Motor to pull the joined CM and LAT away from the launch vehicle and an Attitude Control Motor (ACM) to provide steering and control of the system.

Extensive testing of the Orion launch abort system was conducted by LaRC researchers in both LaRC facilities and in off-site wind tunnels. Interactions due to body-proximity between the CM and separated LAT and due to jet firings were studied (Ref. 55) through force-and-moment testing with powered thrusters in the transonic AEDC Propulsion Wind Tunnel (PWT) 16T (CAP Test 24-AA) and in the 9x7-Foot Supersonic Leg of the ARC UPWT (CAP Test 25-AA). Approximately 2000 runs were performed to obtain data on the effects of vehicle separation distance, thrust settings, Mach number, and Reynolds numbers (e.g. Figure 39).

Aerodynamic performance and jet interaction data for the ACM were obtained (Ref. 56) through force-andmoment testing with powered and un-powered thrusters (e.g. Figure 40) in the 11x11-Foot Transonic Wind Tunnel and 9x7-Foot Supersonic Wind Tunnel legs of the ARC UPWT and also in the LaRC UPWT. Approximately 4000 runs were performed to generate an aerodynamic performance database.

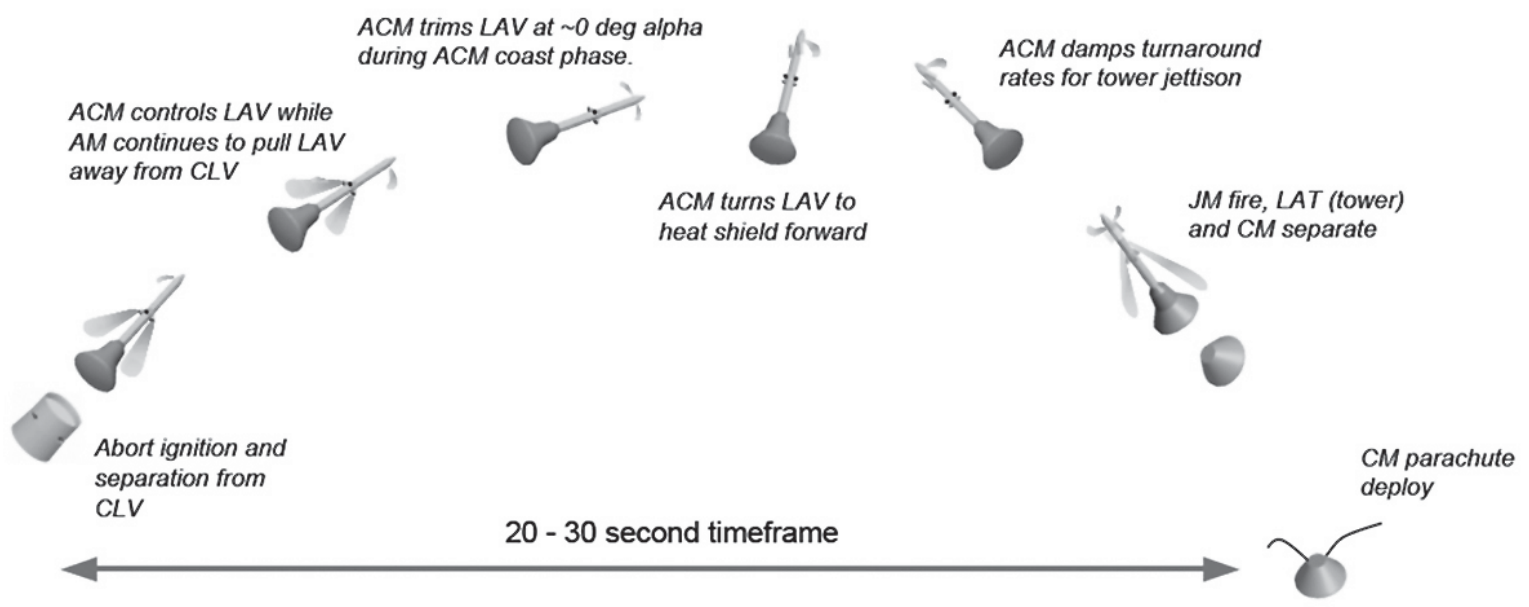

Figure 38. Orion Launch Abort System

19

American Institute of Aeronautics and Astronautics 


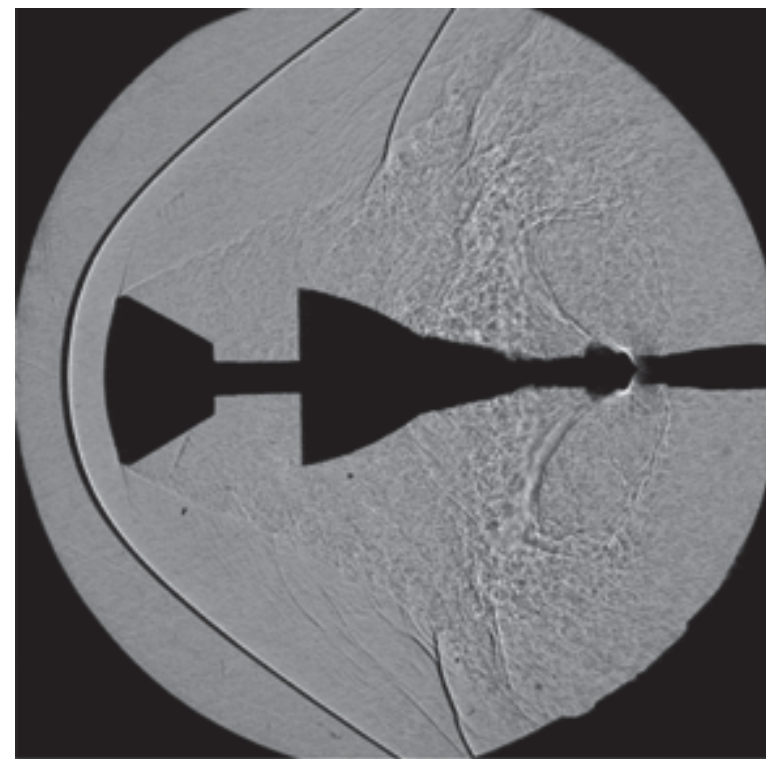

Figure 39. Schlieren image from ARC UPWT showing CM-LAT interactions
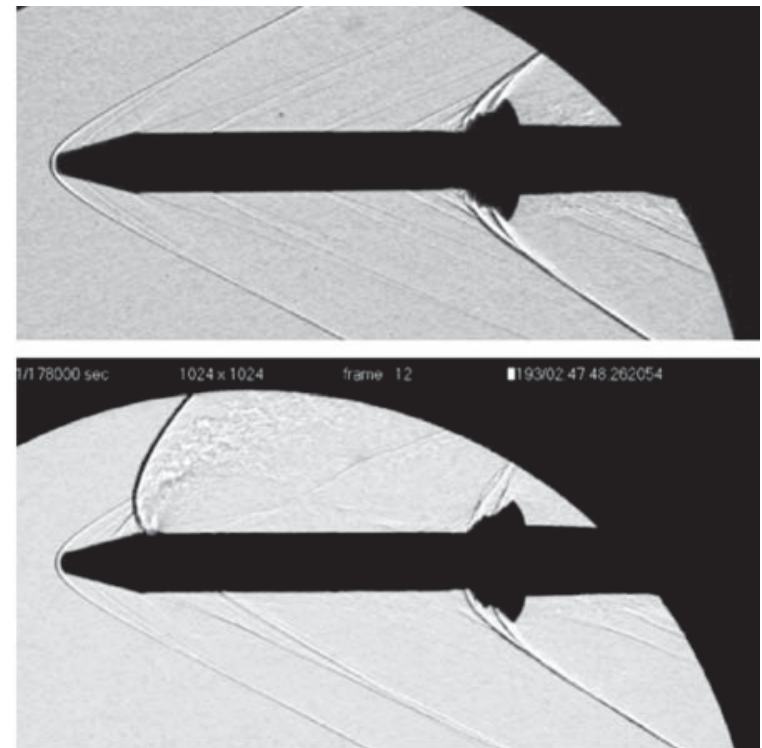

Figure 40. Jet-on and jet-off schlieren images from LaRC UPWT

\section{IRVE}

The IRVE-3 mission in 2012 (Ref. 57) was the second successful flight demonstration (after the IRVE-2 mission) of a hypersonic inflatable aerodynamic decelerator (HIAD). The reentry vehicle (Figure 41) consisted of a solid cylindrical center-body with an aeroshell comprised of seven inflated toroids covered by a flexible TPS (Ref. 58). Because the flexible aeroshell was expected to elastically deform during flight, an experimental aeroheating study was conducted in the LaRC 20-Inch Mach 6 Air Tunnel to determine possible effects on heating and boundary-layer transition. A series of rigid models (e.g. Figure 42) representing various magnitudes of deflection of the OML were tested using global phosphor thermography to measure heating distributions (Figure 43). Even for very small deflections, early boundary-layer transition and heating augmentation above turbulent levels was observed. Fortunately however, for this specific mission the heating augmentation did not affect the design of the vehicle. Because of the unusual mission profile for the flight, which was launched by a small sounding rocket, the nose radius of the vehicle was kept as small as possible to maximize heating levels as a test of the TPS performance. The observed experimental heating levels on the flank of the aeroshell, while considerably higher than smooth OML levels, remained lower than that of the nose stagnation point, which was the design criteria for the TPS.
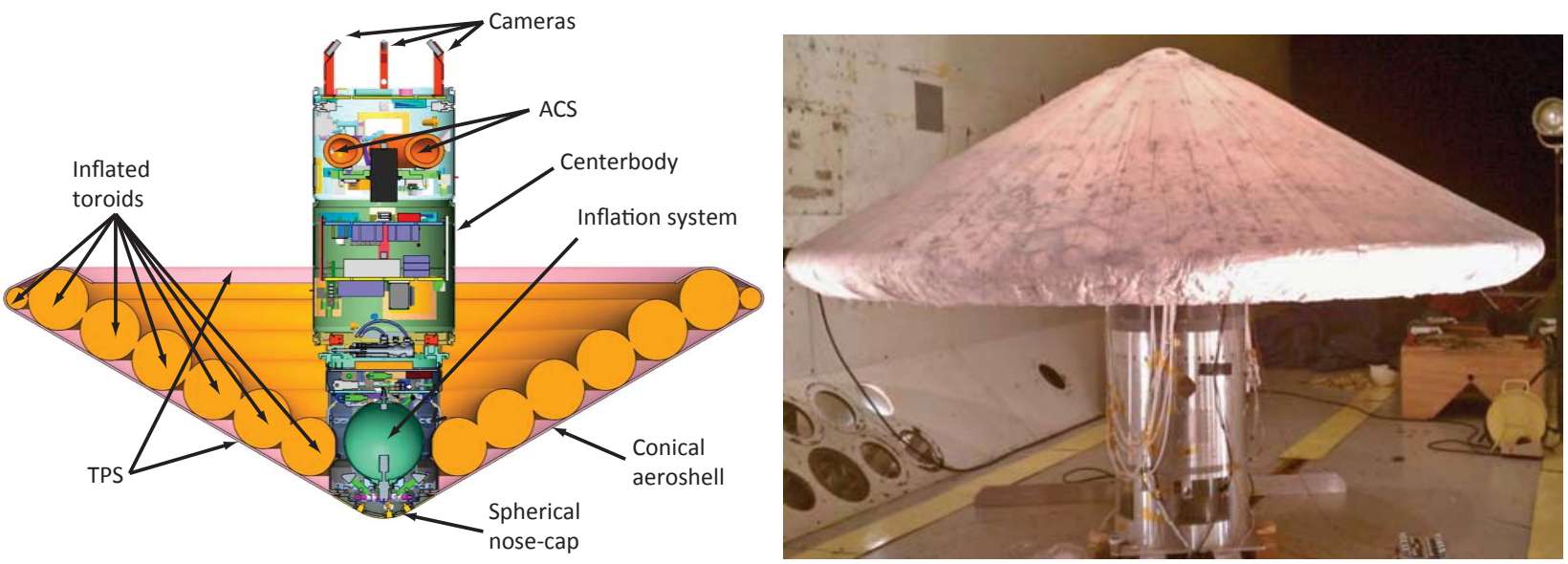

Figure 41. IRVE-3 schematic and photograph of inflated test article 


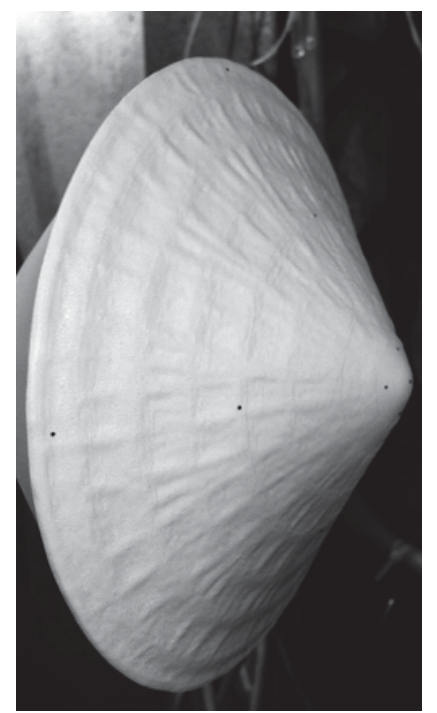

Figure 42. IRVE-3 wind tunnel model with OML deflections
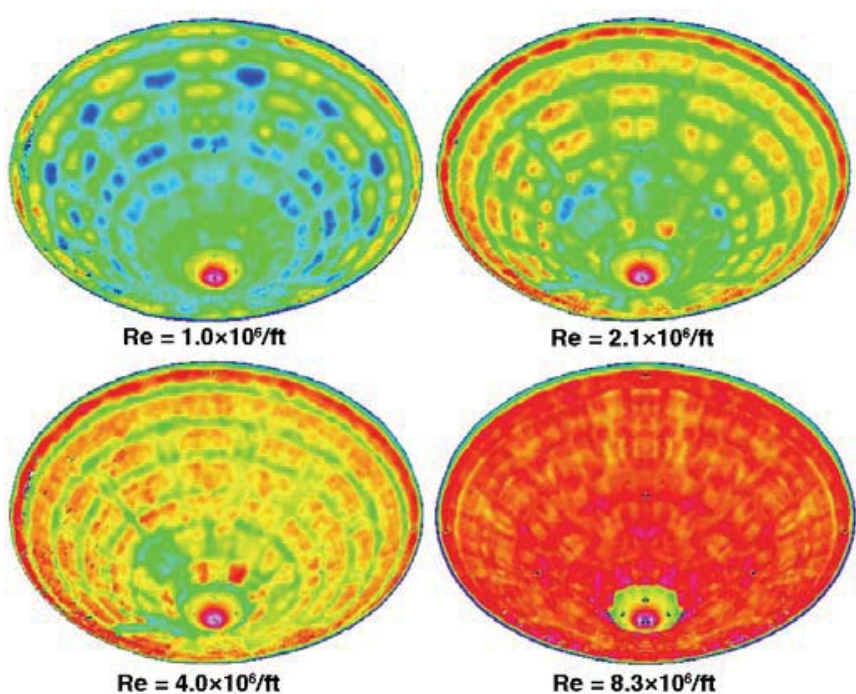

Figure 43. IRVE-3 deflected OML heating data from LaRC 20-Inch Mach 6 Air Tunnel

\section{Genesis Solar-Wind Sample Return Mission}

The Genesis mission (2001-2004) returned solar wind particles to Earth aboard a 60-deg sphere-cone Sample Return Capsule (SRC). The SRC was mounted to the spacecraft bus through attachment points on its heat shield, which left cavities in the heat-shield after separation. To assist in the design of the aeroshell, cavities of various sizes and locations were tested to determine the largest cavity size that could be used while keeping the resulting heating augmentation levels below those of the stagnation point. Aeroheating data were obtained (Ref. 59) using global phosphor thermography in the LaRC 20-Inch Mach 6 Air Tunnel. Sample data are shown in Figure 44, along with correlations of boundary-layer laminar and turbulent boundaries in terms of cavity diameter to boundary-layer height $(w / \delta)$ vs. momentum thickness Reynolds number $\left(\operatorname{Re}_{\theta}\right)$. These correlations were used to size and place the cavities on the flight vehicle.

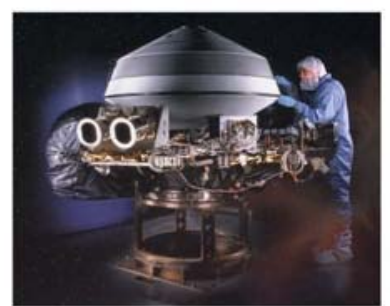

Genesis Sample Return Vehicle stacked on transit stage

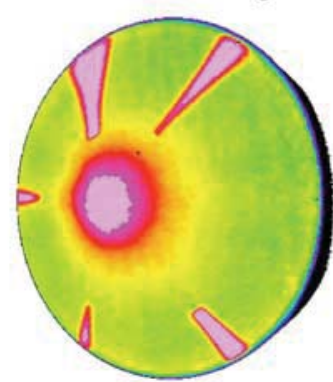

Aeroheating data on model with cavities

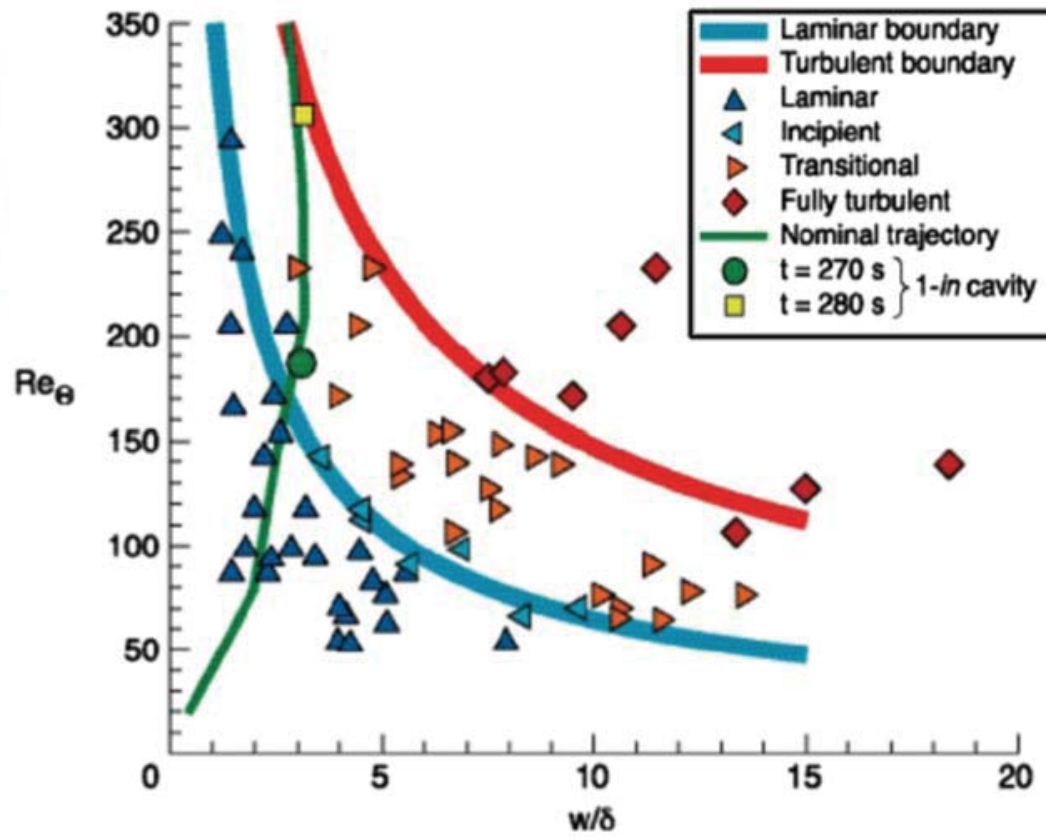

$w / \delta$

Figure 44. Correlation of Genesis heat-shield cavity transition data from LaRC 20-Inch Mach 6 Air Tunnel 


\section{E. Mars Microprobe}

The Mars Microprobes (Figure 45) were carried aboard the failed 1998 Mars Surveyor Mission and were intended to penetrate the Martian surface to return data on subsurface conditions. Testing of the Microprobe geometry was conducted (Ref. 60) in the LaRC 20-Inch Mach 6 Air Tunnel to support development of the TPS system. Data were obtained on a 4-inch diameter model over a range of angles-of-attack using global phosphor thermography. Of particular interest were heating levels on the aftbody of the vehicle. Comparisons were made (Figure 46) between data from the test and predictions for flight, with both scaled to the respective forebody stagnation point heating levels. Good comparisons were obtained, which contributed to validation of the TPS design.

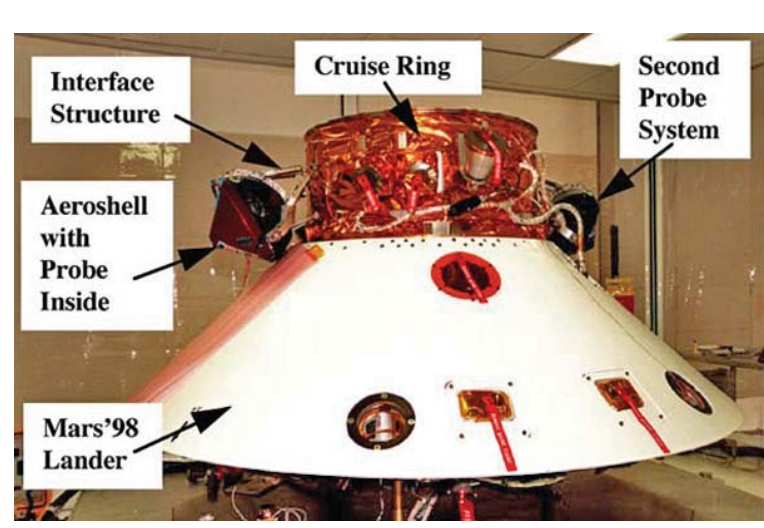

Figure 45. Microprobes attached (top) to Mars 98 Lander

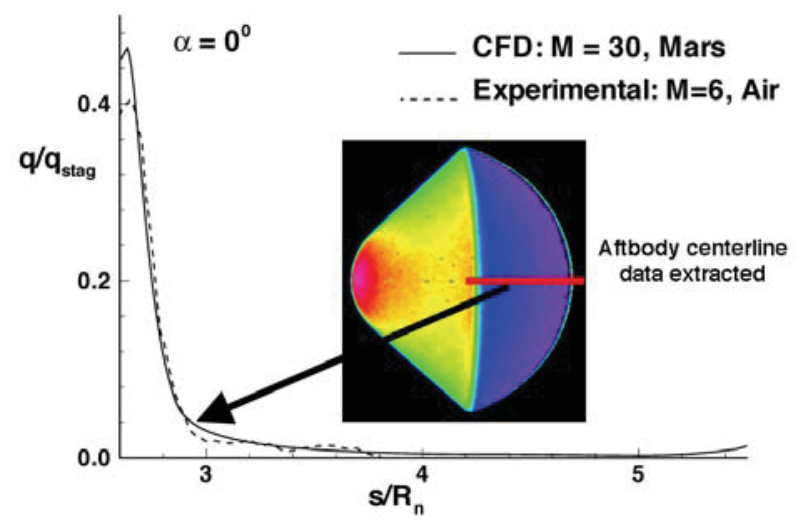

Figure 46. Microprobe aftbody heating predictions compared to LaRC 20-Inch Mach 6 Air Tunnel data

\section{Research and Development}

In addition to direct support for the development of NASA flight programs, Langley's experimental aerothermodynamics capabilities are also employed in the development of EDL technologies, CFD validation, entry vehicle preliminary design studies and configuration assessment, etc. Highlights of recent research and development programs are presented in this section, some of which are ongoing efforts that have not yet been published elsewhere.

\section{A. Mid Lift-to-Drag Ratio Entry Vehicle}

System analysis studies (e.g. Refs. 61 and 62) conducted by NASA have demonstrated that the heritage architecture employed by all previous NASA EDL missions to Mars, that of a 70-deg sphere entry vehicle, cannot provide the aerodynamic performance required to decelerate and accurately land the high-mass payloads (10 mt to $50 \mathrm{mt}$ ) projected for future robotic sample return or human exploration missions. One of the architectural options proposed for such missions is that of a Mid Lift-to-Drag (L/D) ratio entry vehicle. The required L/D performance range of $\sim 0.4$ to 0.8 for these missions could be generated by long, slender geometries such as biconics or ellipsleds.

Testing was performed (Ref. 63) in the 20-Inch Mach 6 Air Tunnel in order to assess the aeroheating characteristics of several Mid-L/D vehicle geometries. Three different configuration families were considered: "Ellipsled" geometries, which consist of an elliptically-blunted nose and a cylindrical aftbody with both circular and flattened cross-sections; "COBRA" geometries (from Co-Optimization of Blunt-body Re-entry Analysis) that were developed through an optimization algorithm (Ref. 64) to meet mission criteria such as landed mass, convective heating rate, aerodynamic performance; and "Hammerhead" geometries based on dual-use (ascent and reentry) application of a launch vehicle shroud (Ref. 65).

Laminar, transitional, and turbulent data were obtained using global phosphor thermography. A sample set of heating data from several configurations is shown in Figure 47. Boundary-layer transition onset characteristics varied with configuration. Centerline, stream-wise transition onset was observed on all but one of the tested configurations with varying lengths of fully-developed turbulent flow. Additionally, "feathered" heating patterns indicative of cross-flow transition were observed off-centerline for several of the geometries. Laminar CFD predictions were found to be in good agreement with laminar data, as were turbulent predictions with turbulent data (Reference 63) as shown in Figure 48. 


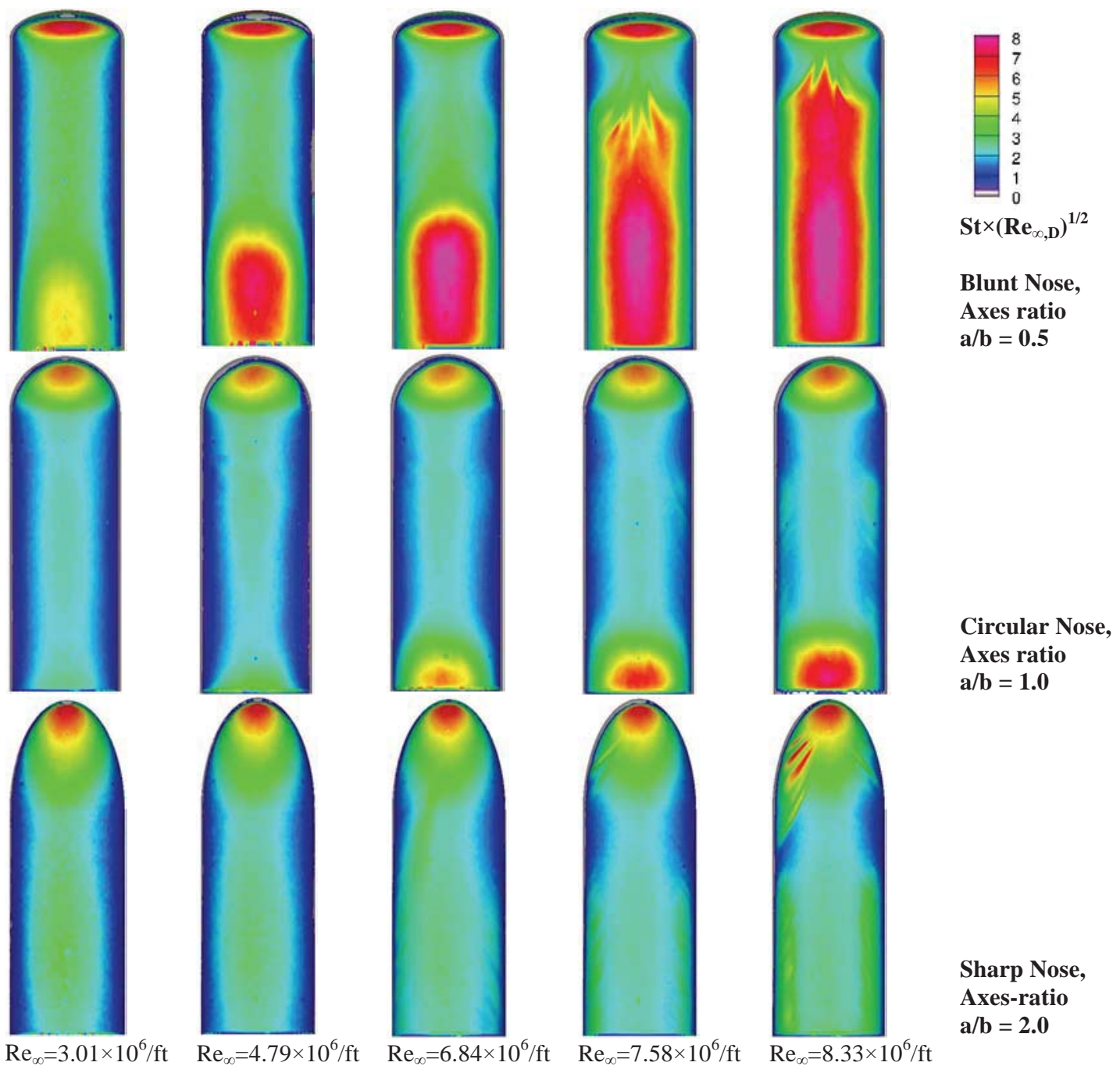

Figure 47. Mid L/D ellipsled global heating distributions from LaRC 20-Inch Mach 6 Air Tunnel

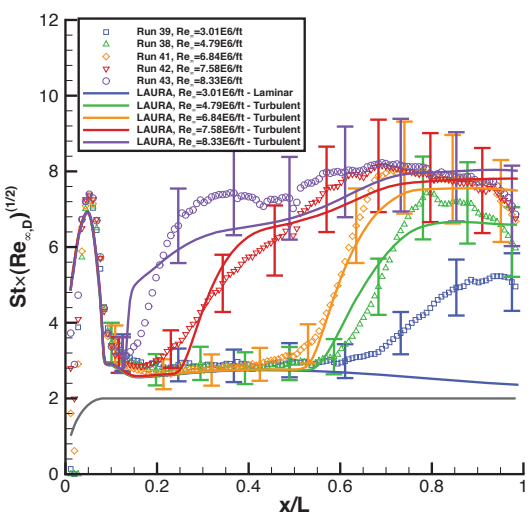

Blunt nose, axes ratio $\mathrm{a} / \mathrm{b}=0.5$

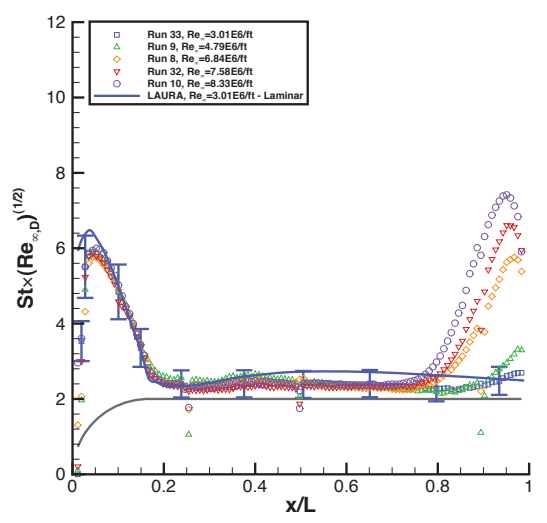

Circular nose, axes ratio $\mathrm{a} / \mathrm{b}=1.0$

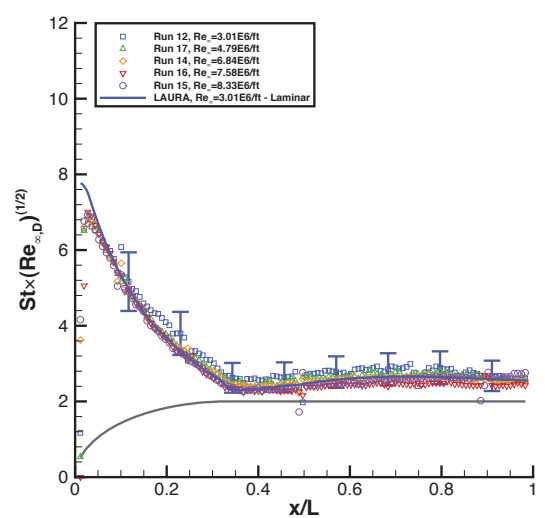

Sharpe nose, axes ratio $\mathrm{a} / \mathrm{b}=2.0$

Figure 48. Comparisons of Mid L/D ellipsled centerline heating predictions vs. data from LaRC 20-Inch Mach 6 Air Tunnel 


\section{B. Supersonic Retropropulsion}

An alternative architecture to Mid-L/D geometries for future high-mass NASA missions (Refs. 61 and 62) is the use of Supersonic Retropropulsion (SRP). An SRP system for EDL would use the aerodynamics of a rigid aeroshell for deceleration through the hypersonic regime, followed by firing of thrusters through the heat-shield for supersonic deceleration. The flow-field created by the thruster exhaust directed into a supersonic flow would be extremely complex (e.g. Figure 49); thus experimental data for computational model development and validation is crucial.

In an ongoing SRP research program, surface pressure, and flow-field data have been generated in the LaRC UPWT (Ref. 66). A 5-in. diam., 70-deg sphere-cone with a 9.55-in. cylinder aftbody was used as the test article (Figure 50). This model was configured to have one to four supersonic nozzles with 4:1 area ratios. Sample schlieren and surface pressure data for a single-nozzle configuration are shown in Figure 51 and Figure 52; trinozzle and quad-nozzle data sets are also available.

In addition to the UPWT test at high supersonic Mach number conditions, data were also obtained in a LaRC-led test at lower supersonic Mach numbers in the Ames Research Center (ARC) 9x7-Foot Supersonic Wind Tunnel (Ref. 67). The model used in the prior LaRC UPWT test was also used in this study. Sample tri-nozzle schlieren and surface pressure data from this test are shown in Figure 53 and Figure 54. CFD studies are being performed to generate comparisons with these data (e.g. Ref. 68).

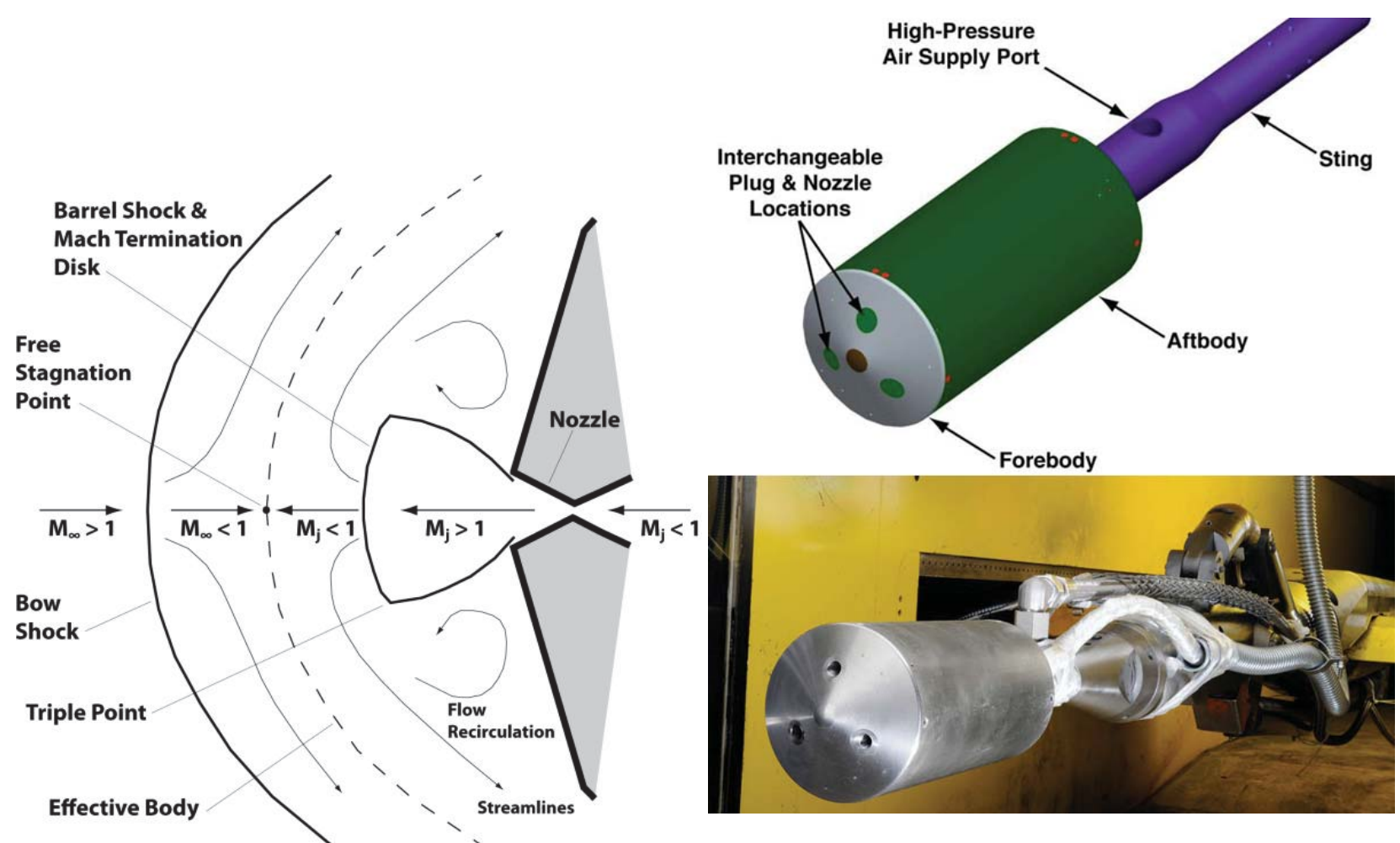

Figure 49. Illustration of flow field produced by supersonic retropropulsion

Figure 50. Supersonic retropropulsion wind tunnel model diagram and photograph 


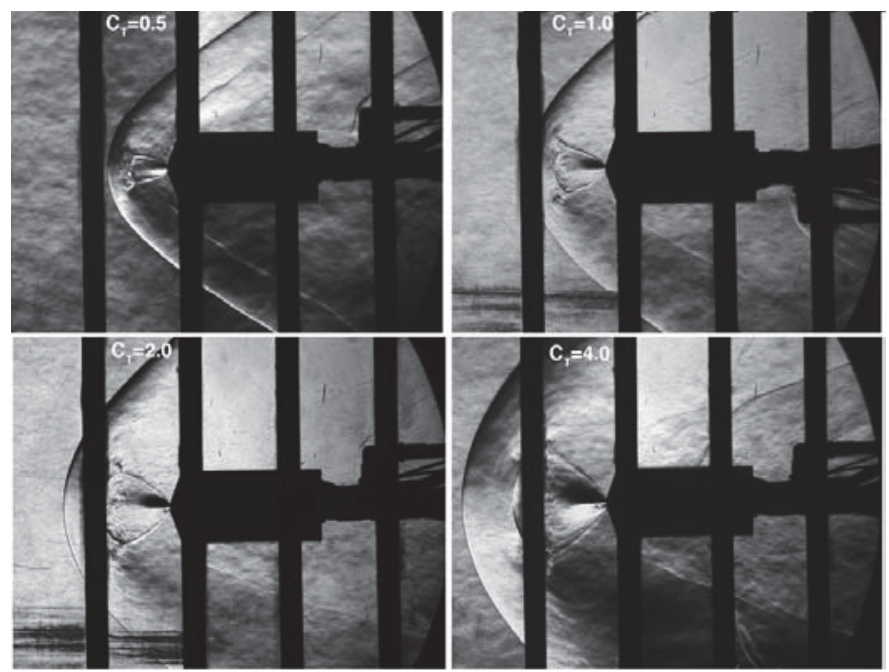

Figure 51. Data from LaRC UPWT showing effects of single-nozzle thrust coefficient on flow field
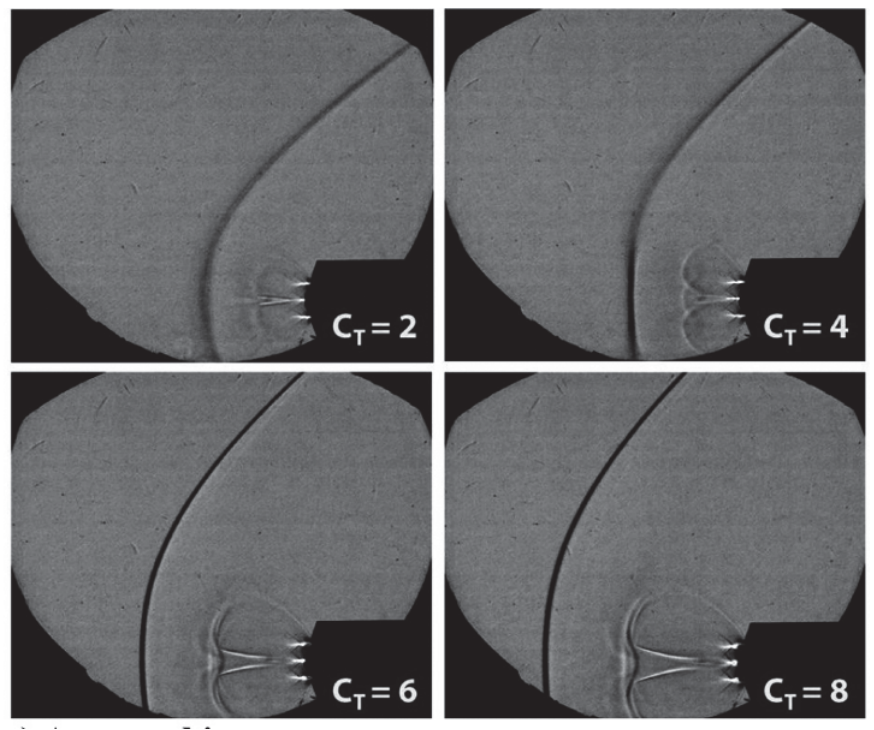

Figure 53. Data from ARC 9x7-Foot Supersonic Tunnel showing effects of tri-nozzle thrust coefficient on flow field

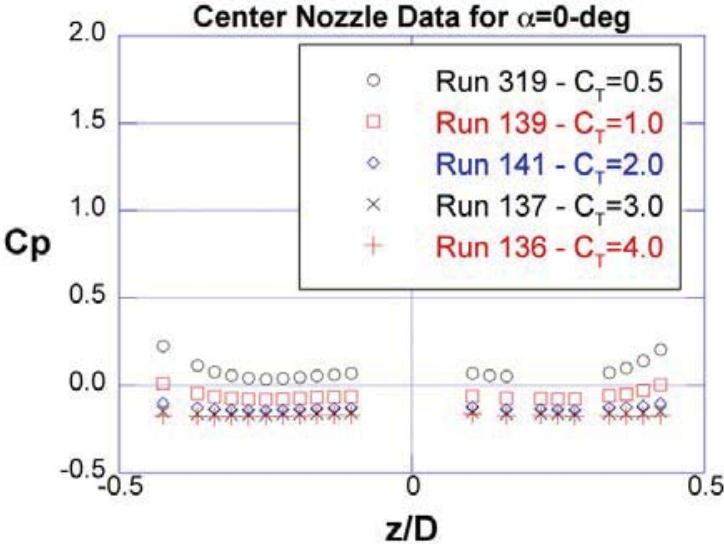

Figure 52. Data from LaRC UPWT showing effects of single-nozzle thrust coefficient on pressure coefficient

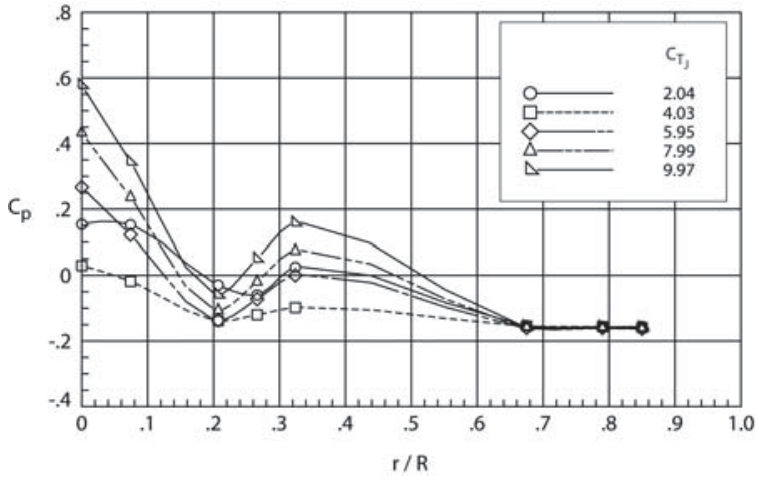

Figure 54. Data from ARC 9x7-Foot Supersonic Tunnel showing effects of tri-nozzle thrust coefficient on pressure coefficient

\section{Aerodynamic Trim-Tabs}

Unlike earlier Mars probes, the recent Mars Science Laboratory entry vehicle flew a guided, lifting trajectory in order to precisely target the landing site for its large payload, the Curiosity Rover. The required lift was generated by using ballast mass offset from the center-of-gravity to trim the vehicle at a high angle-of-attack (for a blunt body) of 16-deg. The use of ballast mass for trim control, while mechanically simple, has the obvious drawback of taking mass away from the missions science payload; for example, the ballast mass on MSL was $318 \mathrm{~kg}$, which was greater than the mass $(174 \mathrm{~kg}$ ) of one of the earlier Mars Exploration Rovers, Spirit and Opportunity. An alternative proposed to ballast mass for trim control is the use of small aerodynamic control surfaces to provide additional pitching moment. The use of these "trim tab" control surfaces was considered for recent Mars missions and has been proposed for future missions.

Aerodynamic testing of proposed trim-tabs for the cancelled Mars Surveyor 2001 Precision Lander was performed (Ref. 69) in the LaRC 20-Inch Mach $6 \mathrm{CF}_{4}$ and 20-Inch Mach 6 Air Tunnels. Three trim-tab configurations were tested at angles-of-attack of 0 -deg to 23-deg to determine their effectiveness and the resulting 
trim-angle (Figure 55). Computational predictions were also performed and matched the data to with less than $1 \%$. The study demonstrated the viability of trim-tabs to provide the required aerodynamic performance, i.e. maintaining a higher trim angle-of-attack.
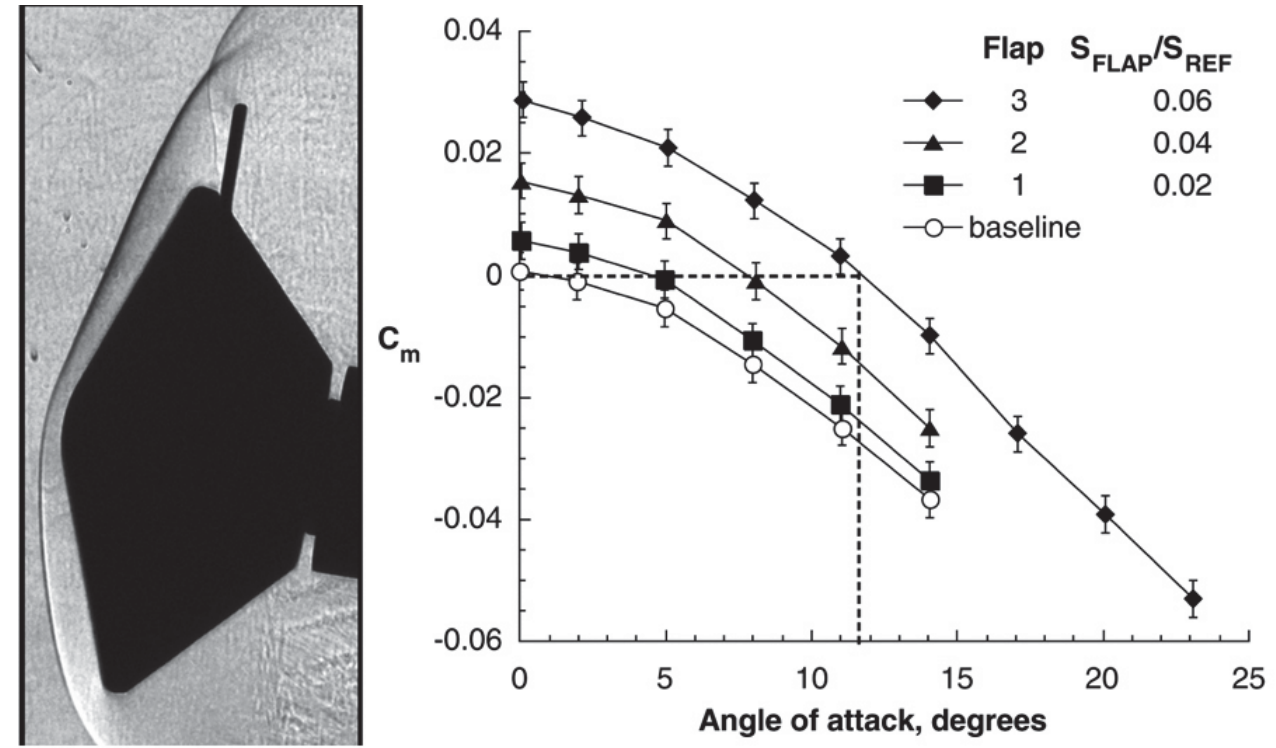

Figure 55. Data from LaRC 20-Inch Mach 6 Air Tunnel showing effects of various trim tab configurations on pitching-moment for proposed 2001 Mars probe

In the early phase of the MSL program when a 2007 launch was planned (and the MSL acronym stood for Mars Smart Lander), both aeroheating and aerodynamic studies were performed on trim tabs for the MSL entry vehicle. Various tab sizes, aspect ratios, and deflections were considered. Aerodynamic data were obtained in the LaRC UPWT (Ref. 70) and aeroheating data were gathered in the LaRC 20-Inch Mach 6 Air Tunnel (Ref. 71). The aerodynamic wind tunnel model with the various tab configurations is shown in Figure 56 along with sample pitching moment data. Each of the trim-tab configurations enabled the vehicle to trim at higher angle-of-attack, thus generating the higher L/D values required for the mission. Sample global phosphor thermography data on trim tab effects from the aeroheating test are given in Figure 57. Heating environments on the shelf configuration were similar to those on the baseline geometry, but heating levels on the canted tab approached or exceeded those at the stagnation point depending on test conditions.
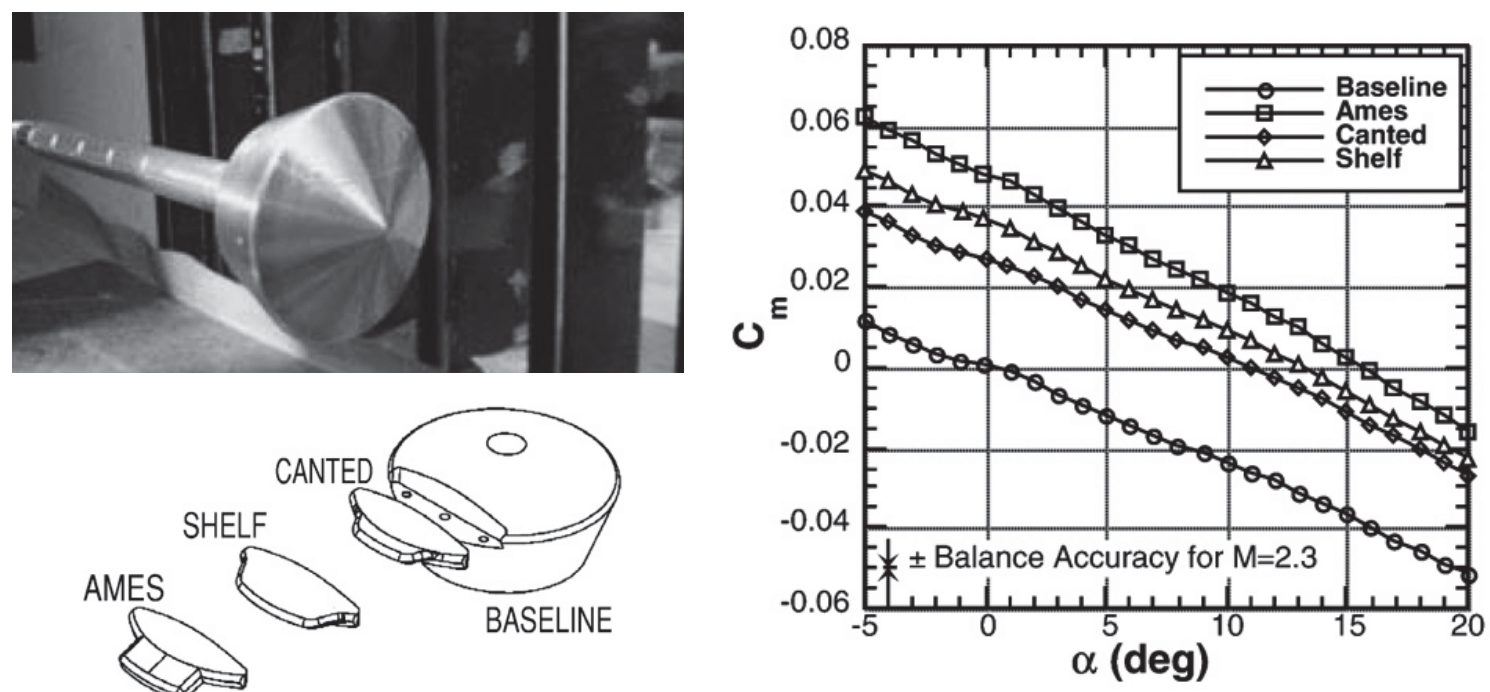

Figure 56. Data from LaRC UPWT showing effects of various trim tabs on pitching-moment coefficient for early MSL configuration

American Institute of Aeronautics and Astronautics 


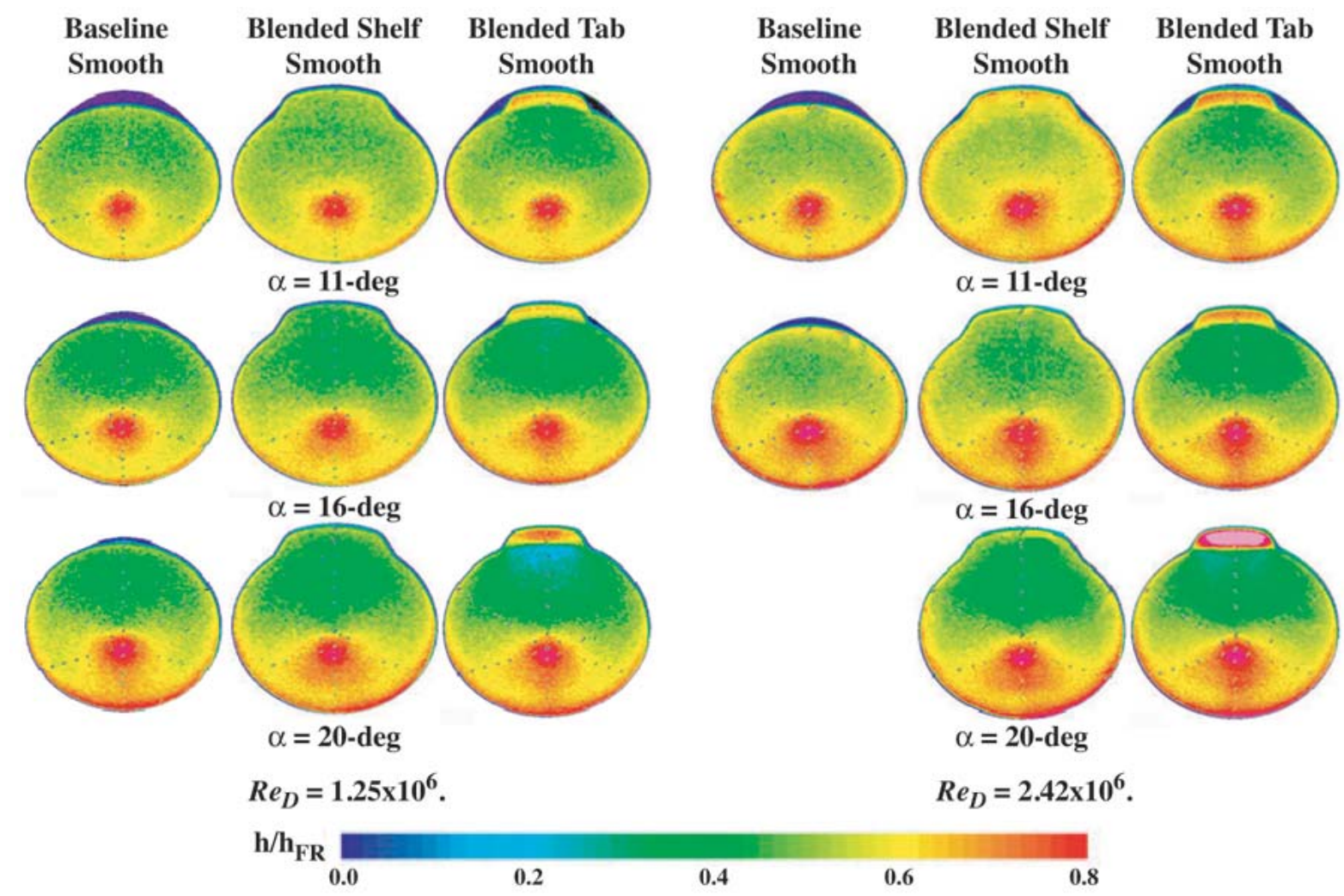

Figure 57. Data from LaRC 20-Inch Mach 6 Air Tunnel showing heating effects on various trim-tab configurations for early MSL configuration

\section{Distributed Roughness}

Ablative heat-shields are employed in most EDL systems, such as Apollo, MSL, Genesis, CEV, etc. While such missions generally do not experience large ablation rates or shape change effects (with the notable exception of the Jupiter Galileo probe), the relatively smooth surface of the TPS does become roughened by ablation throughout the trajectory. At a minimum, this distributed surface roughness acts to promote early onset of boundary-layer transition. For surface roughness heights that are a significant fraction of the boundary-layer height, heating augmentation above turbulent levels can be produced. There have been many studies of roughness effects for lowspeed applications (e.g. pipe flows) and for high-speed, slender bodies (e.g. missiles), but less information is available on blunt-body configurations relevant to NASA EDL missions. Therefore, a study of roughness effects on blunt-bodies was conducted in the LaRC 20-Inch Mach 6 Air Tunnel. Patterned roughness and distributed roughness models were fabricated for a variety of EDL configurations (sphere-cones, hemispheres, hemisphericalcap, and ellipsleds) with roughness heights ranging from essentially smooth to larger than the boundary-layer height. An example is shown in Figure 58 for a 70-deg sphere-cone with various distributed roughness heights. Heating data for these models are shown in Figure 59; heating levels of 65\% higher than predicted smooth-wall turbulent levels were measured for this case. 


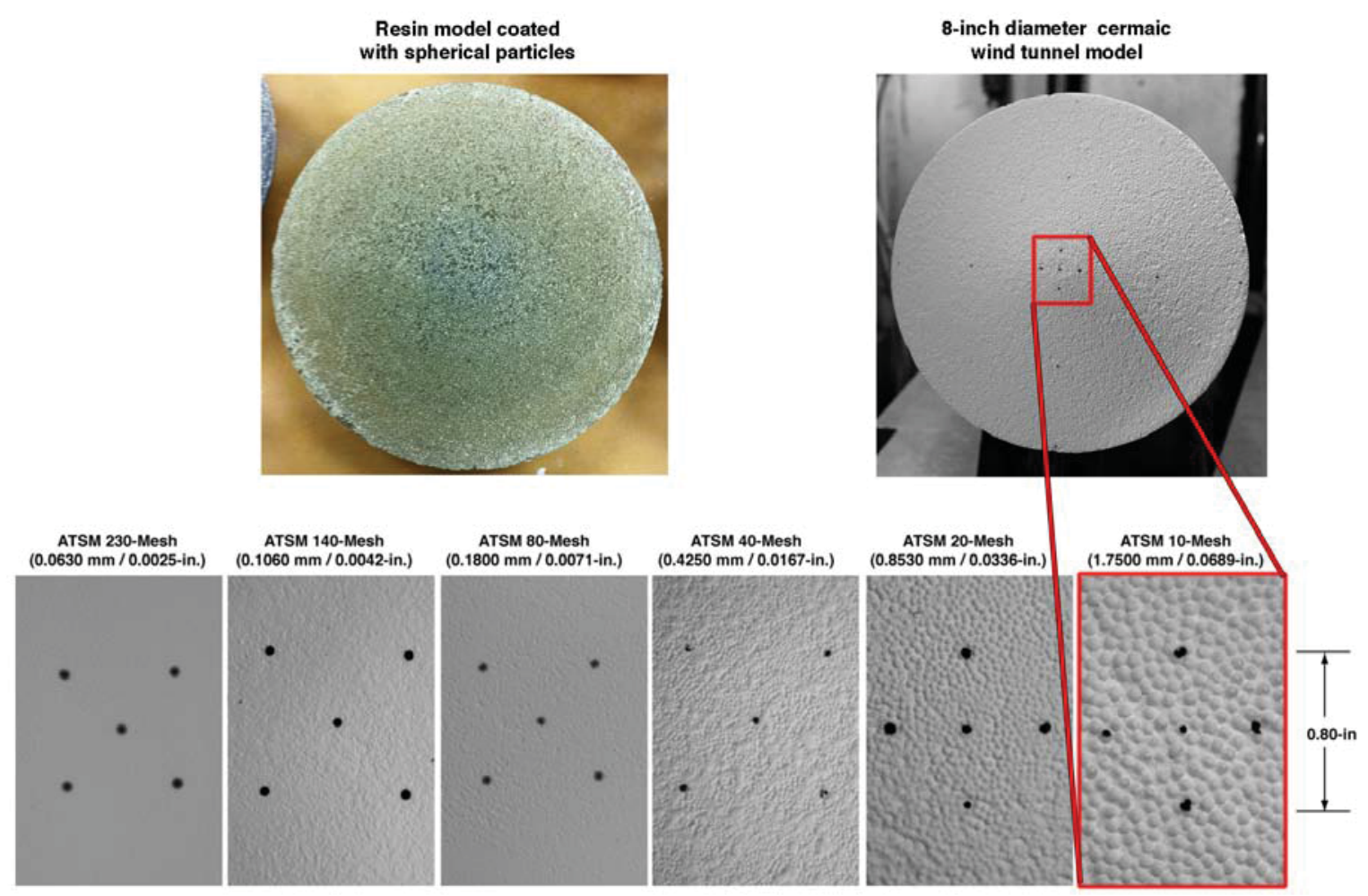

Figure 58. Distributed roughness sizes on 70-deg sphere-cone models tested in LaRC 20-Inch Mach 6 Air Tunnel

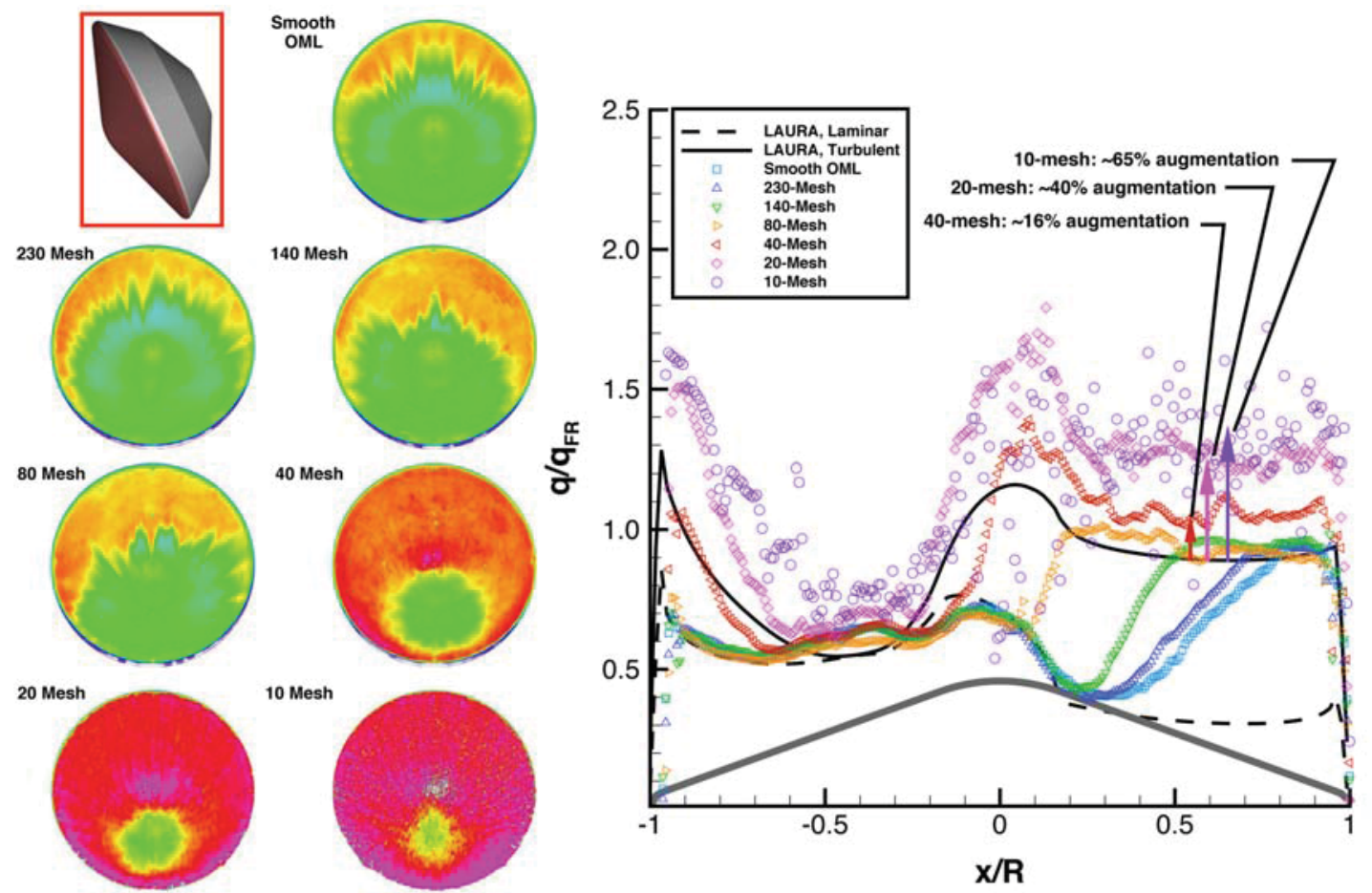

Figure 59. Distributed roughness effects on heating for 70-deg sphere-cone model from the LaRC 20-Inch Mach 6 Air Tunnel 


\section{E. Wake-Flow}

Blunt-body wake flows present significant challenges for both ground testing and CFD simulations. In flight, the wake flow will likely be separated, unsteady, and turbulent. Each of these phenomena presents challenges for modern computational tools, added to which is the difficulty of generating structured computational grids that can capture embedded shocks and shear layer as well as concave aftbody geometries. Because of these issues, bluntbody entry vehicle computations typically include $50 \%$ to $100 \%$ uncertainty margins over the predicted aftbody heating values, which demonstrates the need for high-fidelity experimental data for vehicle design and computational model development and validation. Several studies have been performed in LaRC facilities to obtain such data.

A proposed Mars sample-return mission was to be based on a large payload sheltered behind an asymmetric, AFE-like (Aeroassist Flight Experiment) heat shield. Of critical concern was the question of whether the earthreturn capsule (embedded in the aftbody payload) would be exposed to high heating from shear-layer impingement. To address this problem, tests were performed (Ref. 72) in the LaRC 20-Inch Mach 6 Air and 20-Inch Mach $6 \mathrm{CF}_{4}$ Tunnels to obtain aeroheating and shear-layer visualization data. Testing in these two facilities provided a wide range of Reynolds numbers and shock-density ratio conditions in which to study shear-layer behavior. The wakeflow structure is illustrated in Figure 60 and sample data are shown in Figure 61. The data were correlated to provide models for shear-layer transition and turning angle and for payload impingement heating.

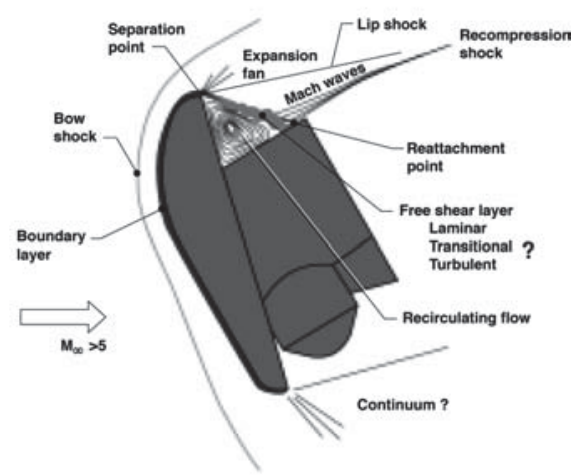

Figure 60. Wake flow structure for Mars Sample Return Orbiter
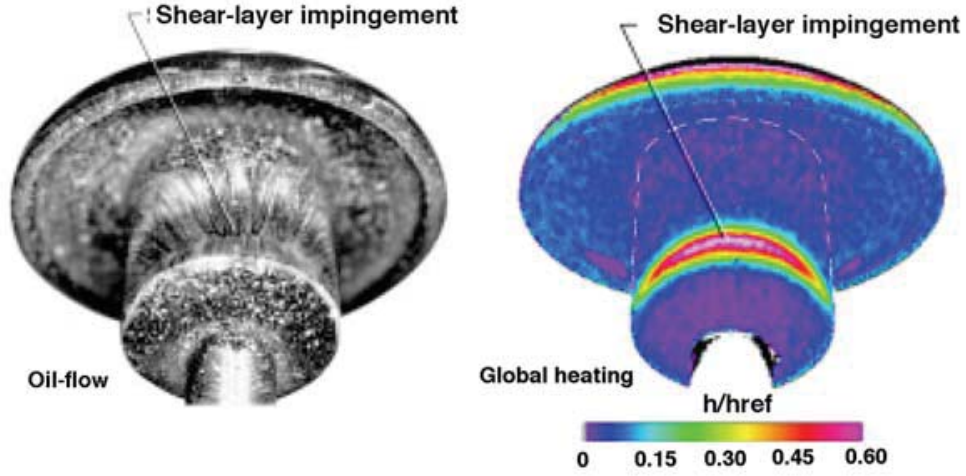

Figure 61. MSRO Oil-flow and aftbody heating data from LaRC 20Inch Mach 6 Air Tunnel

Recognizing the challenges presented in the simulation of blunt-body wake flows, NATO's AGARD (Advisory Group for Aerospace Research and Development) research committee commissioned an international effort (the AGARD-18 working group, e.g. Ref. 73) to obtain wake-flow data on a generic, 70-deg sphere-cone blunt-body geometry in multiple facilities across a wide range of test conditions. Langley contributions to this effort were provided by testing of 2-inch and 6-inch diameter sphere-cone models in the LaRC 31-Inch Mach 10 Air and 20Inch Mach 6 Air Tunnels (Refs. 11, 74, 75). The model geometry and general flow-field features are illustrated in Figure 62.

Both models included discrete heat-transfer sensors (thin-films and/or coaxial thermocouple) on the front and back of the model and along the sting. Additionally, the test of the 6-inch model in the LaRC 20-Inch Mach 6 Air Tunnel included wake flow surveys with pitot probes and hot wires in order to map the location of the shear layer and to determine when and where shear-layer transition occurred (Figure 63). The heat shield and sting data from these tests are shown for both tunnels in Figure 64 - Figure 65. The collapse of the forebody data when cast in terms of the Stanton and Reynolds numbers and a compressibility parameter, $\beta_{\mathrm{L}}$, indicates the laminar nature of the forebody flow in both tunnels for the model scales considered. However, the sting data were found to vary with both Reynolds and Mach numbers. This behavior demonstrates both that the shear layer was non-laminar and that the base-flow recirculation region size and shear-layer reattachment point were dependent on Mach number. 


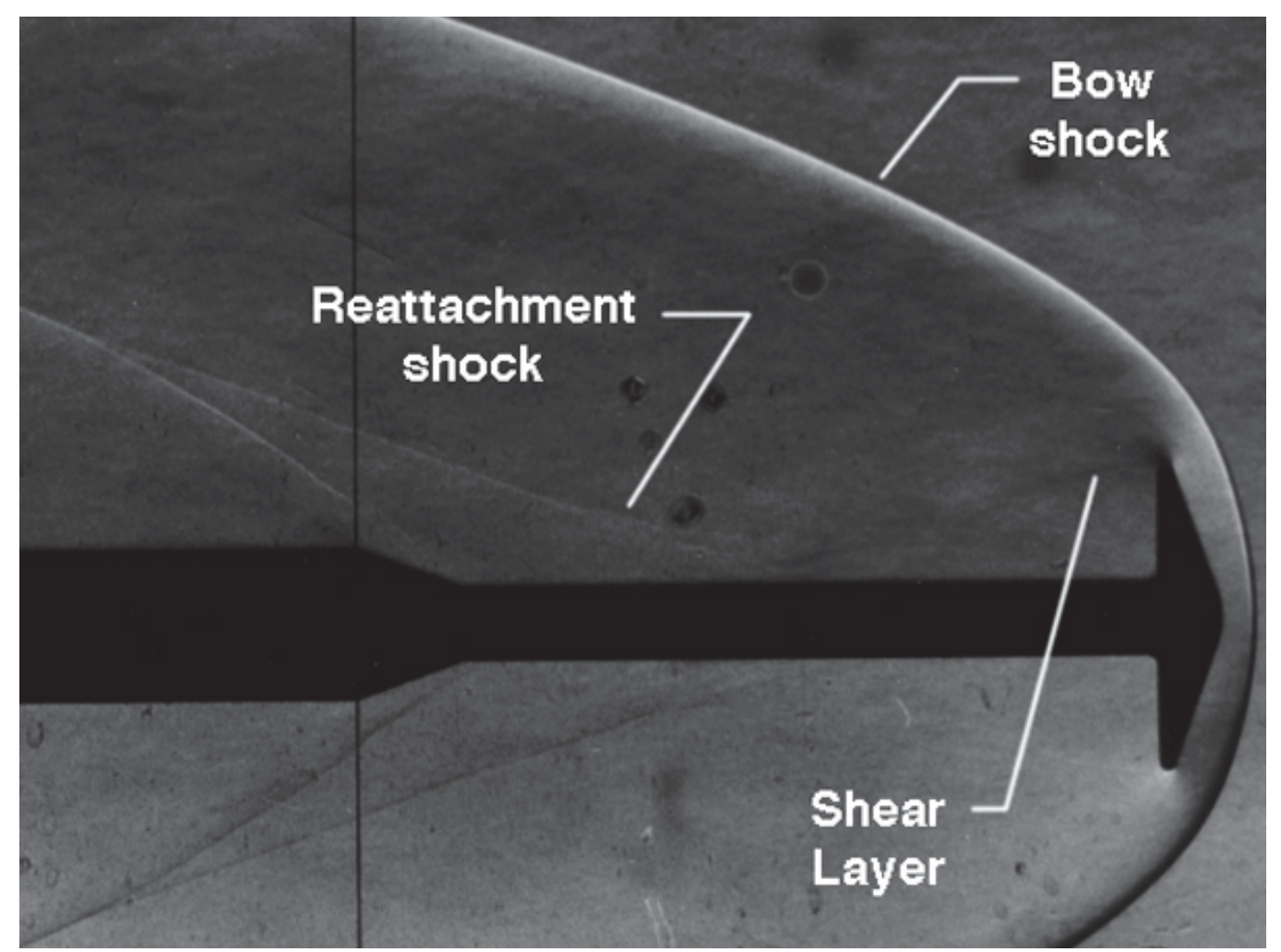

Figure 62. AGARD 18 model wake-flow structure
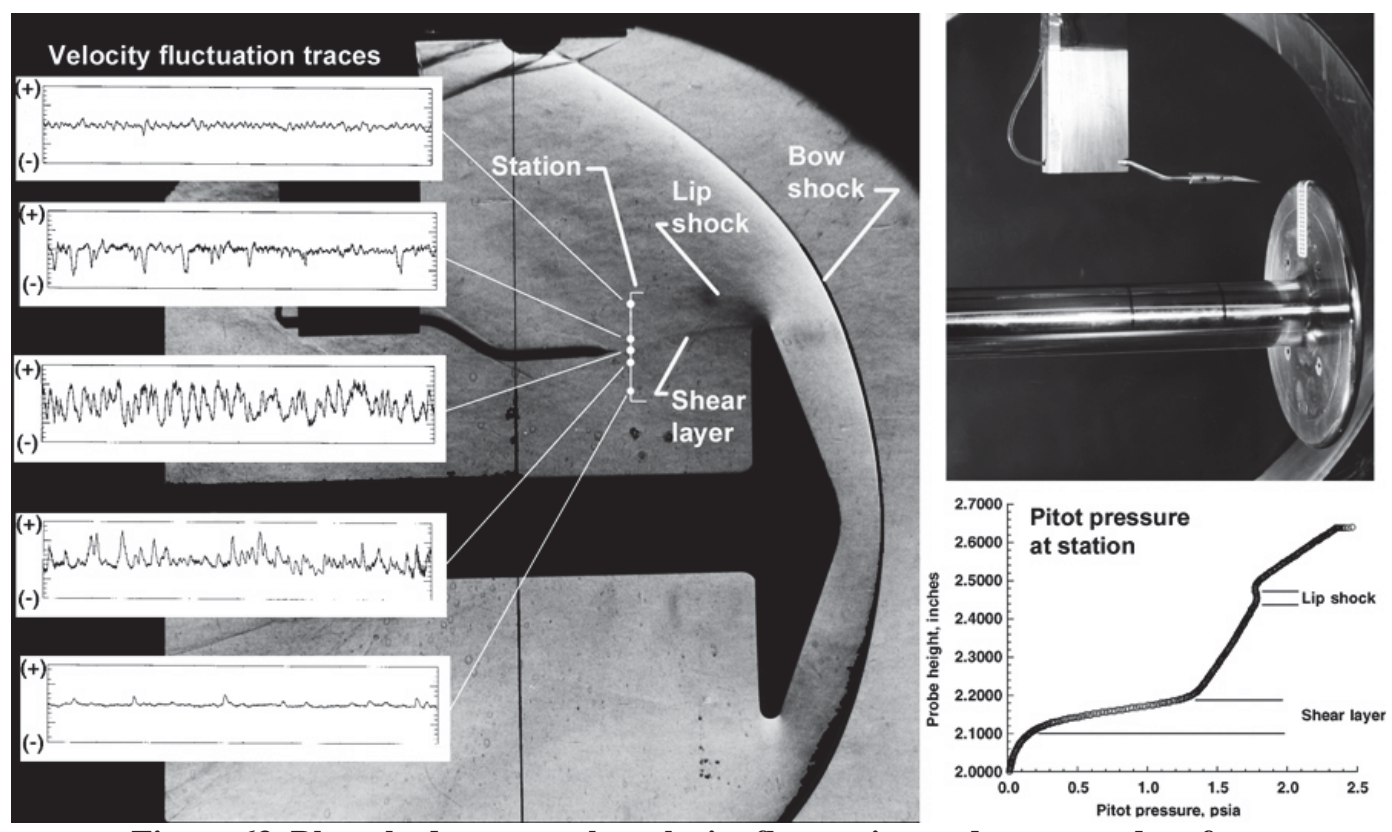

Figure 63. Blunt-body near-wake velocity fluctuation and pressure data from LaRC 20-Inch Mach 6 Air Tunnel 


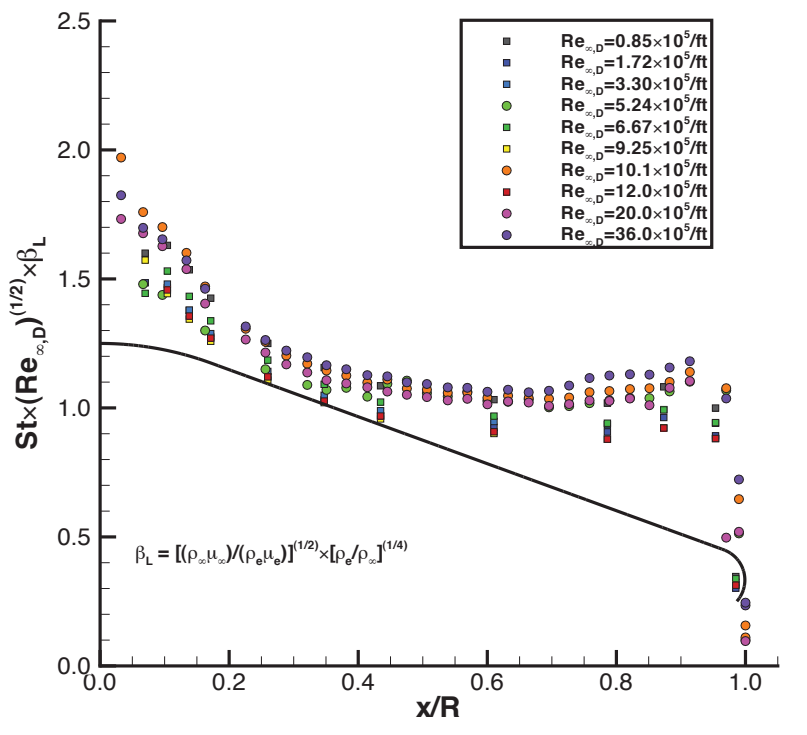

Forebody data

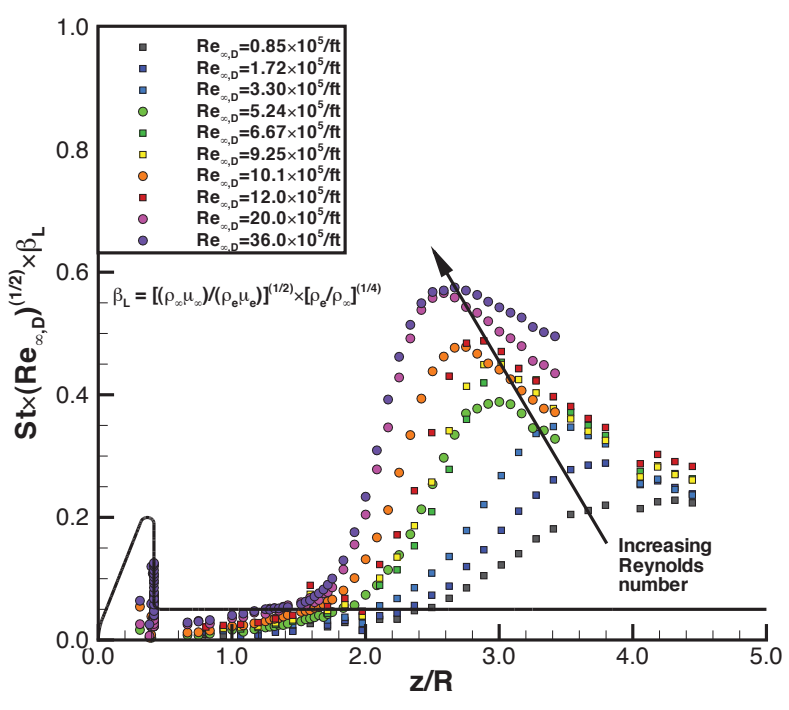

Sting data

Figure 64. Heating along forebody and sting of AGARD 18 models in LaRC 20-Inch Mach 6 Air Tunnel

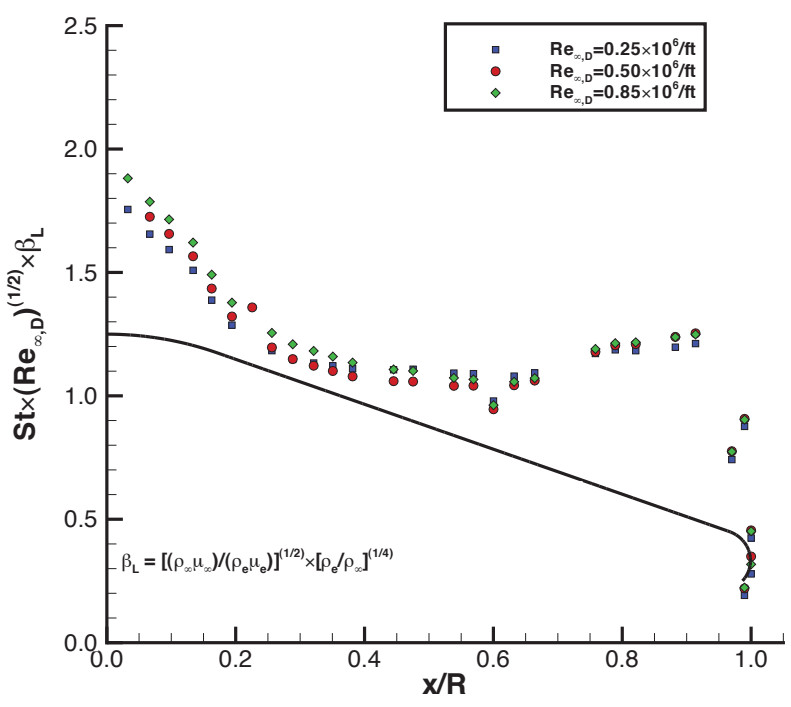

Forebody data

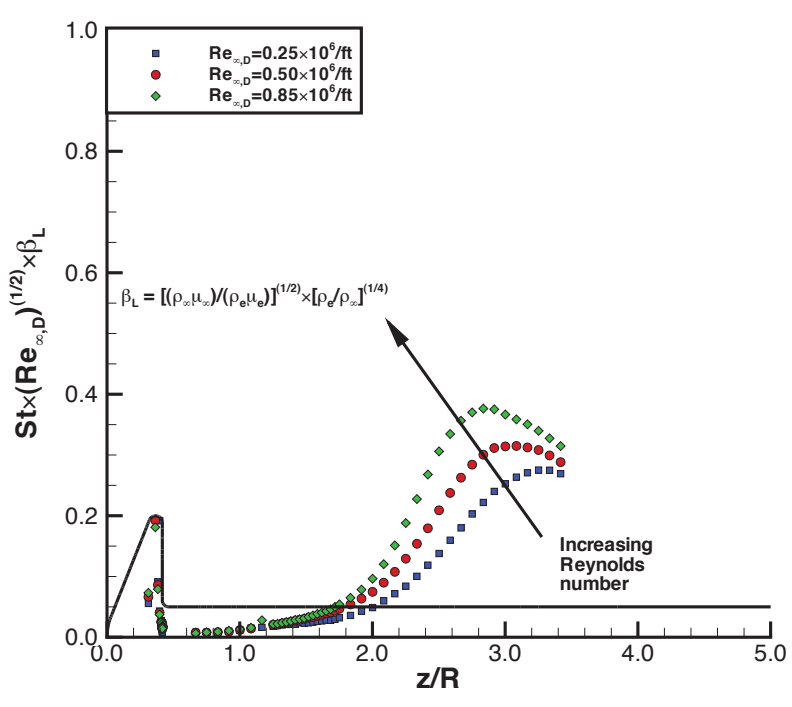

Sting data

Figure 65. Heating along forebody and sting of AGARD 18 model in LaRC 31-Inch Mach 10 Air Tunnel

\section{F. Blunt-Body Transition and Turbulent Heating Augmentation}

Historically, transition and turbulence were not considered to be important for blunt-body EDL systems and little data were available on these phenomena relevant to blunt bodies. However, with the Mars Science Laboratory and future missions under consideration, these issues become more important because of the large aeroshell size, highentry velocities and lifting trajectories. Recently, several studies have been conducted in order to obtain transition and turbulent heating data on blunt bodies. In addition to the programmatic studies previously discussed for MSL (Ref. 28) and Orion (Refs. 35 - 39), data recently have been obtained on a wider range of geometries through additional testing at LaRC in the 20-Inch Mach 6 Air Tunnel. Global phosphor thermography was employed to measure transition onset and turbulent heating augmentation on 50-, 60-, and 70-deg sphere-cones, hyperboloids and ellipsoid-cones of different nose radii. Data were obtained at angles-of-attack from 8-deg to 24-deg across a Reynolds number range sufficient to produce laminar, transitional and turbulent flow. A sample set of data for each cone angle at a 16-deg angle-of-attack is shown in Figure 66. The shape and extent of the transition front was found to vary a great deal with cone angle: at the lowest, 50-deg cone angle separate, off-centerline transition lobes were produced while for the 70-deg cone angle a broad transition front was produced. 
The experimental database from Orion and MSL testing has been correlated (Ref. 76) to develop engineering models for transition onset and turbulent heating augmentation. Data from three facilities, the LaRC 20-Inch Mach 6 Air Tunnel, CUBRC LENS I and AEDC Hypervelocity Tunnel 9 were considered. The best correlation was achieved in terms of the boundary-layer momentum-thickness Reynolds number, $\operatorname{Re}_{\theta}$ vs. the ratio of measured heating to laminar, predicted heating. As show in Figure 67, boundary-layer transition onset occurred around $\operatorname{Re}_{\theta}=$ 200. The correlation curves then follow an "s-curve" shape that asymptotically approaches a linear relationship. The Orion data were found to correlate better than the MSL data because of the more uniform surface conditions over the Orion aeroshell.
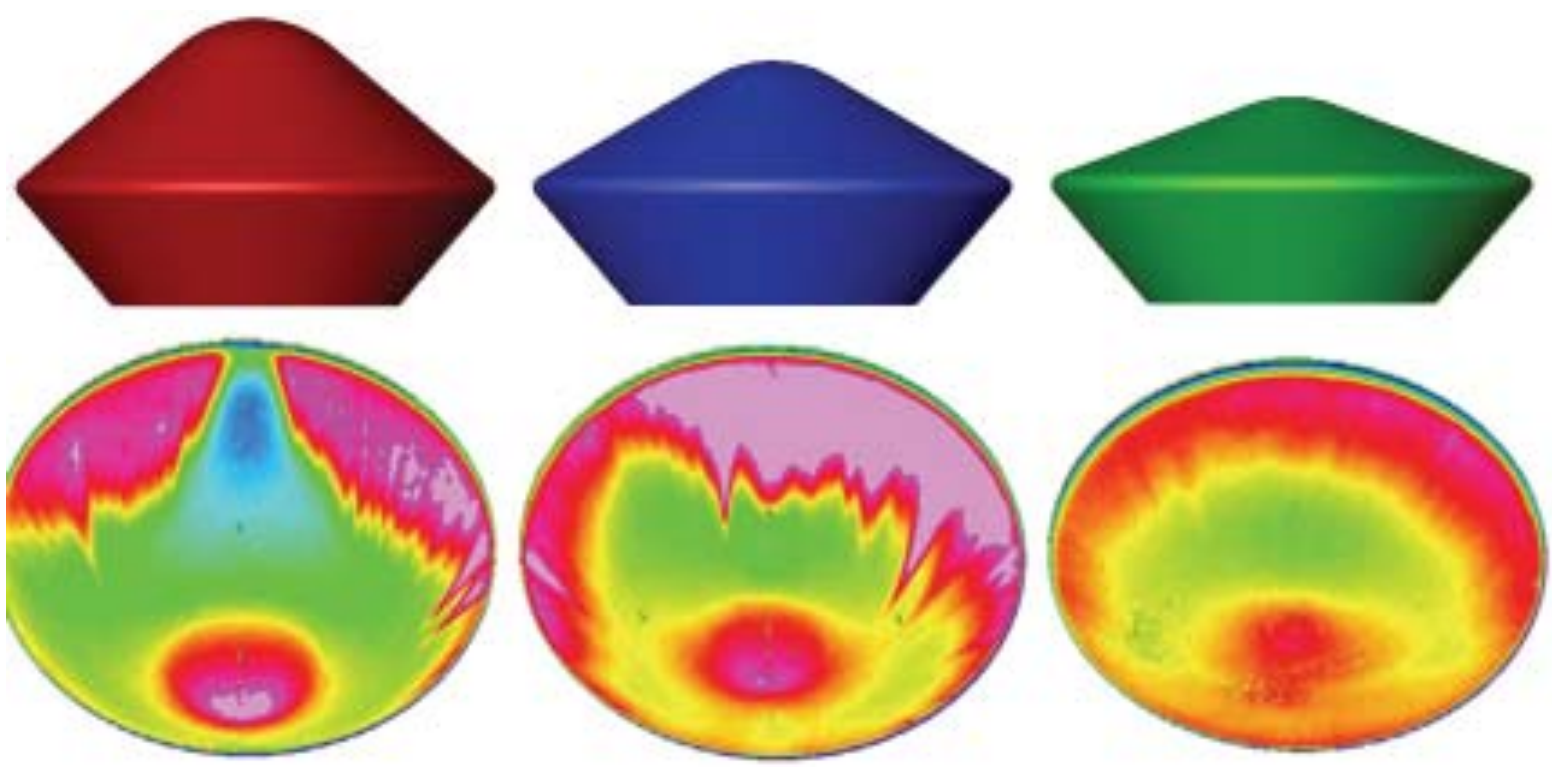

Figure 66. Parametric cone-angle effects on heating and transition in LaRC 20-Inch Mach 6 Air Tunnel

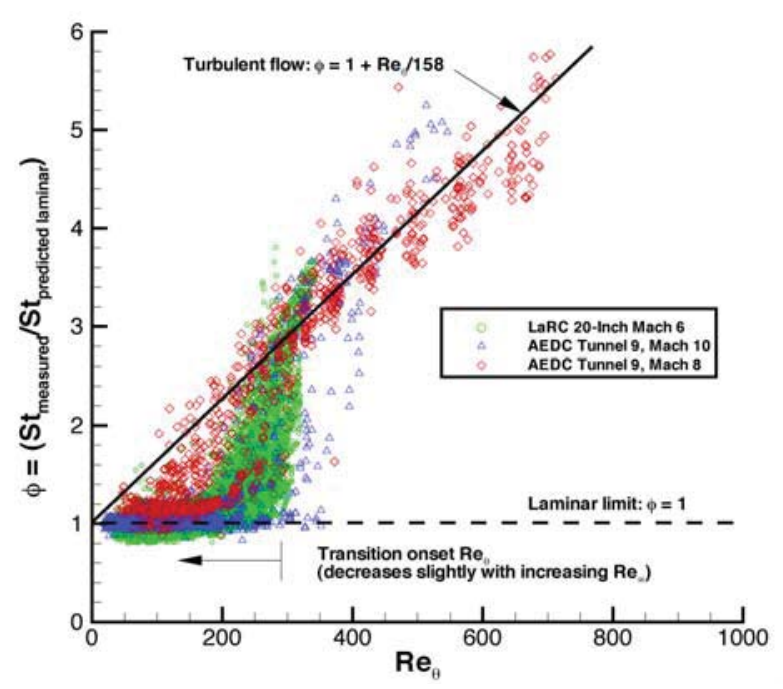

MSL Correlation

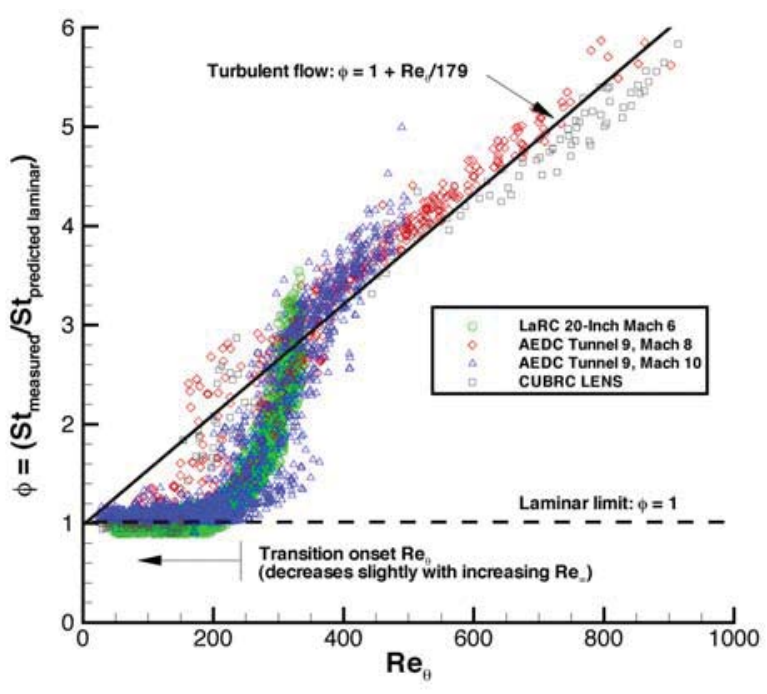

Orion correlation

Figure 67. Transition onset and turbulent heating augmentation correlations for Orion and CEV

\section{G. Ballute Physics}

Ballutes (from "balloon-parachute"), or to use the now more common term, inflatable aerodynamic decelerators (IADs), are under consideration for use at both hypersonic and supersonic speeds as an alternative to rigid aeroshells. The key aspects of ballutes are their large size and low mass in comparison to rigid systems, resulting in a much lower ballistic coefficient that produces lower heating rates and greater deceleration at higher altitudes. 
Ballutes generate unique and challenging aerothermodynamic phenomena that must be understood before their use in actual exploration missions. An inflatable structure may be subjected to large and possibly unsteady aeroelastic deformations that could have effects on static and dynamic aerodynamics, boundary-layer transition, and aerodynamic heating. Additionally, towed ballutes will likely experience unsteady flow-interactions between the bow-shock produced by the ballute and that of the payload.

1. Towed Ballute Heating and Flow-Field Interactions

Testing of a spacecraft with a towed ballute configuration with adjustable tow-length was conducted (Ref. 77) in the LaRC 20-Inch Mach 6 Air and 20-Inch Mach $6 \mathrm{CF}_{4}$ Tunnels. Flow-field schlieren imagery was generated and surface heating levels were measured using global phosphor thermography (Figure 68). Unsteady flow was observed for most tow-lengths. Computational simulations for the test conditions showed large regions of recirculating flow ahead of the ballute and produced shock-structures that were in qualitative agreement with the schlieren imagery.
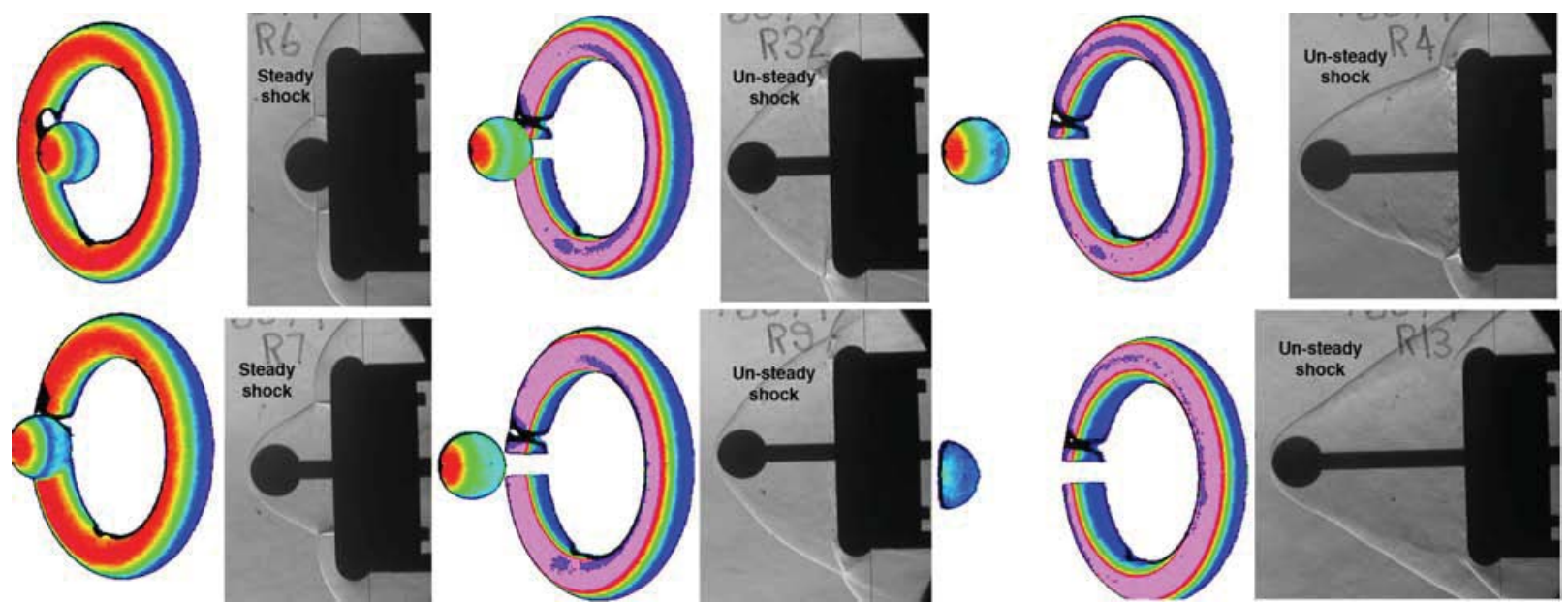

Figure 68. Towed ballute shock-interaction data from LaRC 20-Inch Mach $6 \mathrm{CF}_{4}$ Tunnel

\section{Attached Ballute Aeroelastic Deformations}

Aeroelastic surface deformations of attached ballutes were studied (Ref. 78) in the LaRC 31-Inch Mach 10 Air and 20-Inch Mach $6 \mathrm{CF}_{4}$ Tunnels. Quantitative surface deformations measurements (Figure 69) were made using 60-deg sphere-cone models fabricated with polyimide films representative of a proposed ballute material. Video and still-image recordings were made to show the aeroelastic deflection of the aeroshell under aerodynamic loading. Schlieren imagery showed the resulting effects of the surface deflections on the flow field.
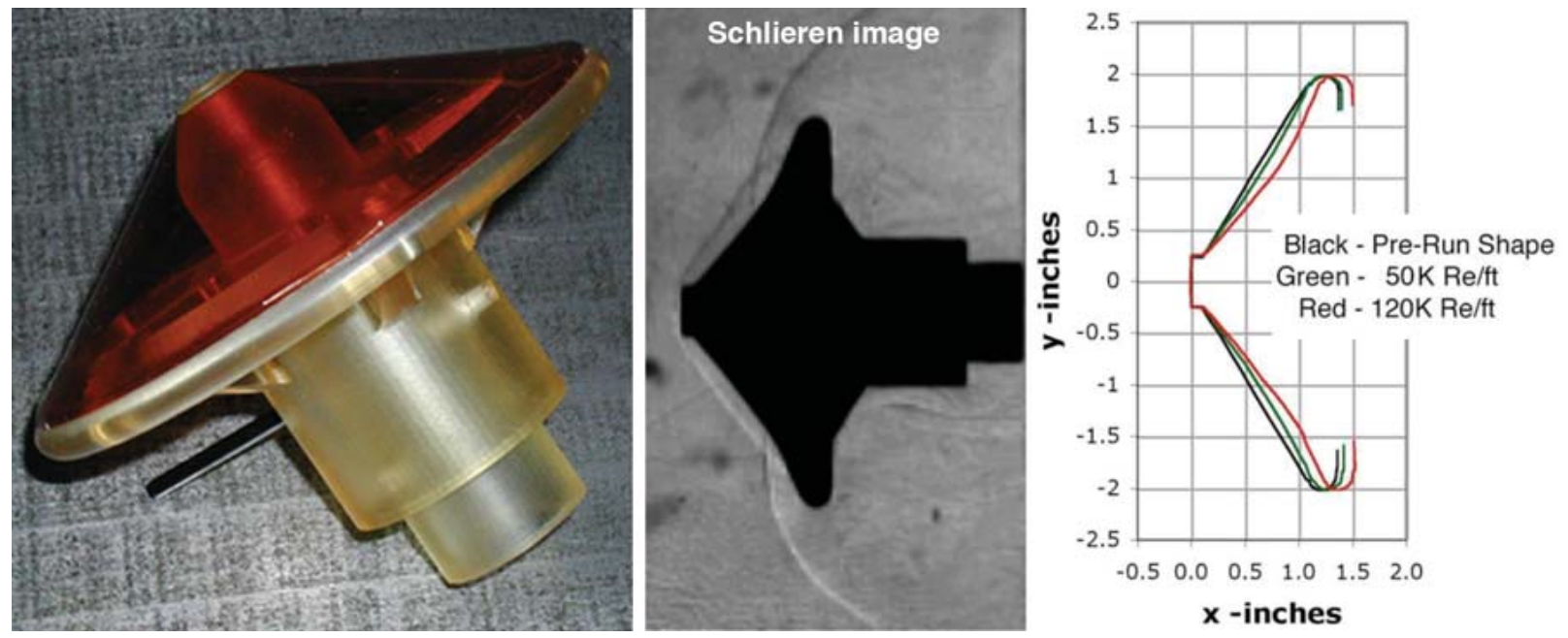

Figure 69. Attached ballute aeroelastic deflection data from LaRC 20-Inch Mach $6 \mathrm{CF}_{4}$ Tunnel 


\section{Summary}

A review has been presented of supersonic/hypersonic experimental capabilities at the Langley Research Center that support the development of Entry, Descent and Landing systems. Facility operating characteristics, model fabrication capabilities and measurement/instrumentation techniques have been discussed. Recent contributions to major NASA flight programs and to research and development activities have been summarized. These capabilities have been, and will continue to be, applied to flight database generation, configuration development, CFD benchmarking and fundamental studies of complex aerothermodynamic phenomena.

\section{References}

1. Micol, J. R., "Langley Aerothermodynamic Facilities Complex: Enhancements and Testing Capabilities," AIAA Paper 19980147, $36^{\text {th }}$ AIAA Aerospace Sciences Meeting and Exhibit, Reno, NV, 12-15 January, 1998.

2. Micol, J. R., "Hypersonic Aerodynamic/Aerothermodynamic Testing Capabilities at Langley Research Center: Aerothermodynamic Facilities Complex," AIAA Paper 1995-2107, 30 ${ }^{\text {th }}$ AIAA Thermophysics Conference, San Diego, CA, 19 - 22 June, 1995.

3. Micol, J. R., "Langley Research Center's Unitary Plan Wind Tunnel: Testing Capabilities and Recent Modernization Activities," AIAA Paper 2001-0456, 39 ${ }^{\text {th }}$ AIAA Aerospace Sciences Meeting and Exhibit, Reno, NV, 8-11 January, 2001.

4. Erickson, G. E., "Overview of Supersonic Aerodynamics Measurement Techniques in the NASA Langley Unitary Plan Wind Tunnel," NASA TM-2007-214894, August 2007.

5. Buck, G. M., “Automated Thermal Mapping Techniques Using Chromatic Image Analysis,” NASA TM-101554, April 1989.

6. Merski, N. R., "Global Aeroheating Wind-Tunnel Measurements Using Improved Two-Color Phosphor Thermography Method," Journal of Spacecraft and Rockets, Vol. 36, No. 2, March-April 1999, pp. 160-170.

7. Daryabeigi, K., Berry, S. A., Horvath, T. J., and Nowak, R. J., "Finite Volume Numerical Methods for Aeroheating Rate Calculations from Infrared Thermography," Journal of Spacecraft and Rockets, Vol. 43, No. 1, January-February 2006, pp. 54-62.

8. Watkins, A. N., Buck, G. M., Leighty, B. D., Lipford, W. E., and Oglesby, D. M., "Using Pressure- and TemperatureSensitive Paint for Global Surface Pressure and Temperature Measurements on the Aft-Body of a Capsule Reentry Vehicle," AIAA Paper 2008-1230, 46 ${ }^{\text {th }}$ AIAA Aerospace Sciences Meeting and Exhibit, Reno, NV, 7-10 January, 2008.

9. Horvath, T. J., Berry, S. A., Merski, N. R., Fitzgerald, S. M., "X-38 Experimental Aerothermodynamics," AIAA Paper 20002685, 34 ${ }^{\text {th }}$ AIAA Thermophysics Conference, Denver, CO., 19-22 June, 2000.

10. Horvath, T. J., Berry, S. A., Hollis, B. R., Chang, C., and Singer, B. A., "Boundary Layer Transition on Slender Cones in Conventional and Low Disturbance Mach 6 Wind Tunnels," AIAA Paper 2002-2743, 32 ${ }^{\text {nd }}$ AIAA Fluid Dynamics Conference and Exhibit, St. Louis, MO., 24-27 June, 2002.

11. Horvath, T. and Hannemann, K., "Blunt Body Near-Wake Flow Field at Mach 10," AIAA Paper 1997-0986, 35 ${ }^{\text {th }}$ AIAA Aerospace Sciences Meeting and Exhibit, Reno, NV, 6-9 January 1997.

12. Schultz, D. L. and Jones, T. V., "Heat-Transfer Measurements in Short-Duration Facilities," AGARD Report AG-165, February 1973.

13. Rufer, S. J. and Berridge, D. C., "Experimental Study of Second-Mode Instabilities on a 7-Degree Cone at Mach 6," AIAA Paper 2011-3877, 41 ${ }^{\text {st }}$ AIAA Fluid Dynamics Conference and Exhibit, Honolulu, HI, 27-30 June 2011.

14. Murphy, K. J., and Scallion, W. I., "Experimental Stage Separation Tool Development in NASA Langley's Aerothermodynamics Laboratory," AIAA Paper 2005-6127, AIAA Atmospheric Flight Mechanics Conference and Exhibit, San Francisco, CA, 15-18 August, 2005.

15. Bathel, B. F., Johansen, C., Inman, J. A., Jones, S. B., and Danehy, P. M., "Review of Fluorescence-Based Velocimetry Techniques to Study High-Speed Compressible Flows," AIAA Paper 2013-0339, 51 ${ }^{\text {st }}$ AIAA Aerospace Sciences Meeting, Grapevine, TX, 7-10 January 2013.

16. Danehy, P. M., Wilkes, J. A., Alderfer, D. W., Jones, S. B., Robbins, A. W., Patry, D. P., and Schwartz, R. J., "Planar LaserInduced Fluorescence (PLIF) Investigation of Hypersonic Flow Fields in Mach 10 Wind Tunnel," AIAA Paper 2006-3442, $25^{\text {th }}$ AIAA Aerodynamic Measurements Technology and Ground Testing Conference, San Francisco, CA, 5-8 June, 2006.

17. Rhode, M. N., and DeLoach, R., "Hypersonic Wind Tunnel Calibration Using the Modern Design of Experiments", AIAA Paper 2005-4274, 41 ${ }^{\text {st }}$ AIAA/ASME/SAE/ASEE Joint Propulsion Conference and Exhibit, Tucson, AS, 10-13 July 2005.

18. Rufer, S. J. and Berridge, D. C., "Pressure Fluctuation Measurements in the NASA Langley 20-Inch Mach 6 Air Tunnel," AIAA Paper 2012-3262, 42 ${ }^{\text {nd }}$ AIAA Fluid Dynamics Conference and Exhibit, New Orleans, LA, 25-28 June, 2012.

19. Buck, G. M., "Rapid Fabrication and Testing for Aerospace Vehicles," AIAA Paper 200-0826, 38 Aerospace Sciences Meeting and Exhibit, Reno, NV, 10-13 January 2000.

20. Buck, G. M., "Rapid Fabrication of Flat Plate Cavity Phosphor Thermography Test Models for Shuttle Return-to-Flight Aero-Heating," NASA TM-2006-214508, November 2006.

21. Mazaheri, A., Gnoffo, P. A., Johnston, C. O., and Kleb, B., "LAURA Users Manual: 5.5-65135," NASA TM-2013-217800, February 2013.

22. Anderson, W. K. and Bonhaus, D. L., "An Implicit Upwind Algorithm for Computing Turbulent Flows on Unstructured Grids," Computers and Fluids, Vol. 23, No. 1, pp. 1-21, 1994. 
23. Jespersen, D., Pulliam, T., and Buning, P., "Recent Enhancements to OVERFLOW (Navier-Stokes code)," AIAA Paper 1997-0644, 35 ${ }^{\text {th }}$ AIAA Aerospace Sciences Meeting and Exhibit, Reno, NV, 6-9 January 1997.

24. Gnoffo, P. A., Wood, W. A., Alter, S., Glass, C., Padilla, J., Hammond, D., and White, J.," Functional Equivalence Acceptance Testing of FUN3D for Entry, Descent, and Landing Applications," AIAA Paper 2013-2558, 21 ${ }^{\text {st }}$ AIAA Computational Fluid Dynamics Conference, San Diego, CA, June 24-27 2013

25. Chang, C.-L., "The Langley Stability and Transition Analysis Code (LASTRAC) Version 1.2 User Manual," NASA TM2004-213233, June 2004.

26. Edquist, K. T., Hollis, B. R., Dyakonov, A. A., Laub, B., Wright, M. J., Rivellini, T. P., Slimko, E. M., Willcockson, W. H., "Mars Science Laboratory Entry Capsule Aerothermodynamics and Thermal Protection System," IEEEAC Paper 1423, Aerospace Conference, 2007 IEEE, 3-10 March 2007.

27. Hollis, B. R. and Liechty, D. S., "Correlations for Boundary-Layer Transition on Mars Science Laboratory Entry Vehicle Due to Heat-Shield Cavities," NASA-TP-2008-215317, June 2008.

28. Hollis, B. R., Liechty, D. S., Wright, M. J., Holden, M. S., Wadhams, T. P., MacLean, M. and Dyakonov, A., "Transition Onset and Turbulent Heating Measurements for the Mars Science Laboratory," AIAA Paper 2005-1437, 43 ${ }^{\text {rd }}$ AIAA Aerospace Sciences Meeting and Exhibit, Reno, NV, 10-13 January, 2005.

29. Hollis, B. R. and Collier, A. S., "Turbulent Aeroheating Testing of Mars Science Laboratory Entry Vehicle," Journal of Spacecraft and Rockets, Vol. 45, No. 3, May-June 2008, pp. 417-427.

30. Schoenenberger, M., Dyakonov, A., Buning, P., Scallion, W. and Van Norman, J., Aerodynamic Challenges for the Mars Science Laboratory Entry, Descent and Landing, AIAA Paper 2009-3914, $41^{\text {st }}$ AIAA Thermophysics Conference, San Antonio, TX, 22-25 June, 2009.

31. Schoenenberger, M., Van Norman, J., Rhode, M., and Paulson, J., "Characterization of Aerodynamic Interactions with the Mars Science Laboratory Reaction Control System Using Computation and Experiment," AIAA Paper 2013-0917, 51 ${ }^{\text {st }}$ AIAA Aerospace Sciences Meeting, Grapevine, TX, 7-10 January, 2013.

32. Johansen, C. T., Novak, L., Bathel, B., Ashcraft, S. W., and Danehy, P. M., "Comparison of MSL RCS Jet Computations with Flow Visualization and Velocimetry", AIAA Paper 2012-0594, 50 ${ }^{\text {th }}$ Aerospace Sciences Meeting, Nashville, TN, 09-12 January, 2012.

33. Berry, S. A., Horvath, T. J., Lillard, R. P., Kirk, B. S., and Cassady, A. M.,” Aerothermal Testing for Project Orion Crew Exploration Vehicle," AIAA Paper 2009-3842, 41 ${ }^{\text {st }}$ AIAA Thermophysics Conference, San Antonio, TX, $22-25$ June, 2009.

34. Murphy, K. J., Bibb, K. L., Brauckmann, G. J., Rhode, M. N., Owens, B., Chan, D. T., Walker, E. L., Bell, J. H., and Wilson, T. M., "Orion Crew Module Aerodynamic Testing," AIAA Paper 2011-3502, $29^{\text {th }}$ AIAA Applied Aerodynamics Conference, Honolulu, HI, 27-30 June, 2011.

35. Berger, K. T., "Aerothermodynamic Testing of the Crew Exploration Vehicle at Mach 6 and Mach 10," Journal of Spacecraft and Rockets, Vol. 46, No. 4, July-August 2009, pp. 758-765.

36. Berger, K. T. and Nowak, R. J., "Aerothermodynamic Testing of the Cycle I Crew Exploration Vehicle Crew Module in the LaRC 20-Inch Mach 6 and 31-Inch Mach 10 Tunnels," NASA EG-CAP-06-156, November 2006.

37. Hollis, B. R., Horvath, T. J., Berger, K. T., Lillard, R. P., Kirk, B. S., Coblish, J. J., Norris, J. D., "Experimental Investigation of Project Orion Crew Exploration Vehicle Aeroheating in AEDC Tunnel 9," NASA-TP-2008-215547, December 2008.

38. Amar, A. J., Horvath, T. J., Hollis, B. R., Berger, K. T., Berry, S., A., and Calvert, N., "Protuberance Boundary Layer Transition for Project Orion Crew Entry Vehicle," AIAA Paper 2008-1227, $46^{\text {th }}$ AIAA Aerospace Sciences Meeting and Exhibit, Reno, NV, 7-10 January, 2008.

39. Hollis, B. R., "Experimental Investigation of Project Orion Crew Exploration Vehicle Aeroheating: LaRC 20-Inch Mach 6 Air Tunnel Test 6931," NASA TM-2009-215718, April 2009.

40. Liechty, D. S., "Aerothermodynamic Testing of Protuberances and Penetrations on the NASA Crew Exploration Vehicle, Heat Shield," AIAA Paper 2008-1240, 46 ${ }^{\text {th }}$ AIAA Aerospace Sciences Meeting and Exhibit, Reno, NV, 7-10 January, 2008.

41. Liechty, D. S., "Aerothermodynamic Testing of Protuberances and Penetrations on the NASA Cycle I Crew Exploration Vehicle Heat Shield in the NASA Langley 20-Inch Mach 6 Air Tunnel: Test 6918," NSA EG-CAP-06-155, November, 2006.

42. Hollis, B. R., "Heating Augmentation in Laminar Flow Due to Heat-Shield Cavities on the Project Orion CEV," AIAA Paper 2008-6558, AIAA Atmospheric Flight Mechanics Conference and Exhibit, Honolulu, HI, August 18-21, 2008.

43. Hollis, B. R., "Compression Pad Cavity Heating Augmentation on Orion Heat Shield," Journal of Thermophysics and Heat Transfer, Vol. 25, No. 3, July-September 2011, pp. 329-340.

44. Hollis, B. R., "Aerothermodynamic Testing of Recessed Compression Pads on the CEV Heat Shield: LaRC 31-Inch Mach 10 Air Tunnel Test 456 and 20-Inch Mach 6 Air Tunnel Test 6954,” NASA EG-CAP-09-03, March 2009.

45. Liechty, D. S., "Experimental Investigation of Project Orion Crew Exploration Vehicle Roughness Augmentation in AEDC Tunnel 9," NASA EG-CAP-09-51, June 2009.

46. Buck, G. M., Watkins, A. N., Danehy, P. M., Inman, J. A., Alderfer, D. W., and Dyakonov, A. A., "Experimental Measurement of RCS Jet Interaction Effects on a Capsule Entry Vehicle," AIAA Paper 2008-1129, 46 ${ }^{\text {th }}$ AIAA Aerospace Sciences Meeting and Exhibit, Reno, NV, 7-10 January, 2008.

47. Buck, G. M., "Aerothermodynamic Testing of RCS Jet Interactions on Apollo and Orion-Type Crew Modules in the NASA Langley 31-Inch Mach 10 Air Tunnel: Test 37-CH,” NASA EG-CAP-07-97, August 2007.

48. Buck, G. M., "Aerothermodynamic Testing of RCS Jet Interactions for the Orion 606D Crew Module in the NASA Langley 31-Inch Mach 10 Air Tunnel: Test 63-CH,” NASA EG-CAP-08-173, 2009. 
49. Buck, G. M., "Aerothermodynamic Testing of RCS Jet Interactions for the Orion 607A Crew Module in the NASA Langley 31-Inch Mach 10 Air Tunnel: Test 95-CH,” NASA EG-CAP-11-95, November 2011.

50. Danehy, P. M., Inman, J. A., Brauckmann, G. J., Alderfer, D. W., Jones, S. B., and Patry, D. P.," Visualization of a Capsule Entry Vehicle Reaction-Control System Thruster," AIAA Paper 2006-1532, 44 ${ }^{\text {th }}$ AIAA Aerospace Sciences Meeting and Exhibit, Reno, NV, 9-12 January 2006.

51. Danehy, P. M., Inman, J. A., Alderfer, D. W., Buck, G. M., and Bathel, B., "Visualization of Flowfield Modification by RCS Jets on a Capsule Entry Vehicle," 46 ${ }^{\text {th }}$ AIAA Aerospace Sciences Meeting and Exhibit, Reno, NV, 7-10 January, 2008.

52. Murphy, K. J., Bibb, K. L., Brauckmann, G. J., Rhode, M. N., Owens, B., Chan, D. T., Walker, E. L., Bell, J. H., and Wilson, T. M., "Orion Crew Module Aerodynamic Testing" AIAA Paper 2011-3502, $29^{\text {th }}$ AIAA Applied Aerodynamics Conference, Honolulu, HI, 27-30 June, 2011.

53. Brauckmann, G. J., "Final Report for CEV Test 9-CA; Mach 6 0-deg to 180-deg Hypersonic Aerodynamics," NASA EGCEV-2006-152, November 2006.

54. Murphy, K. J, Borg, S. E., Watkins, A. N., Cole, D. R., and Schwartz, R. J., "Testing of the Crew Exploration Vehicle in NASA Langley's Unitary Plan Wind Tunnel," AIAA Paper 2007-1005, 45 ${ }^{\text {th }}$ AIAA Aerospace Sciences Meeting and Exhibit, Reno, NV, 8-11 January, 2007.

55. Rhode, M. N., Chan, D. T., Niskey, C. J., and Wilson, T. M., "Aerodynamic Testing of the Orion Launch Abort Tower Separation with Jettison Motor Interactions," AIAA Paper 2011-3342, $29^{\text {th }}$ AIAA Applied Aerodynamics Conference, Honolulu, HI, 27-30 June 2011.

56. Murphy, K. J., Brauckmann, G. J., Paschal, K. B., Chan, D. T., Walker, E. L., Foley, R., Mayfield, D., and Cross, J., "Orion Launch Abort Vehicle Attitude Control Motor Testing," AIAA Paper 2011-3343, $29^{\text {th }}$ AIAA Applied Aerodynamics Conference, Honolulu, HI, 27-30 June, 2011.

57. Olds, A. D., Beck, R. E., Bose, D. M., White, J. P., Edquist, K. T., Hollis, B. R., Lindell, M. C., Cheatwood, F. M., Gsell, V. T., and Bowden, E. L., "IRVE-3 Post-Flight Reconstruction," AIAA paper 2013-1390, AIAA Aerodynamic Decelerator Systems (ADS) Conference, Daytona Beach, FL, 25-28 March, 2013.

58. Lichodziejewski, L., Kelly, C., Tutt, B., Jurewicz, D., Brown, G., Gilles, B., Barger, D., Dillman, R., and Player, C., "Design and Testing of the Inflatable Aeroshell for the IRVE-3 Flight Experiment," AIAA Paper 2012-1515," 53 AIAA/ASME/ASCE/AHS/ASC Structures, Structural Dynamics and Materials Conference, Honolulu, HI, 23-26 April, 2012.

59. Cheatwood, F. M., Merski, N. R., Riley, C. J., and Mitchletree, R. A., "Aerothermodynamic Environment Definition for the Genesis Sample Return Capsule," AIAA Paper 2001-2889, 35 ${ }^{\text {th }}$ AIAA Thermophysics Conference, Anaheim, CA, 11-14 June, 2001.

60. Mitchletree, R. A., DiFulvio, M., Horvath, T. J., and Braun, R. D., “Aerothermal Heating Predictions for Mars Microprobe,” Journal of Spacecraft and Rockets, Vol. 36, No. 3, May-June 1999, pp. 405-411.

61. Dwyer Cianciolo, A., M., Davis, J. L., Komar, D. R., Munk, M. M., Samareh, J. A., et al, "Entry, Descent and Landing Systems Analysis Study: Phase 1 Report,” NASA TM-2010-216720, July 2010,

62. Dwyer Cianciolo, A. M., Davis, J. L., Engelund, W. C., Komar, D. R., Quenn, E. M., et al,” Entry, Descent and Landing Systems Analysis Study: Phase 2 Report on Exploration Forward Systems," NASA TM-2011-217055, February 2011.

63. Hollis, B. R. and Hollingsworth, K. E., "Laminar, Transitional and Turbulent Heating on Mid Lift-to-Drag Ratio Entry Vehicles," Journal of Spacecraft and Rockets, Vol. 50, No. 5, September-November 2013, pp. 937-949.

64. Garcia, J. A., Brown, J. L., Kinney, D. J., Bowles, J. V., Huynh, L. O., Jiang, X. J., Lau, E., and Dupzyk, I. C., "CoOptimization of Mid Lift to Drag Vehicle Concepts for Mars Atmospheric Entry," AIAA Paper 2010-5052. 10 AIAA/ASME Joint Thermophysics and Heat Transfer Conference, Chicago, IL, 28 June - 1 July 2010.

65. Drake, B. G., "Human Exploration of Mars, Design Reference Architecture 5.0," NASA SP-2009-566, July 2009.

66. Berry, S. A., Rhode, M. N., Edquist, K. T, and Player, C. J., "Supersonic Retropropulsion Experimental Results for the NASA Langley Unitary Plan Wind Tunnel," AIAA Paper 2011-3489, 42 ${ }^{\text {nd }}$ AIAA Thermophysics Conference, Honolulu, HI, 27-30 June 2011.

67. Berry, S. A., Rhode, M. N., and Edquist, K. T., "Supersonic Retropropulsion Experimental Results from the NASA Ames 9x 7-Foot Supersonic Wind Tunnel," AIAA Paper 2012-2704, 42 ${ }^{\text {nd }}$ AIAA Fluid Dynamics Conference and Exhibit, New Orleans, LA, 25-28 June, 2012.

68. Kleb, B., Schauerhamer, D. G., Trumble, K., Sozer, E., Barnhardt, M., Carlson, J., and Edquist, K., "Toward Supersonic Retropropulsion CFD Validation," AIAA Paper 2011-3490, 42 ${ }^{\text {nd }}$ AIAA Thermophysics Conference, Honolulu, HI, 27-30 June 2011.

69. Horvath, T. J., O’Connell, T. F., Cheatwood, F. M., Prabhu, R. K., and Alter, S. J., "Experimental Hypersonic Aerodynamics Characteristics of Mars Surveyor 2001 Precision Lander with Flap," Journal of Spacecraft and Rockets, Vol. 43, No. 2, March-April 2006, pp. 270-281.

70. Murphy, K. J., Horvath, T. J., Erickson, G. E., and Green, J. M., "Supersonic Aerodynamics Characteristics of Proposed Mars '07 Smart Lander Configurations," Journal of Spacecraft and Rockets, Vol. 43, No. 2, March-April 2006, pp. $282-292$.

71. Liechty, D. S., Hollis, B. R., and Edquist, K. T., "Mars Science Laboratory Experimental Aerothermodynamics with Effects of Cavities and Control Surfaces," Journal of Spacecraft and Rockets, Vol. 43, No. 2, March-April 2006, pp. 340-353.

72. Horvath, T. J., Heiner, N. C., and Olguin, D. M., "Wake Closure and Afterbody Heating on a Mars Sample Return Orbiter," Journal of Spacecraft and Rockets, Vol. 41, No. 5, September-October 2004, pp. 705-715.

73. Muylaert, J., Kumar, A. and Dujarric, C. (eds.), Hypersonic Experimental and Computational Capability, Improvement and Validation, AGARD Advisory Report 319 Vol. II, December 1998. 
74. Horvath, T. J., McGinley, C. B., and Hannemann, K., "Blunt Body Near-Wake Flow Field at Mach 6," AIAA Paper 19961935, 27 ${ }^{\text {th }}$ AIAA Fluid Dynamics Conference, New Orleans, LA, 17-20 June 1996.

75. Hollis, B. R. and Perkins, J. N.," Transition Effects on Heating in the Wake of a Blunt Body," Journal of Spacecraft and Rockets, Vol. 36, No. 5, September-October 1999, pp. 668-674.

76. Hollis, B. R., "Blunt-Body Entry Vehicle Aerothermodynamics: Transition and Turbulence," Journal of Spacecraft and Rockets, Vol. 49, No. 3, May-June 2012, pp. 435-449.

77. Gnoffo, P., Buck, G., Moss, J., Nielsen, E., Berger, K., Jones, W. T., and Rudavsky, R., “Aerothermodynamic Analyses of Towed Ballutes," AIAA Paper 2006-3771, $9^{\text {th }}$ AIAA/ASME Joint Thermophysics and Heat Transfer Conference, San Francisco, CA, 5-8 June 2006.

78. Buck, G. M., "Testing of Flexible Ballutes in Hypersonic Wind Tunnels for Planetary Aerocapture," AIAA Paper 2006-1319, $44^{\text {th }}$ AIAA Aerospace Sciences Meeting and Exhibit, Reno, NV, 9-12 January 2006. 